\title{
Controlling the Morphology of Self-Assembling Carbamate Systems \\ by
}

Mohammad Moniruzzaman

\author{
A thesis submitted to the \\ Faculty of Graduate Studies and Research \\ in partial fulfillment of the requirements \\ for the degree of
}

Doctor of Philosophy

Carleton University

Department of Chemistry

1125 Colonel By Drive

Ottawa, Ontario, Canada

September, 2004

C Copyright

Mohammad Moniruzzaman, 2004 


$\begin{array}{ll}\begin{array}{l}\text { Library and } \\ \text { Archives Canada }\end{array} & \begin{array}{l}\text { Bibliothèque et } \\ \text { Archives Canada }\end{array} \\ \begin{array}{l}\text { Published Heritage } \\ \text { Branch }\end{array} & \begin{array}{l}\text { Direction du } \\ \text { Patrimoine de l'édition }\end{array} \\ \begin{array}{l}\text { 395 Wellington Street } \\ \text { Ottawa ON K1A 0N4 } \\ \text { Canada }\end{array} & \begin{array}{l}\text { 395, rue Wellington } \\ \text { Ottawa ON K1A ON4 } \\ \text { Canada }\end{array}\end{array}$

Your file Votre référence ISBN: 0-612-97836-2

Our file Notre référence

ISBN: 0-612-97836-2

NOTICE:

The author has granted a nonexclusive license allowing Library and Archives Canada to reproduce, publish, archive, preserve, conserve, communicate to the public by telecommunication or on the Internet, loan, distribute and sell theses worldwide, for commercial or noncommercial purposes, in microform, paper, electronic and/or any other formats.

The author retains copyright ownership and moral rights in this thesis. Neither the thesis nor substantial extracts from it may be printed or otherwise reproduced without the author's permission.
AVIS:

L'auteur a accordé une licence non exclusive permettant à la Bibliothèque et Archives Canada de reproduire, publier, archiver, sauvegarder, conserver, transmettre au public par télécommunication ou par l'Internet, prêter, distribuer et vendre des thèses partout dans le monde, à des fins commerciales ou autres, sur support microforme, papier, électronique et/ou autres formats.

L'auteur conserve la propriété du droit d'auteur et des droits moraux qui protège cette thèse. $\mathrm{Ni}$ la thèse ni des extraits substantiels de celle-ci ne doivent être imprimés ou autrement reproduits sans son autorisation.
In compliance with the Canadian

Privacy Act some supporting forms may have been removed from this thesis.

While these forms may be included in the document page count, their removal does not represent any loss of content from the thesis.
Conformément à la loi canadienne sur la protection de la vie privée, quelques formulaires secondaires ont été enlevés de cette thèse.

Bien que ces formulaires aient inclus dans la pagination, il n'y aura aucun contenu manquant. 
PAGIAATION ERROR.

IEXI COMPLETE.
ERREOR DE PAGINAIION.

LE IEXTE EST COMPLET. 


\begin{abstract}
Hydrogen bond mediated self-assembling carbamates with alkyl side chains of different lengths were investigated with respect to thermal behaviour and morphology. The influence of the length of the alkyl side chain and the cooling rate on the morphology, heat of fusion, crystallinity and crystallite size has been determined. While plasticizers or clarifiers are usually used to modify the crystalline morphology of materials, we examined the possibility of effecting similar changes by blending any two types of carbamates. This has been accomplished without any reduction in the extent of hydrogen bonding. The blends show significant improvement in transparency as compared to the pure carbamates and also offer the advantage of low melt viscosity. Blends of these carbamates with other hydrogen bonded systems, non-hydrogen bonded systems and with the conventional clarifiers were also investigated in this study. Comparison between different blend systems indicates that hydrogen bonding plays an important role in controlling the morphology of self-assembling carbamate systems. These long chain carbamates form birefringent gels in benzonitrile, which show well-defined thermoreversible sol-gel transitions. The length of the alkyl chains affects the gel formation ability, sol-gel transition temperatures and the morphology of the xerogels.
\end{abstract}




\section{ACKNOWLEDGEMENTS}

I was lucky to get an opportunity to do my Ph.D. under the supervision of Professor P.R. Sundararajan. Last few years, I was blessed with his affection and impressed by his wisdom and teaching philosophy. My heart-felt thanks to him for the guidance and continuous support.

This work was supported by the Natural Sciences and Engineering Research Council of Canada (NSERC) and Xerox Research Centre of Canada (XRCC). I was partly supported by Ontario Graduate Scholarship for Science and Technology (OGSST).

I would like to thank my lab mates Dr. F. Khan, D. Yao, B. Tuteja, H. Xue, S. Bhalla and S. Khanna for their help and friendly discussions. My deepest gratitude to my parents and my brothers and sisters; they are thousand miles away from me, but they are always with me with their unconditional love and inspiration.

Finally, I would like to thank my wife Thamina (Rume) who has recently come into my life. I appreciate her patience and support during the period of writing this thesis. 


\section{TABLE OF CONTENTS}

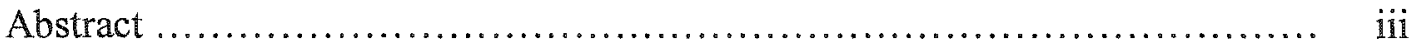

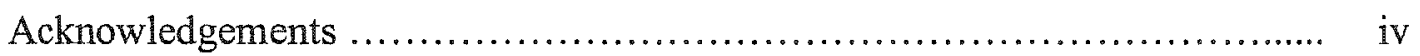

Table of Contents .................................................. $\mathrm{v}$

List of Tables ....................................................... $\mathrm{x}$

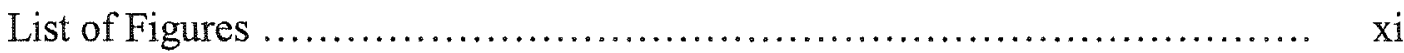

Chapter 1: Introduction............................................ 1

$1.1 \quad$ Molecular Self-Assembly ............................... 2

1.2 Molecular Self-Assembly in Nature........................ 2

1.3 Emerging Materials through Molecular Self-Assembly.......... 3

1.4 Self-Assembling Carbamates............................... 6

1.4.1 Applications of Carbamates........................... 7

1.4.2 Structural Investigations on Carbamates............... 8

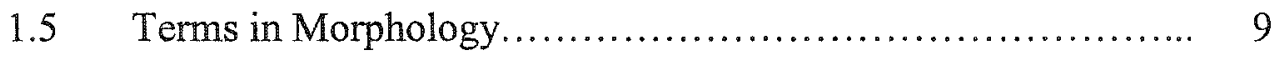

1.5.1 Birefringence.................................... 9

1.5.2 Miller Indices...................................... 9

1.5.3 The Crystallite Size and Long Spacing............... 10

1.5.4 Spherulites................................... 11

1.6 Importance of Controlling the Morphology ................... 12

1.7 Thesis Objectives.......................................... 13

1.8 Thesis Overview....................................... 14

1.9 References................................................ 16 


\section{TARLE OF CONTENTS Continued}

Chapter 2: Materials and Methods.................................... 21

$2.1 \quad$ Introduction............................................. 22

2.2 Synthesis and Characterization of the Carbamates.............. 22

2.2.1 FTIR and ${ }^{1} \mathrm{H}$ NMR spectra of the Carbamates........... 25

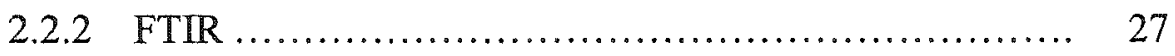

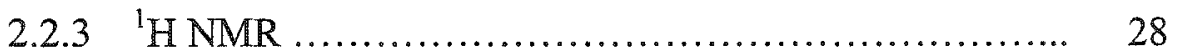

2.3 Preparation of the Blends.............................. 28

$2.4 \quad$ Other Materials............................................ 28

2.4.1 Stearic Acid...................................... 28

2.4.2 Polyethylene....................................... 29

2.4.3 Kemamide $\mathrm{S}$ (Octadecanamide) ................... 30

2.4.4 Kemamide E-180 (Stearyl Erucamide) .............. 31

2.5 Methods of Characterization.................................. 32

2.5.1 Differential Scanning Calorimetry (DSC) ............. 32

2.5.2 Thermogravimetric Analysis (TGA) ................. 34

2.5.3 Optical Microscopy............................... 34

2.5.4 Scanning Electron Microscopy (SEM) .............. 36

2.5.5 X-ray Diffraction................................ 37

2.5.6 Small Angle Light Scattering (SALS) ............... 43

2.5.7 FTIR Spectroscopy............................. 45

2.5.8 Molecular Modeling ................................... 47 


\section{TABLE OF CONTENTS Continued}

$2.6 \quad$ References..................................................... 48

Chapter 3: Morphology and Thermal Behaviour of Self-Assembling

Carbamates and Their Blends............................ 50

$3.1 \quad$ Introduction................................................. 51

3.2 Preparation of the Blends.................................. 52

3.3 Results and Discussion................................... 52

3.3.1 Optical Microscopy................................ 53

3.3.2 Small Angle Light Scattering ...................... 59

3.3.3 Thermal Analysis...................................... 62

3.3.4 X-ray Diffraction.................................. 69

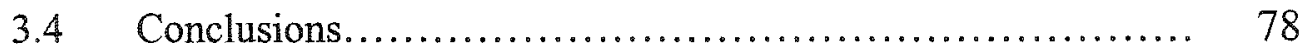

$3.5 \quad$ References................................................ 80

Chapter 4: Hydrogen-Bonding in Heterogeneous Blends: Blends of Carbamate and Stearic Acid $\ldots \ldots \ldots \ldots \ldots \ldots \ldots \ldots \ldots \ldots \ldots \ldots \ldots \ldots \ldots, \quad 81$

4.1 Introduction................................................ 82

4.2 Polymorphic Forms of Stearic Acid,.......................... 83

4.3 Structural Similarities Between $\mathrm{C}_{18}$ and $\mathrm{SA} \ldots \ldots \ldots \ldots \ldots \ldots . \ldots 3$

4.4 Preparation of the Blends.................................... 84

4.5 Results and Discussion.................................... 84

4.5.1 Optical Microscopy..................................... 84

4.5.2 Thermal Analysis.................................. 87 


\section{TABLE OF CONTENTS Continued}

4.5.3 X-ray Diffraction..................................... 91

4.5.4 IR Analysis...................................... 97

4.6 Conclusions ............................................... 99

$4.7 \quad$ Reference.................................................... 101

Chapter 5: The Role of Hydrogen Bonds in Controlling the Morphology of Self-Assembling Carbamate Systems........................ 102

$5.1 \quad$ Introduction............................................... 103

5.2 Preparation of the Blends.................................... 105

5.3 Results and Discussion..................................... 106

5.3.1 $\quad \mathrm{C}_{12} / \mathrm{PE}$ and $\mathrm{C}_{12} / \mathrm{KemS}$ Blends....................... 106

5.3.2 $\quad \mathrm{C}_{12} / \mathrm{KemE}$ Blends .................................. 116

$5.4 \quad$ Conclusions................................................ 125

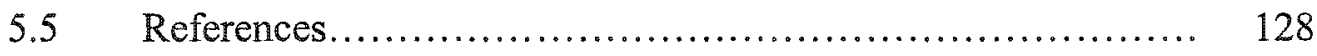

Chapter 6: Low Molecular Weight Organogels Based on Carbamates... 129

$6.1 \quad$ Introduction............................................... 130

6.2 Structural Requirements for LMOGs.......................... 131

6.3 Applications and Potential Applications of LMOG Gels......... 131

6.4 Carbamates as the LMGOs................................... 132

6.5 Preparation of the Gels...................................... 133

6.6 Preparation of the Films................................... 133 


\section{TABLE OF CONTENTS Continued}

$6.7 \quad$ Results and Discussion..................................... 134

6.7.1 Sol-Gel Transitions................................. 136

6.7.2 Morphology of the Xerogels .......................... 139

6.7.3 Films from the Organogels......................... 143

6.8 Conclusions................................................. 145

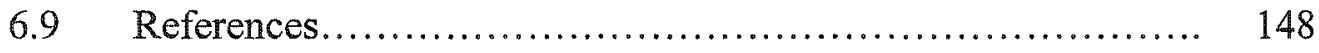

Chapter 7: Conclusions and Recommendations for Future Work.......... 151

$7.1 \quad$ Conclusions................................................ 152

7.2 Recommendations for Future Work......................... 154 


\section{LIST OF TABLES}

Table 2.1 Carbamates obtained from reactions of octadecyl isocyanate with different alcohols.

Table 2.2 Stretching frequencies of the IR bands of the carbamates. 27

Table 3.1 Molecular lengths, melting points and melt viscosities of different carbamates

Table 3.2 Melting points of the binary blends of carbamate. 68

Table 3.3 Interplanar spacings $d(\AA)$ and relative intensities (\%) of X-ray diffraction maxima for the various carbamates. 71

Table 4.1 Melting point(s) of $\mathrm{SA} / \mathrm{C}_{18}$ blends. 88

Table 5.1 Heats of fusion for the $\mathrm{C}_{12} / \mathrm{PE}, \mathrm{C}_{12} / \mathrm{KemS}$ and $\mathrm{C}_{12} / \mathrm{KemE}$ blends. . 113

Table 5.2 $\mathrm{C}=\mathrm{O}$ and $\mathrm{NH}$ frequencies of $\mathrm{C}_{12} / \mathrm{kemE}$ blends. 123 


\section{LIST OF FIGURES}

Figure 1.1 Nanowires (above) and nanotubes (below) formed from the self-assembly of symmetrically (above) and asymmetrically (below) substituted hexabenzocoronene molecules (Left) molecular structures; (center) molecular self-assembly simulation; and (right) scanning and electron microscope images of the respective molecular self-assemblies ...........................................

Figure 1.2 Self-assembly through hydrogen bonding in the carbamates......... 7

Figure $1.3(100),(010)$ and (001) planes of tetragonal and orthorhombic crystal systems. 10

Figure 1.4 Maltese cross in the spherulites of polyethylene ........................ 12

Figure 1.5 (a) large spherulites (b) small spherulites.............................. 13

Scheme 2.1 Preparation of carbamates.................................................... 23

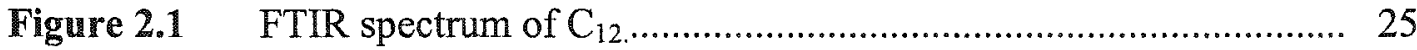

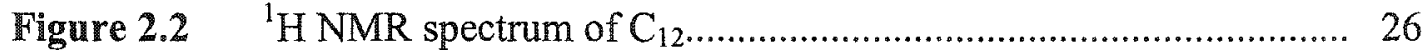

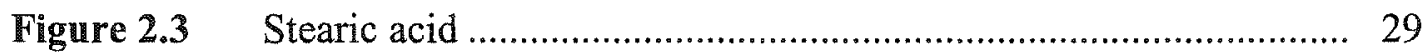

Figure 2.4 DSC thermograms of as received polyethylene and the sample after hot filtration from toluene.................................................... 30

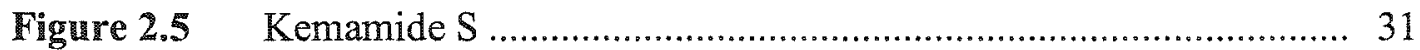

Figure 2.6 Kemamide E180 ........................................................... 32

Figure 2.7 Schematic representation of DSC cell .................................. 33

Figure 2.8 (a) positive spherulite and (b) negative spherulite....................... 35

Figure 2.9 Bragg construction illustrating the principle of diffraction where $d$ is the spacing between two atomic planes.

Figure 2.10 Schematic of the Bragg diffraction with the powder $\mathrm{X}$-ray diffractometer.

Figure 2.11 Fitted profile of a diffractogram with overlap of peaks 


\section{LIST OF FIGURES Continued}

Figure 2.12 Schematic of a Statton-type Warhus flat film camera (top) and the Bragg diffraction (bottom).

Figure 2.13 Small angle light scattering patterns from spherulitic polyethylene using (a) $\mathrm{V}_{\mathrm{v}}$ and (b) $\mathrm{H}_{\mathrm{v}}$ polarization.

Figure 2.14 Schematic of the experimental arrangement for small angle light scattering (from Stein and Rhodes).

Figure 3.1 Optical micrographs of different carbamates: slow cooled samples of $\mathrm{C}_{4}$ and $\mathrm{C}_{8}$ ( $\mathrm{a}$ and $\mathrm{b}$ respectively); quenched samples of $\mathrm{C}_{4}$ and $\mathrm{C}_{8}$ (c and $d$ respectively).

Figure 3.2 Optical micrographs of different carbamates: slow cooled samples of $\mathrm{C}_{12}, \mathrm{C}_{16}$ and $\mathrm{C}_{18}$ ( $\mathrm{a}, \mathrm{b}$ and $\mathrm{c}$ respectively); quenched samples of $\mathrm{C}_{12}, \mathrm{C}_{16}$ and $\mathrm{C}_{18}$ (d, e and $\mathrm{f}$ respectively).

Figure 3.3 Spherulite size as a function of number of carbons at the alkyl side chain derived from alcohol.

Figure 3.4 Optical micrographs of the slow cooled samples of $\mathrm{C}_{12} / \mathrm{C}_{16}$ blends (a) $80 / 20$ (b) $60 / 40$ (c) $50 / 50$

Figure 3.5 Transparency of (a) $\mathrm{C}_{12}$ (b) $\mathrm{C}_{16}$ (c) $80 / 20$ blend of $\mathrm{C}_{12} / \mathrm{C}_{16}$. All the samples are slowly cooled.

Figure 3.6 $\mathrm{H}_{\mathrm{v}}$ scattering pattern for $\mathrm{C}_{12}$ (a) slowly cooled (b) quenched 59

Figure 3.7 $\mathrm{H}_{\mathrm{v}}$ scattering pattern for blends of $\mathrm{C}_{12} / \mathrm{C}_{16}$ at composition of

(a) $80 / 20$ (b) $60 / 40$ (c) $50 / 50$ (d) $40 / 60$; all the samples are slowly cooled.

Figure 3.8 Spherulite size and heat of fusion as a function of wt $\%$ of $\mathrm{C}_{16}$ in the binary blends of $\mathrm{C}_{12}$ and $\mathrm{C}_{16}$

Figure 3.9 TG and DSC curves for $C_{16}$

Figure 3.10 (a) X-ray diffractograms and (b) $\mathbb{R}$ spectra of original $\mathrm{C}_{16}$ and the sample evaporated at $200^{\circ} \mathrm{C}$ and condensed on a microscope slide.

Figure 3.11 Heat of fusion as a function of no. of carbons at the alkyl side chain derived from alcohol 


\section{LIST OF FIGURES Continued}

Figure 3.12 DSC thermographs of binary blends of $\mathrm{C}_{12} / \mathrm{C}_{16}$ at (a) $80 / 20$ and $60 / 40$ (b) $50 / 50,60 / 40$ and $20 / 80$ (c) $90 / 10$ and $95 / 05$ compositions.

Figure 3.13 X-ray diffraction patterns of different carbamates.

Figure 3.14 Diffraction patterns obtained from (a) $\mathrm{C}_{8}$ (b) $80 / 20$ blend of $\mathrm{C}_{12} / \mathrm{C}_{16}$. The $d$-spacings are marked.

Figure 3.15 The distance between the alkyl chains in the hydrogen bonded network of carbamates

Figure 3.16 (a) Crystallite size corresponding to the reflection at $22.8^{\circ}$ and (b) Crystallinity as a function of number of carbon atoms at the alkyl side chain derived from alcohol.

Figure 3.17 $\mathrm{X}$-ray diffractograms of the binary blends of $\mathrm{C}_{12} / \mathrm{C}_{16}$ along with those of $\mathrm{C}_{12}$ and $\mathrm{C}_{16}$

Figure 3.18 Percent $\mathrm{X}$-ray crystallinity as a function of wt $\%$ of $\mathrm{C}_{16}$ in the binary blends of $\mathrm{C}_{12}$ and $\mathrm{C}_{16}$

Figure 4.1 Structures of $\mathrm{C}_{18}$ and SA.

Figure 4.2 Optical micrographs of $\mathrm{C}_{18}$ ( $\mathrm{a}$ and b) and SA (c and d). (a) and (c): slow cooled; (b) and (d): quenched.

Figure 4.3 Optical micrographs of $\mathrm{SA} / \mathrm{C}_{18}$ blends. All the samples were quenched from the melt.

Figure 4.4 DSC thermograms of slow cooled and quenched blends of $S A / C_{18}$ with $80 / 20$ composition.

Figure 4.5 Heat of fusion of slow cooled blends of $\mathrm{SA}_{\mathrm{N}} \mathrm{C}_{18}(--)$ and $\mathrm{C}_{12} / \mathrm{C}_{16}(-\mathrm{o}-)$

Figure 4.6 X-ray diffractograms of SA and $C_{18}$ and of their $50 / 50$ blend. All the samples are slowly cooled.

Figure 4.7 X-ray diffractograms of (a) SA and its blend with $30 \% \mathrm{C}_{18}$ (b) $\mathrm{C}_{18}$ and its blends with $30 \% \mathrm{SA}$. All the samples are slowly cooled. 


\section{LIST OF FIGURES Continued}

Figure 4.8 Intensity ratio of the diffraction maxima at $d=4.1 \AA$ and $40 \AA$ for the slow cooled and quenched blends.

Figure 4.9 Unit cell of stearic acid ....................................................... 96

Figure 4.10 IR spectra of $\mathrm{SA}$ and $\mathrm{C}_{18}$ and of their 50/50 blend.................. 97

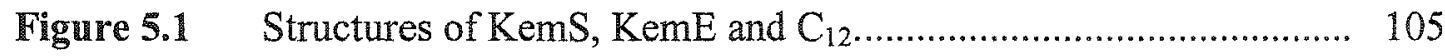

Figure 5.2 Optical micrographs of different samples: (a) $\mathrm{C}_{12}$, slow cooled (b) $\mathrm{C}_{12}$, quenched (c) KemS, slow cooled and (d) $\mathrm{KemS}$, quenched.(e) PE, slow cooled (f) KemE, slow cooled. Note: Scale bars represent $100 \mu \mathrm{m}$. The magnification is same for sample a-d.

Figure 5.3 Optical micrographs of the $\mathrm{C}_{12} / \mathrm{PE}$ blends (a) $90 / 10$, slow cooled (b) quenched; (c) 80/20, slow cooled (d) quenched. The magnification is same for $a$ and $b$. $c$-f have the same magnification.

Figure 5.4 Spherulite size of $\mathrm{C}_{12}$ in the slow cooled blend as a function of wt $\%$ of PE or KemS

Figure 5.5 Optical micrographs of the slow cooled blends of $\mathrm{C}_{12} / \mathrm{KemS}$ (a) $90 / 10$ (b) $85 / 15$ (c) and (d) $80 / 20$.

Figure 5.6 $\quad \mathrm{H}_{\mathrm{V}}$ scattering pattern for the $90 / 10$ blend of $\mathrm{C}_{12} / \mathrm{PE}$ (a) slowly cooled and (b) quenched.

Figure 5.7 X-ray diffractograms of the binary blends of (a) $\mathrm{C}_{12} / \mathrm{PE}$ and

(b) $\mathrm{C}_{12} / \mathrm{KemS}$.

Figure 5.8 Optical micrographs of the slow cooled blends of $\mathrm{C}_{12} / \mathrm{KemE}$

(a) $90 / 10$ (b) $85 / 15$ and (c) $80 / 20$

Figure 5.9 Transparency of different samples (a) $\mathrm{C}_{12}$ (b) $\mathrm{C}_{12} / \mathrm{PE}=80 / 20$

(c) $\mathrm{C}_{12} / \mathrm{KemS}=80 / 20$ (d) $\mathrm{C}_{12} / \mathrm{KemE}=80 / 20$. All the samples are slow-cooled.

Figure 5.10 $\mathrm{H}_{\mathrm{v}}$ scattering pattern for the quenched sample of (a) $\mathrm{C}_{12}$ and $\mathrm{C}_{12} / \mathrm{kemE}$ blends at composition of (b) $98 / 02$ (c) $90 / 10$

(d) $85 / 15$. 


\section{LIST OF FIGURES Continued}

Figure 5.11 Spherulite size as a function of $w t \%$ of $\mathrm{KemE}$ in $\mathrm{C}_{12} / \mathrm{KemE}$ blends.

Figure 5.12 DSC thermograms of $\mathrm{C}_{12}, \mathrm{KemE}$ and of their blends.

Figure 5.13 X-ray diffractograms of the binary blends of $\mathrm{C}_{12} / \mathrm{KemE}$ along with those of $\mathrm{C}_{12}$ and $\mathrm{KemE}$.

Figure 5.14 The crystallite size and the full width at half maximum corresponding to the reflection at $22.8^{\circ}$ as a function of $\mathrm{C}_{12} / \mathrm{KemE}$ blend composition.

Figure 5.15 FTIR spectra of $\mathrm{C}_{12}, \mathrm{KemE}$ and their blends.

Figure 6.1 Sol-gel transition temperatures for carbamate/benzonitrile gels as a function of number of carbons of the carbamates at the alkyl side chain derived from alcohol. ( $\bullet$ ) from gel to solution; (o) from solution to gel

Figure 6.2 DSC curves of $\mathrm{C}_{8}$ /benzonitrile gel with $\mathrm{C}_{8}$ concentration of 0.04 mol dm${ }^{-3}$. Heating and cooling rate: $10^{\circ} \mathrm{C} \mathrm{min}$.

Figure 6.3 Sol-gel transition temperatures for $\mathrm{C}_{8}$ /benzonitrile gels as a function of concentration of $\mathrm{C}_{8}:(\bullet)$ from gel to solution; (o) from solution to gel.

Figure 6.4 SEM images of the xerogels obtained from the quenched gels of $\mathrm{C}_{7}$ and $\mathrm{C}_{8}$ (a and $\mathrm{b}$ respectively); from the slow cooled gels of $\mathrm{C}_{7}$ and $\mathrm{C}_{8}$ (c and d respectively).

Figure 6.5 SEM images of the xerogels obtained from the quenched gels of $\mathrm{C}_{10}$ and $\mathrm{C}_{12}$ ( $\mathrm{a}$ and $\mathrm{b}$ respectively); from the slow cooled gels of $\mathrm{C}_{10}$ and $\mathrm{C}_{12}$ (c and $\mathrm{d}$ respectively).

Figure 6.6 SEM images of the dried samples obtained from the slow cooled solutions of (a) $\mathrm{C}_{16} /$ benzonitrile and (b) $\mathrm{C}_{18}$ /benzonitrile

Figure 6.7 (a) $\mathrm{X}$-ray diffraction pattem obtained from the fibers of $\mathrm{C}_{8}$ xerogel

(b) schematic of $x$-ray and (c) molecular packing in $C_{8}$. 144

Figure 6.8 SEM images of the xerogels obtained from $\mathrm{C}_{8}$ /benzonitrile gels at different concentration of $\mathrm{C}_{8}$ : (a) $0.04 \mathrm{M}$ (b) $0.08 \mathrm{M}$ (c) $0.1 \mathrm{M}$ 
Chapter 1

Introduction 


\subsection{Molecular Self-Assembly}

Molecular self-assembly is the spontaneous organization of molecules under thermodynamic equilibrium conditions into structurally well-defined and rather stable arrangements through a number of noncovalent interactions ${ }^{1,2,3}$. The key elements in molecular self-assembly are chemical complementarity and structural compatibility ${ }^{4}$. Self-assembling systems contain molecular building blocks that are able to undergo spontaneous stepwise interactions and assemblies through the formations of numerous noncovalent weak chemical bonds e.g. hydrogen bonds, ionic bonds and van der Waal's bonds ${ }^{5}$. The collective interactions of these weak chemical bonds can result in very well defined and stable hierarchical macroscopic structures and materials.

\subsection{Molecular Self-Assembly in Nature}

Molecular self-assembly is ubiquitous in nature. Self-assembly in silk is a well-known example. The monomeric silk fibroin protein is approximately $1 \mu \mathrm{m}$ but a single silkworm can spin fibroins into silk materials over $2 \mathrm{~km}$ in length, two billion times longer ${ }^{6,7}$. Spiders can produce many types of spider silks through self-assembly of the building blocks in a variety of ways, thus, producing spider silk fiber with tremendous strength and flexibility. These building blocks are often at the nanometer scale ${ }^{4}$. Similarly, individual phospholipid molecules are approximately $2.5 \mathrm{~nm}$ in length, but they can self-assemble into millimeter-size lipid tubules with defined helical twist, many million times larger. Collagen and keratin can self-assemble into ligaments and hair, respectively ${ }^{4}$. In cells, the self-assembly of many individual chaperone proteins results into a well-defined ring structure to sort out, fold and refold proteins ${ }^{8}$. Mammals build 
their teeth through self-assembly of a protein scaffold that recruit calcium ions for biomineralization ${ }^{4}$.

The essential features of biological self-assembly are well recognized. For example, proteins require specific sequences of amino acid to act as enzymes. The elements in proteins must fold up into a required shape to create a substrate-specific docking site. Combinations of several interactions create minima in the local free energy as a function of different chain conformations for proteins 9 .

\subsection{Emerging Materials through Molecular Self-Assembly}

Molecular self-assembly has recently emerged as a new approach in chemical synthesis, nanotechnology, polymer science, material science and engineering. In the last decade, considerable advances have been made in the use of peptides, phospholipids and DNA as building blocks to produce potential bio-based materials for a wide range of applications ${ }^{10}$. Structural order over many length scales can be created in self-assembling materials by the presence of several molecular interactions including (i) hydrophobic and hydrophilic effects, (ii) hydrogen bonding, (iii) coulombic interactions, and (iv) van der Waals forces ${ }^{1}$. A number of synthetic self-assembling materials have been created that depend essentially on a single molecular interaction. These materials provide the basis for future materials that will require multiple organizing processes.

Lehn and co-workers ${ }^{11}$ have introduced base-pair structures into oligomeric units that imitate nucleic acids. By preparing matched base-pair segments, molecular ropes were 
produced that forms strands of complexed units. These strands mimic some of the natural fiber-forming polymers but are held together entirely by hydrogen bonds. Similar basepair chemical groups have been introduced by Stadler et $a l^{I^{2}}$ into elastomers to form thermally reversible networks by taking advantage of the modest thermal stability of these weak noncovalent bonds. Kato et $a l^{13}$ and Bazuin et $a l^{14}$ have attached LC groups to polymer backbones by using single hydrogen bonds. These structures are thermally stable at the required processing temperatures. Simple surfactants have been hydrogen-bonded to polymer backbones by Ruokalainen et $\mathrm{al}^{15}$ to create ordered mesomorphic materials.

Stoddard and co-workers ${ }^{16}$ used $\pi$-stacking interactions between aromatic rings to construct catenanes which are large interlinked molecular ring structures with oligomeric properties. Such materials display unusual optical properties. Another example of supramolecular assembly is the preparation of rotaxanes, macromolecules in which a polymer backbone is threaded through several macrocycles and locked in place by capping the chain ends ${ }^{17}$. Development of molecular devices based on rotaxanes and catenanes is a subject of current interest ${ }^{18}$.

Another strategy involves the formation of complexes between polyelectrolyte molecules and oppositely charged surfactant micelles ${ }^{9}$. Typically, many surfactant micelles adsorb on a single polyelectrolyte chain. The stability and size of such complexes can be adjusted by the ionic strength of the solution and charge density of the micelle. Complexes between polycations and proteins of net positive charge can be produced by using negatively charged patches on the protein surface ${ }^{9}$. Other research has focused on building solid-state materials by combining polyelectrolytes and surfactants ${ }^{19}$. 
The self-assembly of block copolymers have been utilized for drug delivery. In solution, amphiphilic diblock copolymers form micelles. The drug is either entrapped in the hydrophobic core of the micelle or covalently bound to the hydrophobic block ${ }^{20,21}$. The advantage of such drug delivery systems derive from alterations of the pharmacokinetic profile of entrapped drugs, drug solubilization and/or stabilization, or from overcoming the efflux pump-type form of multidrug resistance ${ }^{21,22}$.

Molecular self-assembly is a highly promising field of research in nanotechnology today. The accurate and controlled application of intermolecular forces on a molecular scale can lead to new, previously unachievable, nanostructures ${ }^{23}$. As shown in Figure 1.1, symmetrically substituted hexabenzocoronene (HBC) molecules self-assemble in solutions into nanowires several hundreds nanometers in length and $3 \mathrm{~nm}$ in diameter ${ }^{23}$. The ordered alignments in the molecules ensure a homogenous electronic coupling along the length of the nanowire. Hill $e t a l^{24}$ have recently reported the self-assembly of asymmetric substituted amphiphilic $\mathrm{HBC}$ molecules into remarkably defect-free large nanotubular objects, with a clearly defined helicity.

These are only a few examples of the immense possibilities that molecular self-assembly can offer. New technology through molecular self-assembly as a fabrication tool will become tremendously important in the coming decades ${ }^{4}$. 

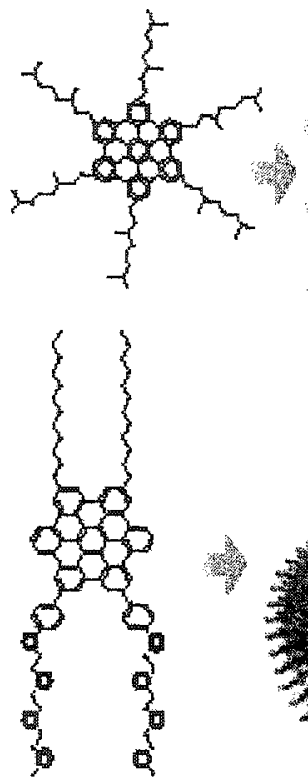
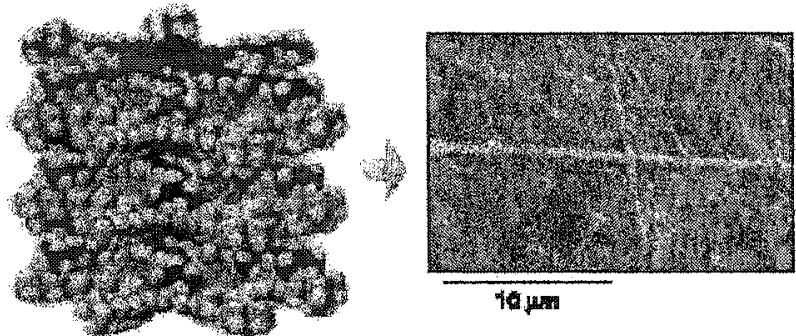

10 H.

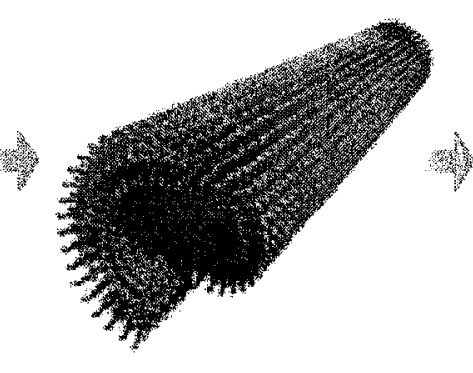

Figure 1.1 Nanowires (above) and nanotubes (below) formed from the self-assembly of symmetrically (above) and asymmetrically (below) substituted hexabenzocoronene molecules $^{23,24 .}$ (Left) Molecular structures; (center) Molecular self-assembly simulation; and (right) scanning and electron microscope images of the respective molecular selfassemblies.

\subsection{Self-Assembling Carbamates}

This thesis deals with the morphological investigations of some self-assembling carbamates which are the analogue of the hard segment of polyurethanes. The association process in carbamates is similar to the biological self-assembly (e.g. protein molecules) involving hydrogen bonding (Figure 1.2). 


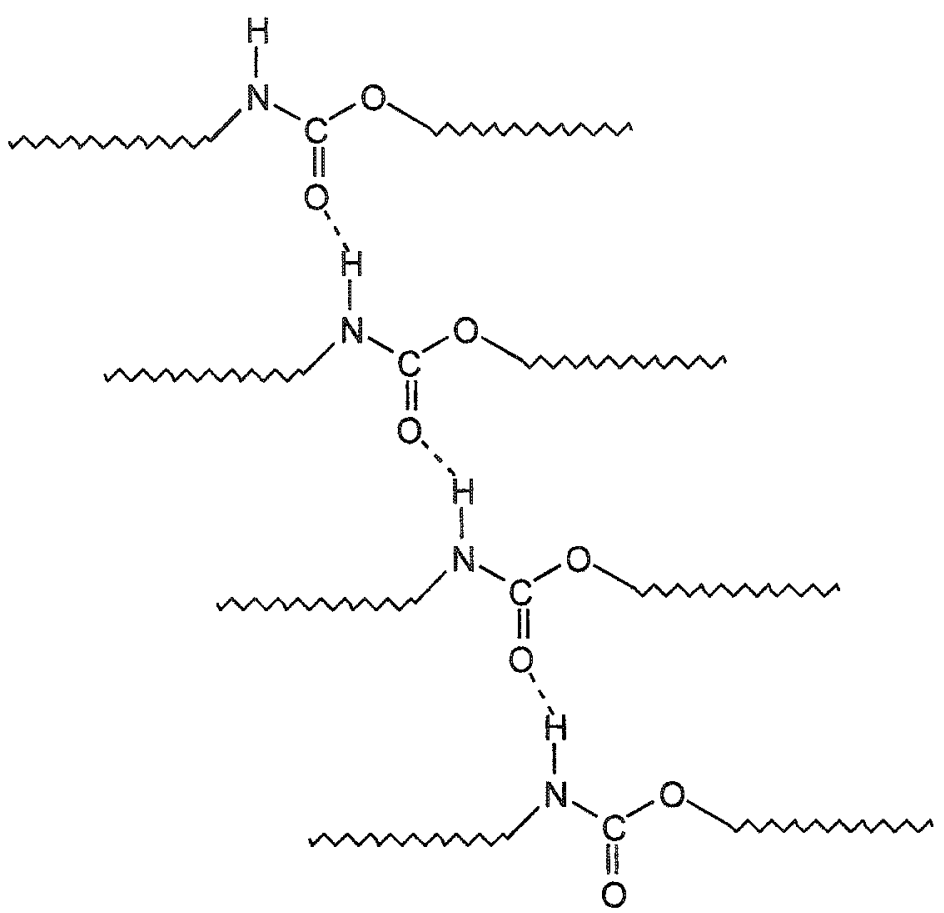

Figure 1.2 Self-assembly through hydrogen bonding in the carbamates

\subsubsection{Applications of Carbamates}

Carbamates have potential for many scientific and technological applications. They have been used to understand some catalytic processes and the kinetics of the reactions accompanying the polyurethane synthesis process ${ }^{25,26}$. The structural similarities of polyurethanes and carbamates were also utilized in hydrolytic stability and thermal resistance tesís of these polymers ${ }^{27,28}$. They can be used for increasing the abrasion resistance of polyurethane compositions ${ }^{29}$, improving the hardness of urethane-based adhesives and sealants ${ }^{30}$, and as additives for adjusting viscosity values of oils and 
greases $^{31,32}$. Some carbamates and thiocarbamates have biological activity and can be utilized as insecticides ${ }^{33}$. Their melt viscosity is usually of the order of a few centipoises, and they crystallize rapidly. Hence, carbamates with alkyl side chains have potential applications as vehicles in reprography and ink jet printing technologies ${ }^{34,35,36}$.

\subsubsection{Structural Investigations on Carbamates}

There are very few examples in the literature that deals with the structure and properties of carbamates. Furer computed the dynamic and electro-optical parameters (EOPs) of carbamates by the MNDO/3 method ${ }^{37}$. He reported an extensive study on the hydrogen bonding and IR spectra of different carbamates in conjunction with quantum-chemical calculations that can provide a probe of the actual conformations and associates present in the different phases of carbamates ${ }^{38,39,40}$. Deetz et al $l^{41}$ used hydrogen bonding templates to control the syn-anti $\mathrm{C}-\mathrm{N}$ rotamer equilibrium in pyridyl carbamates, leading to an effective "conformational switch". Krol et $a l^{42}$ utilized X-ray diffraction and thermal analysis to investigate the structure and properties of some short chain mono- and dicarbamates as model compounds for urethane polymers. They found that carbamates, which were single compounds, developed their crystal structures far better than mixtures of the two isomers did. The diffractograms for the mixtures of two isomers showed lower intensity and wider peaks indicating lower crystal organization and/or defective crystal structures of those compounds. The thermal stability of monocarbamates was found to be higher than that of dicarbamates obtained from the same alcohol. 


\subsection{Terms in Morphology}

In the next chapters, some basic terms related to morphology will be used very frequently. These terms are briefly introduced below.

\subsubsection{Birefringence}

Crystalline materials may have different indices of refraction associated with different crystallographic directions. A common situation with many crystals is that there are two distinct indices of refraction, and they are called birefringent materials. Birefringence is the numerical difference between the refractive indices in an anisotropic crystal. It appears as a band of polarization colors under crossed polars.

Birefringence $=\mathrm{n}_{2}-\mathrm{n}_{1}$

where $n_{2}$ is the higher refractive index and $n_{1}$ is the lower refractive index.

\subsubsection{Miller Indices}

A universally accepted system of indices has been developed to describe the positions of crystallographic planes and crystal faces relative to crystallographic axes. This convention is called the system of Miller indices.

For a three- dimensional unit cell, three indices are required and are conventionally designated $h, k$ and $l$. Figure 1.3 shows the (100), (010) and (001) planes of tetragonal and orthorhombic crystal systems. 

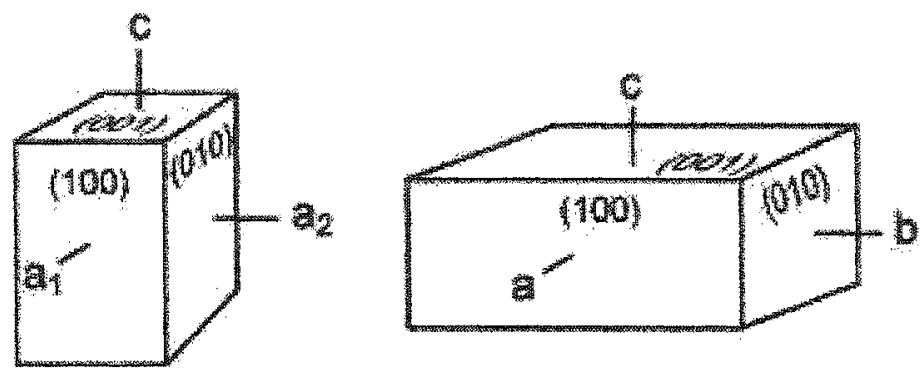

(a) Tetragonal

(b) Orthorhombic

Figure $1.3(100),(010)$ and (001) planes of tetragonal and orthorhombic crystal systems.

\subsubsection{The Crystallite Size and Long Spacing}

In the crystallization of crystalline or semicrystalline compounds, we deal with two parameters related to growth and perfection: the crystallite size and the long spacing or lamellar spacing.

The crystallite size is the growth of a crystalline region along a specific lattice direction. These are calculated from $x$-ray line broadening. The larger the crystallite size, the sharper will be the $\mathrm{x}$-ray reflection corresponding to that lattice direction. In reporting the crystallite size, the Miller indices of the reflection have to be specified. This is usually of the order of $100 \AA$.

The long spacing is the overall size of a crystalline lamellar domain. This is obtained from small angle $\mathrm{X}$-ray scattering (or neutron diffraction). This is usually in the range of 200 to $1000 \AA$. Since this is an "average overall", no directional specifications apply. 


\subsubsection{Spherulites}

Spherulites are a ubiquitous form of crystalline aggregates that occur in a wide range of materials and are characterized by radial growth leading to spherical symmetry. Spherulites are optically anisotropic due to the arrangement of the anisotropic crystallites within the spherulites with differing radial and tangential refractive indices denoted by $n_{r}$ and $n_{t}$ respectively ${ }^{43}$. This optical anisotropy gives rise to birefringence, which is defined as

$$
\Delta n=n_{r}-n_{t}
$$

If the spherulite has its larger refractive index in the radial direction, it has a positive birefringence; if the tangential direction has the higher refractive index, the spherulite has a negative birefringence ${ }^{44}$. For example, polyethylene spherulites exhibit negative birefringence, whereas starch and polyamide spherulites exhibit positive birefringence.

When a thin section of a sample containing spherulites is examined between crossed polars in a polarized optical microscope, it shows a dark extinction pattern in the shape of a Maltese cross of which one arm is aligned with the vibration direction of the polarizer and the other arm is aligned with the vibration direction of the analyzer. Figure 1.4 shows the Maltese cross in the spherulites of a polyethylene sample. On rotation of the specimen, the arms of the Maltese cross remain parallel to the vibration directions of the polars. This shows that the section of the spherulite has circular symmetry which could be either radial or tangential ${ }^{44}$. 


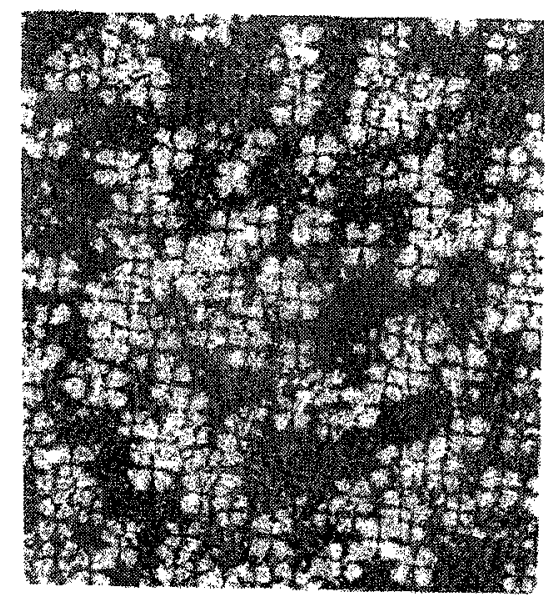

Figure 1.4 Maltese cross in the spherulites of polyethylene ${ }^{45}$

\subsection{Importance of Controlling the Morphology}

Control of spherulite or crystal size and crystallinity during crystallization is very critical for application of a material. As an example, we can consider the case of self-assembling carbamates. As mentioned above, due to the low melt viscosity and semi-crystalline nature, long chain carbamates can be used as a vehicle in ink formulation for ink-jet printers ${ }^{6-8}$. In such applications, the vehicle should crystallize with high transparency and should be crease resistant. If the vehicle is opaque, the color of the dye will be affected, especially in overhead transparencies. The average size of the spherulites upon crystallization should be of the order of the wavelength of light to impart transparency. Such small spherulites also increase the crease resistance. The large spherulites in Figure $1.5 \mathrm{a}$ will lead to hazy and brittle prints, whereas the small spherulites in Figure $1.5 \mathrm{~b}$ will lead to transparent prints. Thus, control of the crystalline morphology is an important factor for the sophisticated use of a material. 

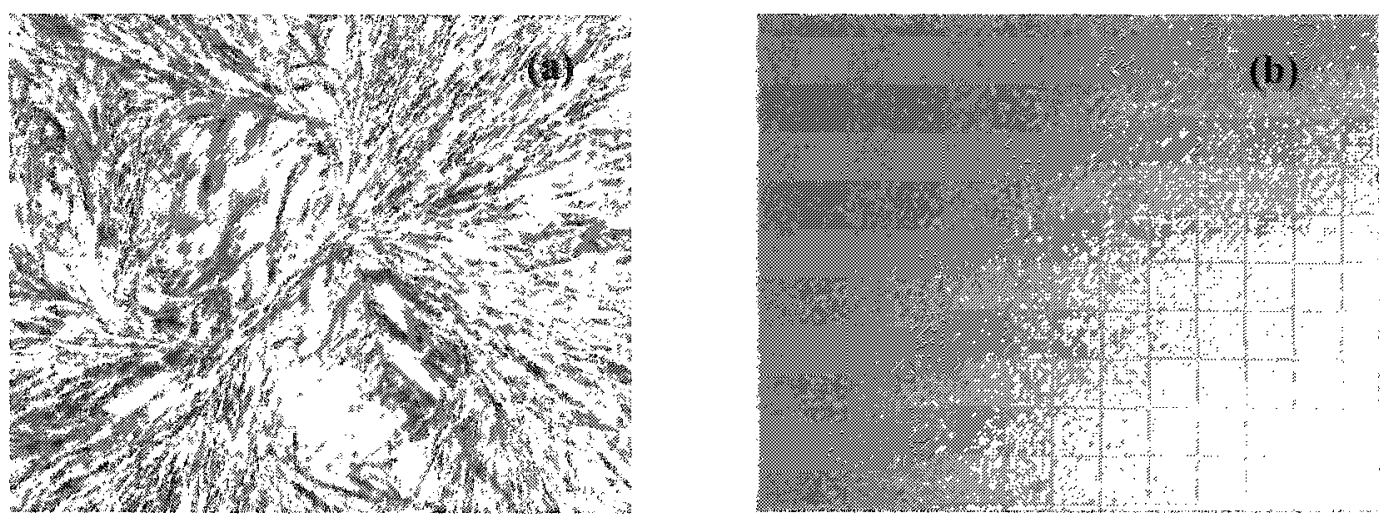

Figure 1.5 (a) large spherulites (b) small spherulites

\subsection{Thesis Objectives}

The overall objective of this thesis was to investigate the role of hydrogen bonding in controlling the morphology in the blends of self-assembling systems. Long chain carbamates were used in this study because of their potential industrial applications, as mentioned in section 1.4.1.

The basic objectives of this thesis were:

1. To synthesize some long chain monocarbamates which have alkyl side chains of different lengths;

2. To investigate the thermal behaviour and morphology of these carbamates;

3. To examine the effect of cooling rate on the morphology of these carbamates;

4. To study the blend systems of two homologous carbamates with a view to controlling the morphology; 
5. To study the blends of these carbamates with other hydrogen bonded systems and non-hydrogen bonded systems;

6. To compare the above blend systems with commercial clarifiers; and

7. To prepare low molecular weight organogels based on these carbamates and study the thermal properties of the organogels and morphology of the xerogels obtained from the gels.

\subsection{Thesis Overview}

This thesis is divided into seven chapters. In chapter 1, we have given a general introduction to the molecular self-assembly, discussed the importance of self-assembling compounds, literature review on self-assembling carbamates and applications of the carbamates, some basic concepts of morphology, and the importance of controlling the morphology.

Chapter 2 describes the synthesis of the carbamates, chemical structures and physical properties of the other materials used in this study, procedure used for sample preparation and the different methods used for the characterization of the carbamates and their blends.

Chapter 3 presents the results of the morphological investigations of the carbamates as well as the blends of two homologous carbamates and discussion of the results thus obtained. The effect of cooling rate on the morphology of the samples is also discussed here. 
Chapter 4 presents the results for the blends of carbamate and stearic acid and discussion of the results obtained.

Chapter 5 discusses the changes in the morphology of the blends of a carbamate with low molecular weight polyethylene as well as with two commercial clarifiers, namely Kemamide $\mathrm{S}$ and Kemamide $\mathrm{E}$. The role of hydrogen bonding in controlling the morphology of self-assembling carbamate systems is also discussed in this chapter.

Chapter 6 describes the preparation of a new family of low molecular weight organogels based on long chain carbamates. The results from the thermal investigations of the gels and morphological investigations of the xerogels obtained from these organogels are presented. The effect of gel formation procedure, structure and concentration of the carbamates on the morphology and thermal behaviour is also discussed in this chapter.

Chapter 7 presents the main conclusions from the present work and recommends some ideas for future work. 


\subsection{References}

1 Whitesides, G. M.; Mathias, J. P.; Seto, C. T. Science 1991, 254, 1312-9.

2 Lehn, J. M. Science 1993, 260, 1762-3.

3 Ball, P. Nature 1994, 367, 323-4.

$4 \quad$ Zhang, S. Biotechnology Advances $2002,20,321$.

5 Pauling, L. Nature of the Chemical Bond and the Molecular Crystals: An Introduction to Model Chemistry. 3rd ed; Cornell University: New York, 1960.

6 Feltwell, J. The story of silk; Alan Sutton Publishing: UK, 1990.

7 Winkler, S.; Szela, S.; Avtges, P.; Valluzzi, R.; Kirschner, D. A.; Kaplan, D. Int. J. Biol. Macromol. 1999, 24, 265-70.

8 Sigler, P. B.; Xu, Z.; Rye, H.S.; Burston, S. G.; Fenton, W.A.; Horwich, A. L. Annu. Rev. Biochem. 1998, 67, 581-608.

9 Muthukumar, M.; Ober, C.K.; Thomas, E.L. Science, 1997, 277, 1225.

10 (a) Schnur, J. Science 1993, 262, 1669-76.

(b) Ghadiri, M. R.; Granja, J. R.; Buehler L. K. Nature 1994, 369, 301-4.

(c) Bong, D. T.; Clark T. D.; Granja, J. R.; Ghadiri, M. R. Angew. Chem. Int. Ed. $2001,40,988-1011$.

(d) Zhang, S.; Holmes, T.; Lockshin, C.; Rich, A. Proc. Natl. Acad. Sci. USA $1993,90,3334-8$.

(e) Holmes, T.; Delacalle, S.; Su, X.; Rich, A.; Zhang S. Proc. Natl. Acad. Sci. USA 2000, 97, 6728-33. 
(1) Aggeli, A.; Bell, M.; Boden, N.; Keen, J. N.; Knowles, P. F.; McLeish T. C.; Pitkeathly, M. Nature 1997, 386, 259-62.

(g) Aggeli, A.; Nyrkova, I. A.; Bell, M.; Harding, R.; Carrick, L.; McLeish, T.C.B.; Somenov, A.N.; Proc. Natl. Acad. Sci. USA 2001, 98, 11857-62.

(h) Alivisatos, A. P.; Johnsson, K. P.; Peng, X.; Wilson ,T. E.; Loweth, C. J.; Bruchez, Jr. M. P.; Schultz, P. G. Nature 1996, 382, 609-11.

(i) Mirkin, C.A.; Letsinger, R.L.; Mucic, R. C.; Storhoff, J. J. Nature 1996, 382, 607.

(j) Winfree, E.; Liu, F.; Wenzler, L. A.; Seeman, N. C. Nature 1998, 394, 539-44.

11 (a) Gulik-Krzywicki, T.; Fouquey, C.; Lehn, J.-M. Proc. Natl. Acad. Sci. U.S.A. $1993,90,163$.

(b) Kotera, M.; . Lehn, J.-M; Vigneron, J.-P. Tetrahedron 1995, 51, 1953.

12 Müller, M.; Kremer, F.; Stadler, R.; Fischer, E. W; Seidel, U. Colloid Polym. Sci. 1995, 273, 38 .

13 (a) Kato, T.; Kihara, H.; Kumar, U.; Uryu, T.; Fréchet, J. M. J. Angew. Chem. Int. Ed. Engl. 1994, 33, 1644.

(b) Kato, T.; Nakano, M.; Moteki, T.; Uryu, T.; Ujiie, S. Macromolecules 1995, 28,8875 .

14 (a) Brandys, F. A; Bazuin, C. G. Chem. Mater.1996, 8, 83.

(b) Bazuin, C. G.; Tork, A. Macromolecules 1995, $28,8877$.

15 (a) Ruokalainen, J. Macromolecules 1995, 28, 7779. 
(b) Ruokalainen, J.; ten Brinke, G.; Ikkala, O.; Torkkeli, M.; Serimaa, R. ibid. $1996,29,3409$.

16 Ashton, P. R. Angew. Int. Ed. Engl. 1997, 36, 735.

17 (a) Gong, C.; Gibson, H. Macromolecules 1996, 29, 7029.

(b) Wenz, G. Angew. Chem. Int. Ed. Engl. 1994, 33, 803.

18 (a) Qu, D. H.; Wang, Q.C.; Ren, J.; Tian, H. Org. Lett. 2004, 6, 2085.

(b) Mobian, P.; Kern, J.M.; Sauvage, J.P. Angew. Chem. Int. Ed. 2004, 43, 2392.

(c) Vingon, S. A.; Jarrosson, T.; Iijima, T.; Tseng, H.R.; Sanders, J.K.M.; Stoddart, J. F. J. Am. Chem. Soc. 2004, 126, 9884.

19 Ober, C. K.; Wegner, G. Adv. Mater. 1997, 9, 17.

20 Kataoka, K.; Harada, A.; Nagasaki, Y. Adv. Drug Deliv. Rev. 2001, 47, 113.

21 Kabanov, A. V.; Batrakova, E.V.; Alakhov, V.Y. Adv. Drug. Del. Rev. 2002, 54, 759.

22 Kown, J.S.; Okano, T. Drug Deliv. Pharm. Res. 1999, 16, 597.

23 Blau, W. J.; Fleming, A.J. Science, 2004, 304, 1457.

24 Hill, J.P.; Jin, W.; Kosaka, A.; Fukushima, T.; Ichihara, H.; Shimomura, T.; Ito, K.; Hashizume, T.; Ishii, N.; Aida, T. Science 2004, 304, 1481.

25 Wong, S.; Frisch, C. Polym. Mater. Sci. Eng. 1984, 50, 480.

26 Liptova, T.E.; Bakalo, L.A.; Kzirkova, L.J. Sint. Fiz.-Khim. Polim. 1978, $23,74$.

27 Kordomenos, P.I.; Kusta, I.E.; Frisch, K.C.; Reegen, S.L. Polym. Sci. Polym. Chem. Ed. 1973, 11, 1683.

28 De Aquirre, I.; Collot, J. Bull. Soc. Chim. Belg. 1989, 98, 19. 
29 Steichele, K. Belg. Patent 882, 922 (1980). Chem. Abstr. 94, 66768d.

30 Saka, K.; Noda, K; Jpn. Kokai Tokkyo Koho JP 62179584 (1987) Chem. Abstr. 108,39820 .

31 Tanaka, K.; Kano, Y.; Yoshida, K. Jpn. Kokai Tokkyo Koho JP 63248894 (1988). Chem. Abstr. 110, 79137w.

32 Kinoshita, H.; Sekiya, M.; Mishima, M. Eur. Pat. EP 274756 (1988). Chem. Abstr. 109, 233979k.

33 Kochansky, J.; Cohen, C. F. J. Agric. Ent. 1990, 7, 293.

34 Jpn. Kokai Tokkyo Koho JP 58201758 (1983). Chem. Abstr. 100,174289z.

35 Tanaka, T.; Yoshitomi, T.; Hanada, Y.; Ohashi, M.; Takeda, Y. Jpn. Kokai Tokkyo Koho JP 6290 289. Chem. Abstr. 107, 20896b.

36 Goodbrand, B.; Boils, D.;. Sundararajan, P. R.; Wong, R.; Malhotra, S. U. S. Patent 6,187,082 (2001).

37 Furer, V. L. J. Mol. Struct. 1992, 56, 43.

38 Furer, V. L. J. Mol. Struct. 1998, 449, 53.

39 Furer, V. L. J. Mol. Struct. 1999, 513,1.

40 Furer, V. L. J. Mol. Struct. 2000, 520, 117

41 Deetz, M. J.; Jonas, M.; Malerich, J. P.; Smith, B. D. Supramolecular Chemistry $2002,14,487$.

42 Krol, P.; Wietrzynska-Lalak, Z. Eur. Polym. J. 1995, 31, 689.

43 Stein, R. S.; Rhodes, M.B. J. Appl. Phys. $1960,31,1873$. 
44 Saville, B.P. in Applied Polymer Light Microscopy; Hemsley, D.A., Ed.; Elsevier Science Publishers Ltd.: New York, 1989; Chap. 4.

45 Sharples, A. Introduction to Polymer Crystallization; Ermond Arnold Pub: London, 1966. 
Chapter 2

Materials and Methods 


\subsection{Introduction}

The materials used for the present study were:

(i) A homologous series of long-chain monocarbamates which have alkyl side chains of different lengths

(ii) Stearic acid

(iii) Low molecular weight polyethylene

(iv) Commercial clarifiers Kemamide S and Kemamide E-180

(v) Blends of carbamates with the above materials.

This chapter describes the synthesis, purification and characterization of the carbamates. The chemical structures and physical properties of the other materials used in this study and the procedure for the preparation of the blends are discussed. The principle of operation of the various techniques that were used for the characterization of the carbamates and their blends is also discussed in brief in this chapter.

\subsection{Synthesis and Characterization of the Carbamates}

The carbamates were synthesized by reactions of octadecyl isocyanate with 1-butanol, 1 heptanol, 1-octanol, 1-decanol, 1-dodecanol, 1-hexadecanol and 1-octadecanol. All the reagents were purchased from Aldrich. Reactions between the isocyanate $(0.1 \mathrm{~mol})$ and the suitable alcohol $(0.1 \mathrm{~mol})$ were carried out in toluene solution $(200 \mathrm{ml})$, at $60^{\circ}-70^{\circ} \mathrm{C}$ for two hours (Scheme 2.1). 1,4-diaza bicyclo [2.2.2] octane (DABCO) was used as the catalyst. $\mathrm{DABCO}$ is commonly used to catalyze urethane formation; it is a more effective 
catalyst than most other tertiary amines, possibly because the rigid cyclic system minimizes stearic interference ${ }^{1}$.

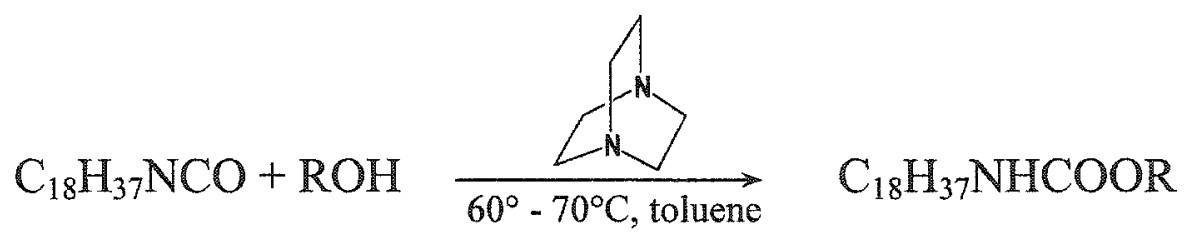

\section{Scheme 2.1 Preparation of carbamates}

The hot solution was cooled down using an ice bath and the reaction products were isolated by filtration. The isolated products were dissolved in a minimum amount of toluene at $50^{\circ} \mathrm{C}$ for recrystallization and were cooled down slowly. The recrystallization procedure was repeated twice to get rid of the impurities or unreacted reagents. The yields of the products were $>90 \%$.

There is no report in the literature of the synthesis of these long chain carbamates. However, $\mathrm{Kim}$ et $a l^{2}$ recently reported the synthesis of a similar carbamate, $\mathrm{C}_{18} \mathrm{H}_{37} \mathrm{NHCOOC}_{14} \mathrm{H}_{29}$, without using the catalyst. The reaction required longer time (12 hours) and the yield was low (59.5\%).

The reaction products were confirmed by $I R$ and ${ }^{1} H$ NMR. The carbamates that were synthesized are listed in Table 2.1 with the samples identified as $\mathrm{CX}_{\mathrm{X}}$, which stands for the carbamate having $X$ number of carbon atoms at the alkyl side chain derived from alcohol, For convenience, this sample ID will be used through out this thesis. 
Table 2.1 Carbamates obtained from reactions of octadecyl isocyanate with different alcohols

\begin{tabular}{lcccc}
\hline Parent alcohol & Carbamate ID & N-Octadecyl- & Formula & $\mathrm{T}_{\mathrm{m}}\left({ }^{\circ} \mathrm{C}\right)$ \\
& \multicolumn{5}{c}{ carbamate } \\
\hline 1-butanol & $\mathrm{C}_{4}$ & butyl ester & $\mathrm{C}_{18} \mathrm{H}_{37} \mathrm{NHCOOC}_{4} \mathrm{H}_{9}$ & 61 \\
1-heptanol & $\mathrm{C}_{7}$ & heptyl ester & $\mathrm{C}_{18} \mathrm{H}_{37} \mathrm{NHCOOC}_{7} \mathrm{H}_{15}$ & 66 \\
1-dectanol & $\mathrm{C}_{8}$ & octyl ester & $\mathrm{C}_{18} \mathrm{H}_{37} \mathrm{NHCOOC}_{8} \mathrm{H}_{17}$ & 66 \\
1-dodecanol & $\mathrm{C}_{10}$ & decyl ester & $\mathrm{C}_{18} \mathrm{H}_{37} \mathrm{NHCOOC}_{10} \mathrm{H}_{21}$ & 69 \\
1-hexadecanol & $\mathrm{C}_{12}$ & dodecyl ester & $\mathrm{C}_{18} \mathrm{H}_{37} \mathrm{NHCOOC}_{12} \mathrm{H}_{25}$ & 74 \\
1-octadecanol & $\mathrm{C}_{16}$ & hexadecyl ester & $\mathrm{C}_{18} \mathrm{H}_{37} \mathrm{NHCOOC}_{16} \mathrm{H}_{33}$ & 83 \\
\hline
\end{tabular}




\subsubsection{WTIR and ${ }^{1}$ H NMR Spectra of the Carbamates}

The FTIR and ${ }^{1} \mathrm{H}$ NMR spectra of the carbamate $\mathrm{C}_{12}$ are shown in Figure 2.1 and 2.2 respectively. To take the FTIR spectrum, $5 \mathrm{mg}$ of the carbamate were mixed with dried $\mathrm{KBr}$ and were ground into a fine powder. High pressure was then applied by means of a hydraulic press to coalesce the sample into a transparent or semitransparent disk. The prepared disk was mounted in the beam of the spectrometer. The ${ }^{1} \mathrm{H}$ NMR spectrum was taken in deuterated chloroform using a $400 \mathrm{MHz}$ NMR spectrometer (Bruker). All the other carbamates show similar spectra. The ${ }^{1} \mathrm{H}$ NMR spectrum is shown in two parts for clarity. Some important bands in these spectra are mentioned below.

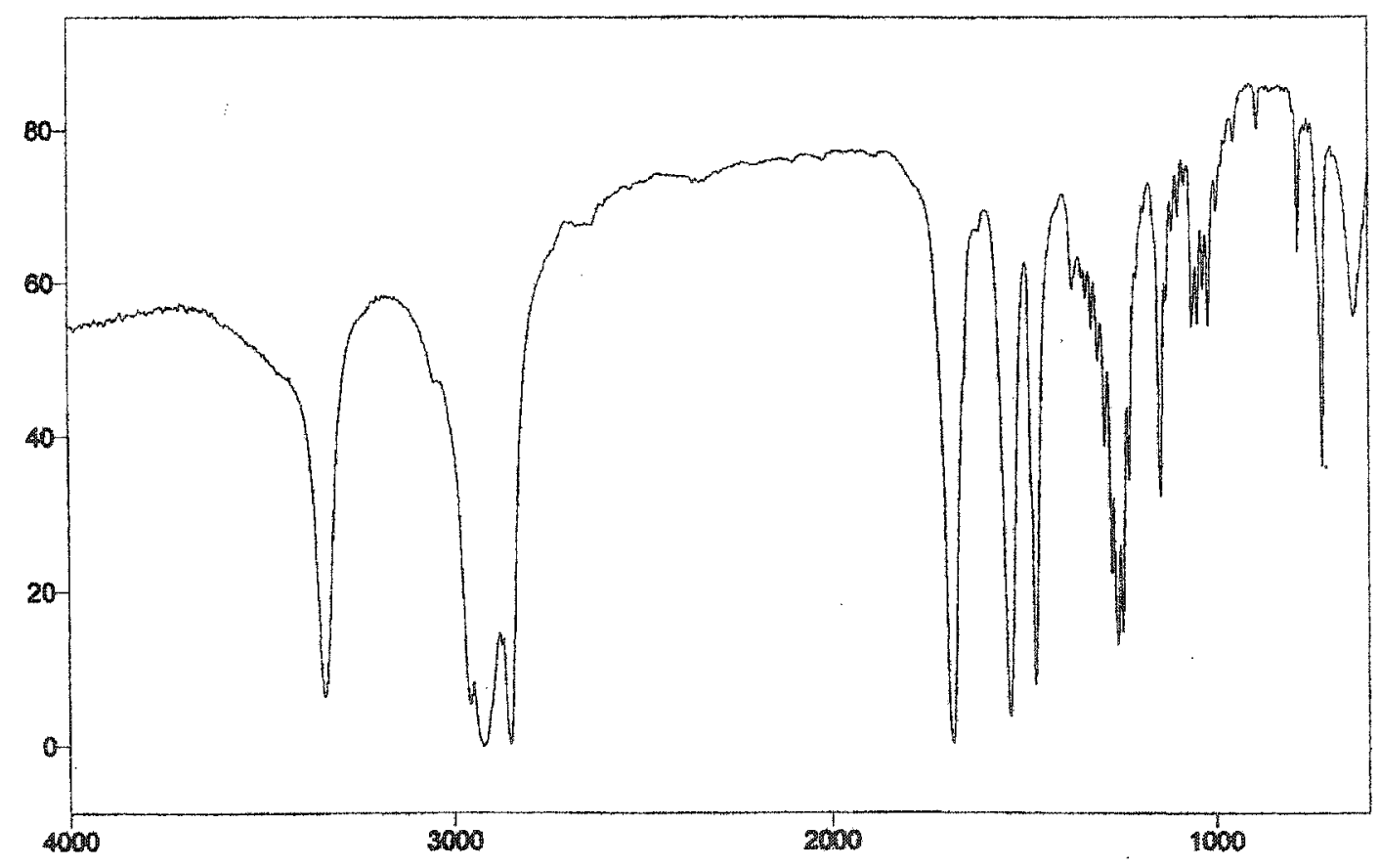

Figure 2.1 FTIR spectrum of $\mathrm{C}_{12}$. 

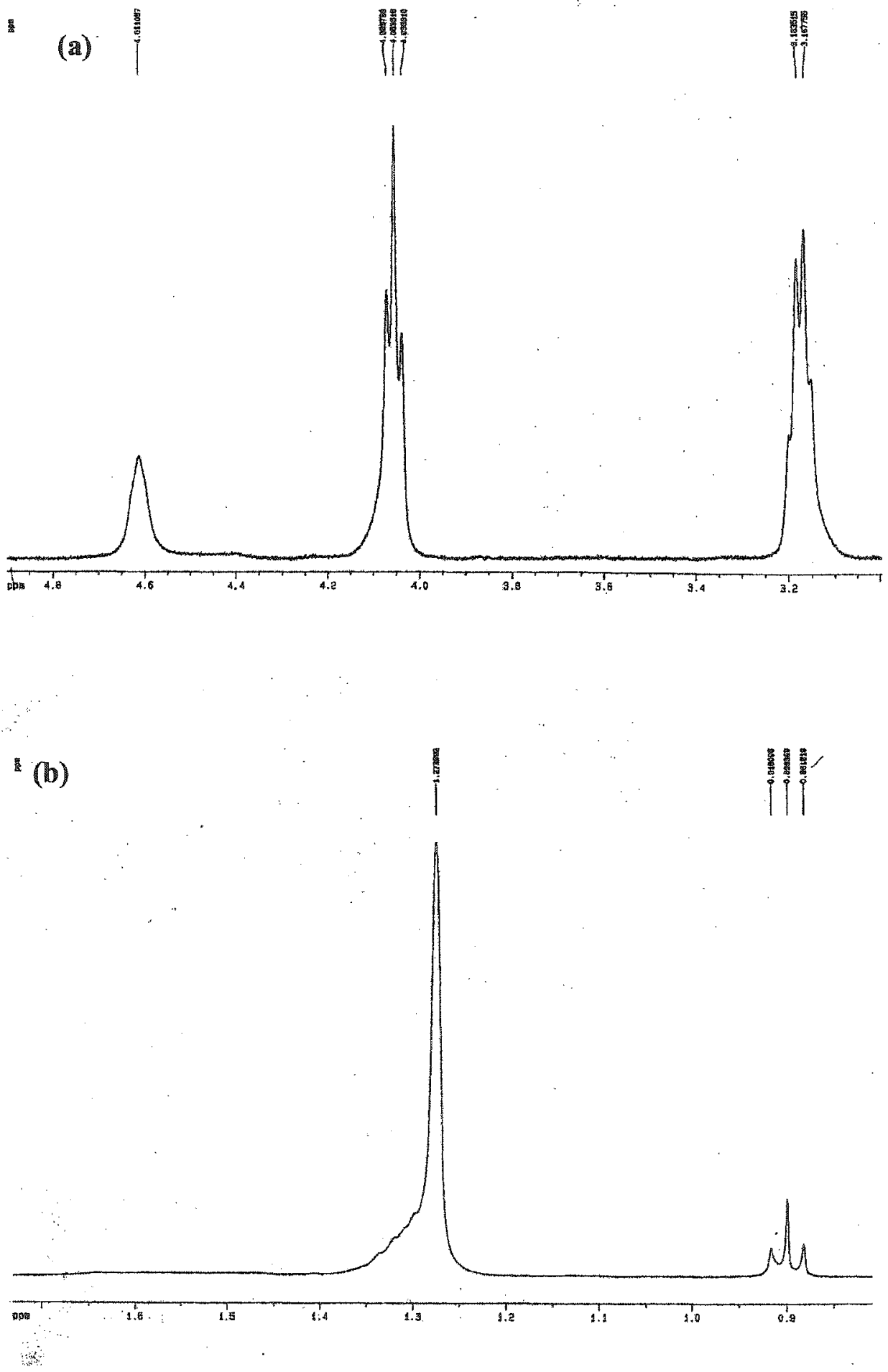

Figure 2.2 ${ }^{1} \mathrm{H}$ NMR spectrum of $\mathrm{C}_{12}$ 


\subsubsection{WTIR}

In the FTIR spectra, all the carbamates show a strong band at $1686 \mathrm{~cm}^{-1}$ which is attributed to the $\mathrm{C}=\mathrm{O}$ stretching vibrations (amide I band). The amide II band, which is due to $\mathrm{NH}$ bending, is observed at $1536 \mathrm{~cm}^{-1}$. The NH stretching frequency is observed at $3337 \mathrm{~cm}^{-1}$. The band at $782 \mathrm{~cm}^{-1}$ represent the $\mathrm{C}=\mathrm{O}$ out-of-plane vibrations. This band is highly characteristic and is used as an internal standard in the experimental IR spectra study of polyurethanes ${ }^{3}$. Table 2.2 lists the stretching frequencies of some of the bands observed in the IR spectra of the carbamates.

Table 2.2 Stretching Frequencies of the $\mathbb{R}$ bands of the carbamates

\begin{tabular}{ccl}
\hline Frequency $\left(\mathrm{cm}^{-1}\right)$ & Band Intensity* & \multicolumn{1}{c}{ Assignment } \\
\hline 2956 & $\mathrm{~ms}$ & $\mathrm{CH}_{3}$ assymetrical stretching \\
2919 & $\mathrm{~ms}$ & $\mathrm{CH}_{2}$ asymmetrical stretching \\
1470 & $\mathrm{~s}$ & $\mathrm{CH}_{2}$ symmetrical stretching \\
1275 & $\mathrm{~s}$ & $\mathrm{CH}_{3}$ bending \\
1146 & $\mathrm{~m}$ & $\mathrm{C}-\mathrm{O}$ stretching \\
720 & $\mathrm{~ms}$ & $\mathrm{C}-\mathrm{N}$ stretching \\
632 & $\mathrm{~s}$ & $-\left(\mathrm{CH}_{2}\right)$ n- in- phase rocking ${ }^{4}$ \\
& $\mathrm{~ms}$ & $\mathrm{C}-\mathrm{N}$ deformation \\
\hline $\mathrm{s}=$ strong, $\mathrm{ms}=$ medium strong & &
\end{tabular}




\subsubsection{2 ${ }^{1}$ NMR}

In the ${ }^{1} \mathrm{H}$ NMR spectra of all the carbamates, the N-H proton shows a broad signal around $\delta 4.6$ and the $\mathrm{N}-\mathrm{CH}_{2}$ absorption at around $\delta 3.17$ splits into a quartet by coupling with the N-H and the neighboring $\mathrm{CH}_{2}$ protons (Fig. 2.2a). It should be mentioned that the $\mathrm{N}-\mathrm{H}$ proton rarely appears as a multiplet. This signal is affected by the magnetic and electric properties of ${ }^{14} \mathrm{~N}$ nucleus in such a way as to make it appear as a broad signal ${ }^{5}$. The $-\mathrm{O}-\mathrm{CH}_{2}$ protons show a triplet at around $\delta 4$. The splitting of the rest of the $\mathrm{CH}_{2}$ protons was not observed; rather they show a strong intensity singlet at around $\delta 1.2$ (Fig. 2.2b). The $\mathrm{CH}_{3}$ protons show a triplet at around $\delta 0.9 \mathrm{ppm}$.

\subsection{Preparation of the Blends}

Binary blends of homologous carbamates or heterogeneous blends of carbamates (with stearic acid/ polyethylene/ Kemamide S/ Kemamide E-180) were prepared by melt mixing. Pre-weighed mixtures of the blending components (total $0.5 \mathrm{~g}$ ) were heated in a $10 \mathrm{ml}$ beaker at $120^{\circ} \mathrm{C}$ with continuous stirring. After 1 hour, the melt was slowly cooled to room temperature.

\subsection{Other Materials}

\subsubsection{Stearic Acid}

The chemical structure of the stearic acid is shown in Figure 2.3. Stearic acid has applications as emulsifiers and thickeners, in rubber processing, soap and lubricants and in cosmetics $^{6}$. 


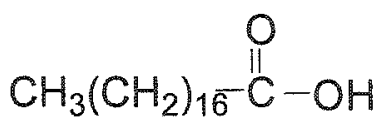

Figure 2.3 Stearic acid

Stearic acid of $98 \%$ purity was purchased from Aldrich. The melting point of the stearic acid is $68{ }^{\circ} \mathrm{C}$ and the heat of fusion is $217 \mathrm{~J} / \mathrm{g}$, as obtained from DSC.

\subsubsection{Polyethylene}

Polyethylene of molecular weight 655 (Petrolite Corporation; courtesy of Xerox Research Centre of Canada (XRCC)) was used. The DSC thermogram (Fig. 2.4) indicated a broad molecular weight distribution in the sample. Hence the sample was partially dissolved in hot toluene at $80^{\circ} \mathrm{C}$, filtered at that temperature and was washed with hot toluene. The sample was dried under vacuum at $50^{\circ} \mathrm{C}$ for two days. The dried sample shows a sharper and narrower peak in DSC (Fig. 2.4), indicating a narrower molecular weight distribution. The melting point is $99^{\circ} \mathrm{C}$ and the heat of fusion is $245 \mathrm{~J} / \mathrm{g}$. 


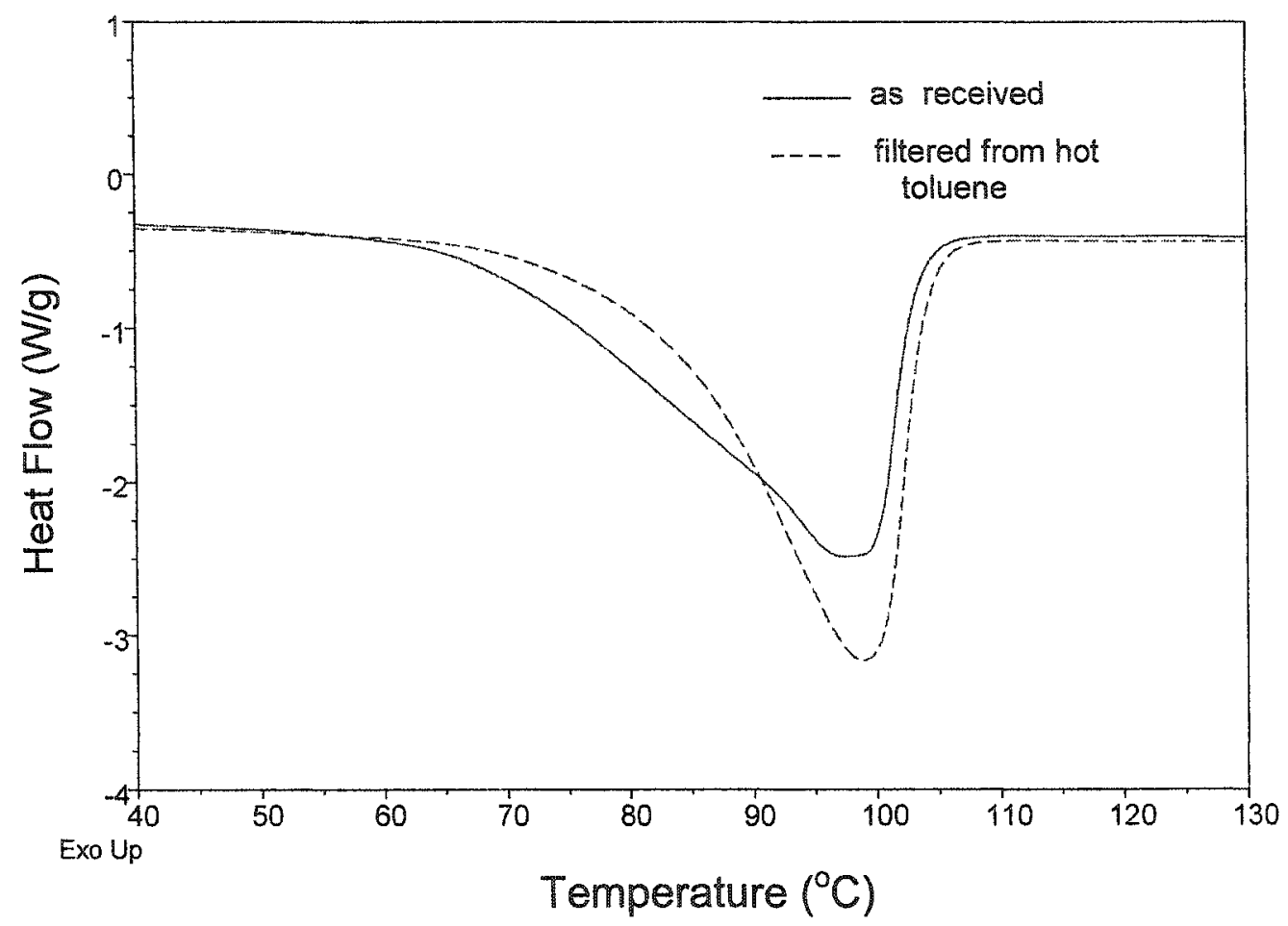

Figure 2.4 DSC thermograms of as received polyethylene and the sample after hot filtration from toluene

\subsubsection{Kemamide S (Octadecanamide)}

The commercial clarifier Kemamide $S$ powder was purchased from Crompton Corporation. This product is available in powder and bead form.

Kemamide $S$ is a saturated fatty primary monoamide, derived from stearic acid. It shows exceptional stability to light and air and is resistant to dilute acids and bases. Most uses of Kemamide $\mathrm{S}$ fatty amide are based on its antiblock properties. It serves as a lubricant and 
release agent in plastics, waxes, and rubber; as an intermediate to mar-resistance agents, softeners, and water repellents for textiles; as an emulsion stabilizer for cosmetics; as a corrosion inhibitor for metal surface and aqueous systems; and as a blending agent for waxes and resins. This product improves the adherence of resins to glass fibers. Sometimes Kemamide $S$ is used to improve the peel strength of printing inks ${ }^{7}$. The chemical structure of Kemamide $\mathrm{S}$ is shown in Figure 2.5.<smiles>CCCC(N)=O</smiles>

Figure 2.5 Kemamide S

The melting point of Kemamide $\mathrm{S}$ is $108^{\circ} \mathrm{C}$. It has a melt viscosity of $5.8 \mathrm{cps}$ at $130^{\circ} \mathrm{C}$. The heat of fusion of Kemamide $\mathrm{S}$ is $235 \mathrm{~J} / \mathrm{g}$. Kemamide $\mathrm{S}$ is relatively insoluble at ambient temperatures in water and all common organic solvents.

\subsubsection{Kemamide E-180 (Stearyl Erucamide)}

The Kemamide E-180 was purchased from Crompton Corporation. It is a secondary fatty amide. It is a white, free-flowing powder which can withstand temperatures over $260^{\circ} \mathrm{C}$ $\left(500^{\circ} \mathrm{F}\right)$ without extensive decomposition. Kemamide E-180 fatty amide imparts slip and anti-block properties in thermoplastic resins and finds wide application where high processing temperatures are necessary ${ }^{7}$. Figure 2.6 shows the chemical structure of Kemamide E-180. 


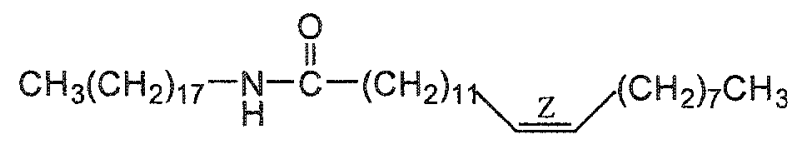

Figure 2.6 Kemamide E180

The melting point of Kemamide E-180 is $74{ }^{\circ} \mathrm{C}$ and the heat of fusion is $150 \mathrm{~J} / \mathrm{g}$, as measured by DSC.

\subsection{Methods of Characterization}

Thermal behaviour of the carbamates and of their blends was investigated by differential scanning calorimetry (DSC) and thermogravimetric analysis (TGA). Optical microscopy (OM), scanning electron microscopy (SEM), small angle light scattering (SALS) and powder X-ray diffraction (XRD) were used to investigate the morphology of the samples.

\subsubsection{Differential Scanning Calorimetry (DSC)}

Differential scanning calorimetry is one of the most common techniques for quantitative studies of thermal transitions in polymers, organic materials, metals, ceramics and composites. In DSC, the sample and an inert reference are heated, usually in a nitrogen atmosphere, and thermal transitions in the sample are detected and measured. Figure 2.7 is a schematic representation of the DSC cell. The sample and the reference in Figure 2.7 are provided with individual heaters, and energy is supplied to keep the sample and reference temperatures constant. The electrical power difference between sample and 
reference $(\mathrm{d} \Delta \mathrm{Q} / \mathrm{dt})$ is recorded. This heat flow/temperature data provides valuable information of physical/chemical properties of the materials. For example, the crystalline melting temperature $\left(T_{m}\right)$, the crystallization temperature $\left(T_{c}\right)$ and the heat of fusion $\left(H_{f}\right)$ of a crystalline or semicrystalline substance can be obtained from DSC. The glass transition temperature $\left(\mathrm{T}_{\mathrm{g}}\right)$ and the specific heat capacity $(\mathrm{Cp})$ of a polymer can also be determined from DSC. Polymorphic transitions are also detectible ${ }^{8}$.

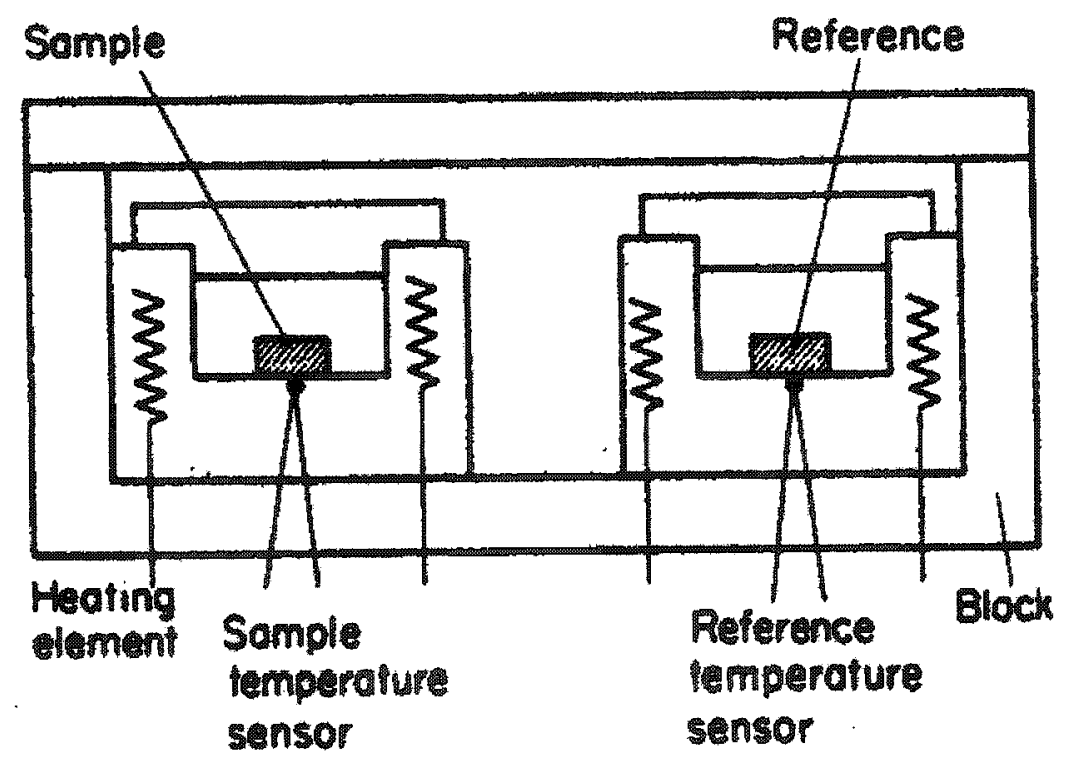

Figure 2.7 Schematic representation of DSC cell

In this study, thermal analysis was performed using a DuPont 910 differential scanning calorimeter at a heating rate of $10^{\circ} \mathrm{C} / \mathrm{min}$. The instrument was calibrated for temperature and energy with indium and tin reference samples. DSC traces were recorded with about 
7-10 mg of sample, in a nitrogen atmosphere. The uncertainty in the measurement was \pm 1 ${ }^{\circ} \mathrm{C}$ for the melting point and $\pm 2 \mathrm{~J} / \mathrm{g}$ for the heat of fusion.

\subsubsection{Thermogravimetric amalysis (TGA)}

TGA is used primarily to determine the thermal stability of a compound. The weight loss from a compound due to the evaporation of the residual moisture or solvent or due to the decomposition of the compound (which usually occurs at high temperatures) can be easily determined by TGA. Two types of TGA methods are commonly used: nonisothermal and isothermal. Nonisothermal TGA is based on continuous measurement of weight on a sensitive balance (called a thermobalance) as the sample temperature is increased in air or in an inert atmosphere ${ }^{9}$. Data are recorded as a thermogram of weight versus temperature. Isothermal TGA records weight loss with time at a constant temperature.

The thermogravimetric analysis was carried out using a Seiko $2200 \mathrm{TG}$ at a heating rate of $10^{\circ} \mathrm{C} / \mathrm{min}$ from $25-300^{\circ} \mathrm{C}$ under nitrogen flow $(50 \mathrm{~mL} / \mathrm{min})$. The onset temperature for decomposition for all the samples was taken at $5 \%$ weight loss.

\subsubsection{Optical Microscopy}

Optical microscopy is a convenient and relatively inexpensive technique to study the surface and bulk morphology. It can resolve surface characteristics of the order of 2000 $\AA^{9}$. In our study, optical microscopy was used extensively to study the spherulitic morphology of the carbamates. Optical microscopy also helps to determine the sign of 
birefringence of the spherulites when the spherulites are examined with a $\lambda$ plate. This plate adds to or subtracts from the path difference of the spherulite, depending on whether the birefringent units in the spherulite are oriented parallel to the plate or perpendicular to it. This means that one pair of quadrants of a spherulite will be raised up the scale of colors and the other will be lowered. Therefore, with spherulites showing only first-order white, which is normal in a thin section, one pair will be raised to blue and the other lowered to orange ${ }^{10}$. The housing of the $\lambda$ plate has an arrow showing the polarization direction. If the quadrants of the spherulites parallel to the arrow appears orange and the other quadrants appear blue, the spherulites are called negative spherulites and vice versa are called positive spherulites. Depending on the thickness of the sample, the colors may vary. Figure 2.8 shows the appearance of the positive and negative spherulite under optical microscope.
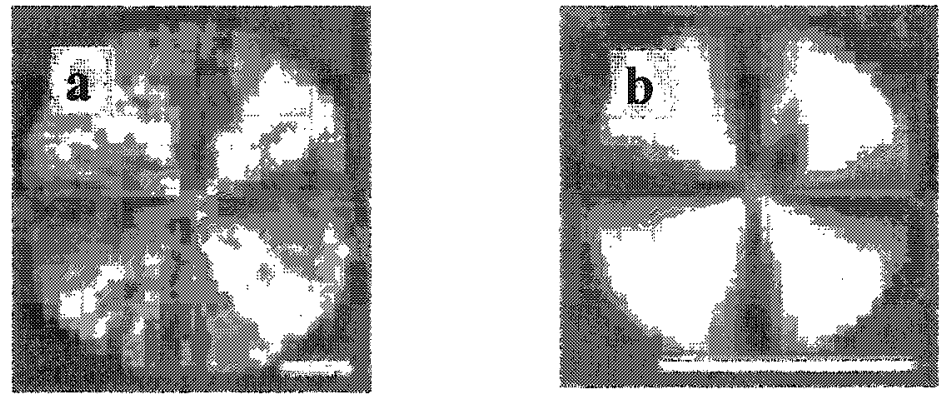

Figure 2.8 (a) positive spherulite and (b) negative spherulite

In this study, the optical micrographs were recorded using a Zeiss Axioplan polarized optical microscope (OM), equipped with a Linkam hot stage. All the optical micrographs 
were taken in transmission mode. Northern Eclipse (version 6.0) image processing software was used to record the images as well as to calculate the spherulite size (where it was possible). The samples for the optical microscopy were prepared by melting a small amount of the material on the microscope slide at a temperature $20^{\circ} \mathrm{C}$ higher than its melting point, holding it isothermally for 10 minutes to remove any morphological history and then cooling it down slowly to room temperature at the rate of $10^{\circ} \mathrm{C} / \mathrm{min}$. Another set of samples was prepared following the same procedure, but this time the samples were quenched from the melt, instead of slow cooling.

\subsubsection{Scanning Electron Microscopy (SEM)}

In SEM, a fine electron incident beam is scanned across the surface of an opaque specimen to which a light conducting film has been applied by evaporation ${ }^{11}$. Scattered electrons are used to produce a signal that modulates the intensity of the electron beam in a cathode-ray tube, scanning in synchronism with the microscope beam. The resulting images have great depth of field ${ }^{11},{ }^{12}$ and a remarkable three-dimensional appearance ${ }^{11}$. SEM provides useful information on surface topology with a resolution of about $100 \AA^{9,11}$.

SEM images were obtained using a JEOL JSM-6400 scanning electron microscope. Samples were prepared for SEM by mounting on carbon tape and sputter coating with $60: 40 \mathrm{Au} / \mathrm{Pd}$. The accelerating voltage of SEM was $15 \mathrm{kV}$. 


\subsubsection{X-ray Diffraction}

The X-ray diffraction method is a powerful tool for investigating orderly arrangement of atoms or molecules through the interaction of electromagnetic radiation to give interference effects with structures comparable in size to the wavelength of radiation ${ }^{\text {". }}$. The wavelengths of X-rays are comparable to interatomic distances in crystals. Most of our knowledge about atomic positions and intramolecular distances is gained from X-ray diffraction measurements. To get complete information of the molecular ordering in a crystalline or semicrystalline material, it is necessary to obtain a single crystal of the compound. The crystal is rotated at an angle perpendicular to the incident beam so that diffraction patterns at all possible angles are recorded. However, when a single crystal is not available, powder X-ray diffraction can provide valuable information regarding the interplanar distances between atomic planes ( $d$ spacing), crystallite size and crystallinity. In powder X-ray diffraction, the reflections are obtained from several microcrystals with different orientation. This method is more convenient, but gives less information than the single crystal method. It gives at best 20 reflections whereas single crystals can usually give $>2000$ reflections. Direct methods are available to determine the crystal structure using single crystals; this is not the case with the powder pattern.

The basic equation of $\mathrm{X}$-ray diffraction is the Bragg formula:

$$
2 d \sin \theta=n \lambda
$$


Where $\lambda$ is the wavelength of $\mathrm{X}$-ray radiation, $d$ the distance between atomic planes, $\theta$ the angle of incidence of the $\mathrm{x}$-ray beam on the atomic planes and $\mathrm{n}(1,2,3 \ldots, \mathrm{n})$ is the order of the reflection.

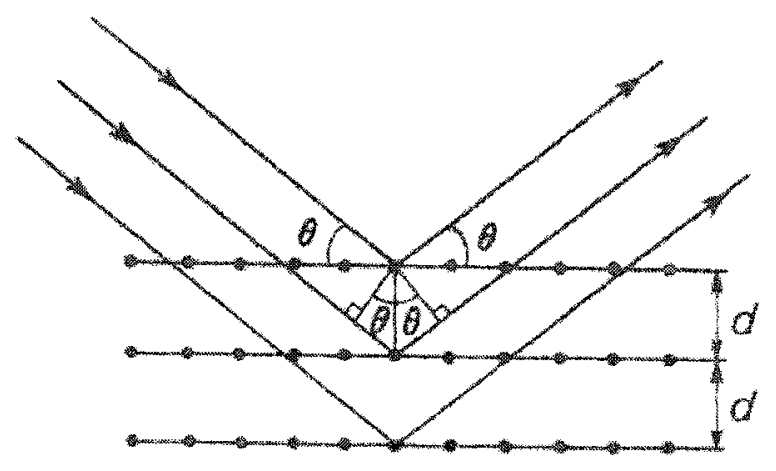

Figure 2.9 Bragg construction illustrating the principle of diffraction where $d$ is the spacing between two atomic planes.

In real cases, higher order reflections corresponding to $n>1$ are extremely weak in intensity. Hence only those corresponding to $n=1$ are observed. Thus, the above equation reduces to

$$
2 d \sin \theta=\lambda
$$

Rearrangement of Bragg's equation gives the $d$-spacing as

$$
d=\frac{\lambda}{2 \sin \theta}
$$

Equation 2.3 shows that when the distance ( $d$ ) between the two planes in the lattice is large, the scattering angle $(2 \theta)$ has to be small to produce a diffraction pattern. The 
diffractions obtained at angles smaller than $2^{\circ}(d>44 \AA)$ are called Small Angle X-ray Diffractions $(\mathrm{SAXS})^{13}$. The diffractions obtained at all larger angles, theoretically extending up to $180^{\circ}$ are called Wide Angle X-ray Diffractions (WAXS) ${ }^{13}$. WAXS provides information about the spatial arrangement of atoms, whereas SAXS provides information about domain arrangements (e.g. long spacing) ${ }^{11}$.

In our study, X-ray diffraction data were collected within the range of $2^{\circ} \leq 2 \theta \leq 50^{\circ}$ using a Philips automated powder diffractometer, Model PW 1710. Nickel-filtered $\mathrm{Cu} \mathrm{K}_{\alpha}$ radiation $(\lambda=1.542 \AA)$ was used. The possible presence of texture was checked by taking additional diffractograms with samples turned in the plane of measurement by $90^{\circ}$. Figure 2.10 shows a schematic of the Bragg diffraction with this diffractometer.

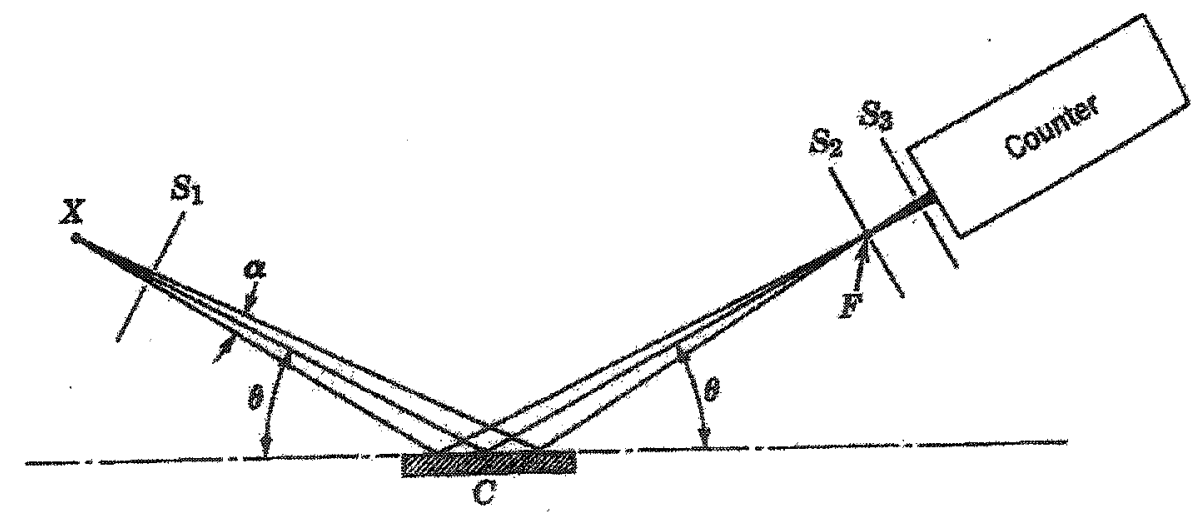

Figure 2.10 Schematic of the Bragg diffraction with the powder X-ray diffractometer used for the present study [from Alexander ${ }^{13}$ ]. Here, $S_{1}, S_{2}$ and $S_{3}$ are the divergence slit, receiving slit and scatter slit respectively; $\alpha=1-4^{\circ}$. 
The MDI Datascan 3.2 software (Materials Data Inc., Livermore, CA) was used for data

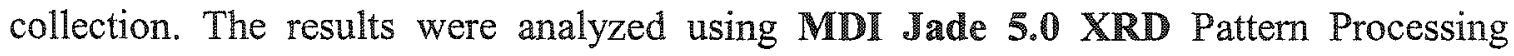
software.

Percent crystallinity of the sample, $X_{C}$, was calculated using the formula

$$
X c=\left(I_{C} / I_{\text {total }}\right) \times 100
$$

Where $I_{C}$ is the crystalline area under the peak and $I_{\text {total }}$ is the total crystalline and amorphous area. The reproducibility in the calculation was $\pm 2 \%$.

The crystallite size, $L$ corresponding to a particular reflection was calculated by the Scherrer Equation ${ }^{13}$

$$
L=K \lambda / \beta \cos \theta
$$

where $\lambda$ is wavelength of the $X$-ray, $\theta$ is half the scattering angle, and $\beta$ is the half width of the peak on the $2 \theta$ scale in radians; $K=0.9$.

When there was an overlap of peaks in the diffractogram, the profile was first fitted using the MDI Jade 5.0 XRD Pattern Processing software before calculating the crystallite size corresponding to a particular reflection. A diffractogram with overlap of peaks and the fitted profile is shown in Figure 2.11. 


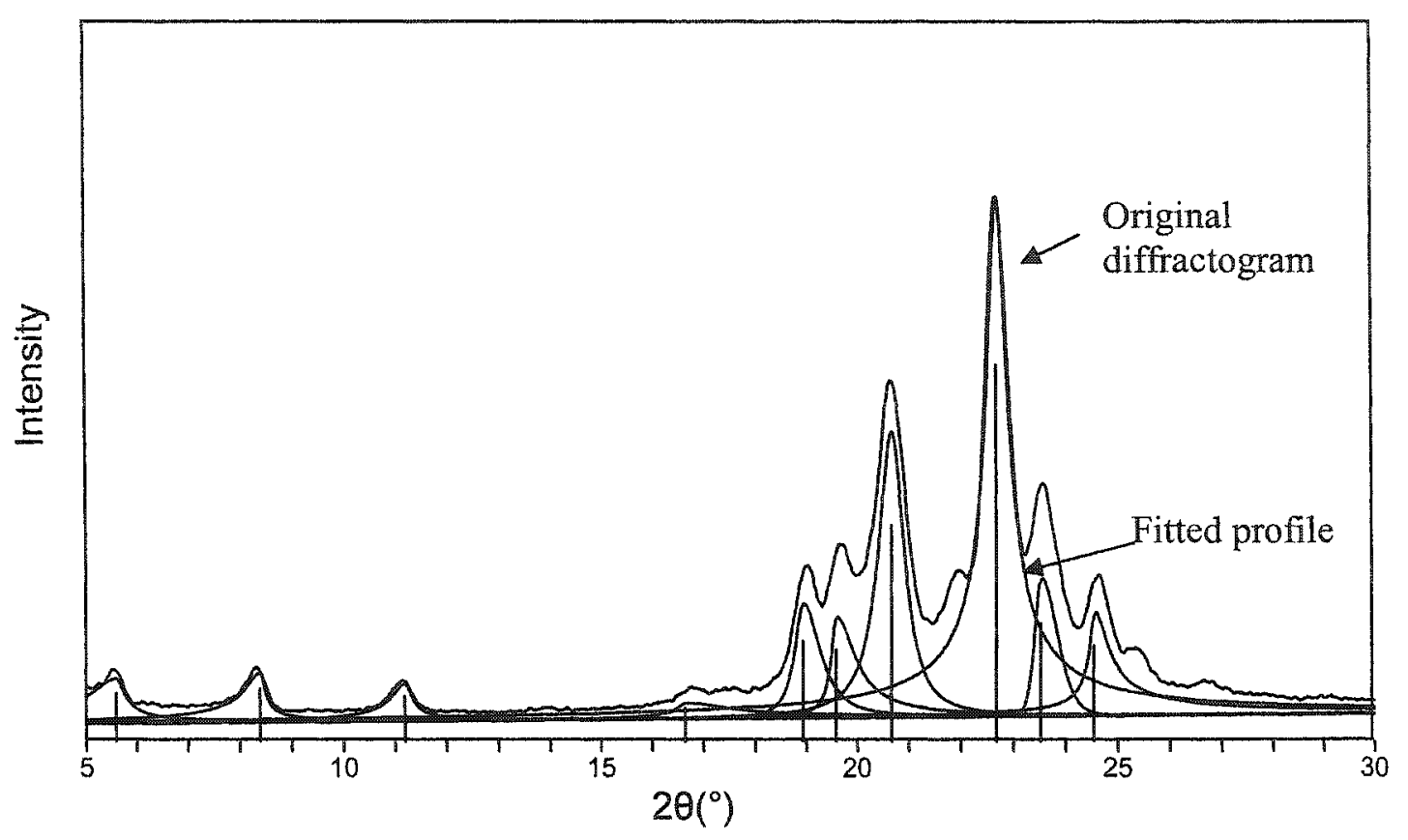

Figure 2.11 Fitted profile of a diffractogram with overlap of peaks.

Considering the molecular length of the carbamates, significant X-ray reflections were expected at $2 \theta<5^{\circ}(d>17.7 \AA)$. The diffraction patterns obtained below $5^{\circ}$ by the above diffractometer were not reliable; i.e., the peaks were not well resolved because of overlap with the background. Hence, additional diffraction pattems were recorded under vacuum with a Statton-type Warhus flat film camera (William Warhus Co., Wilmington, DE), using $\mathrm{Cu} \mathrm{K}_{\alpha}$ radiation $(\lambda=1.542 \AA)$, with sample to film distance of $10 \mathrm{~cm}$ and $17 \mathrm{~cm}$. A schematic of a Statton-type Warhus flat film camera and the Bragg diffraction is shown in Figure 2.12. 

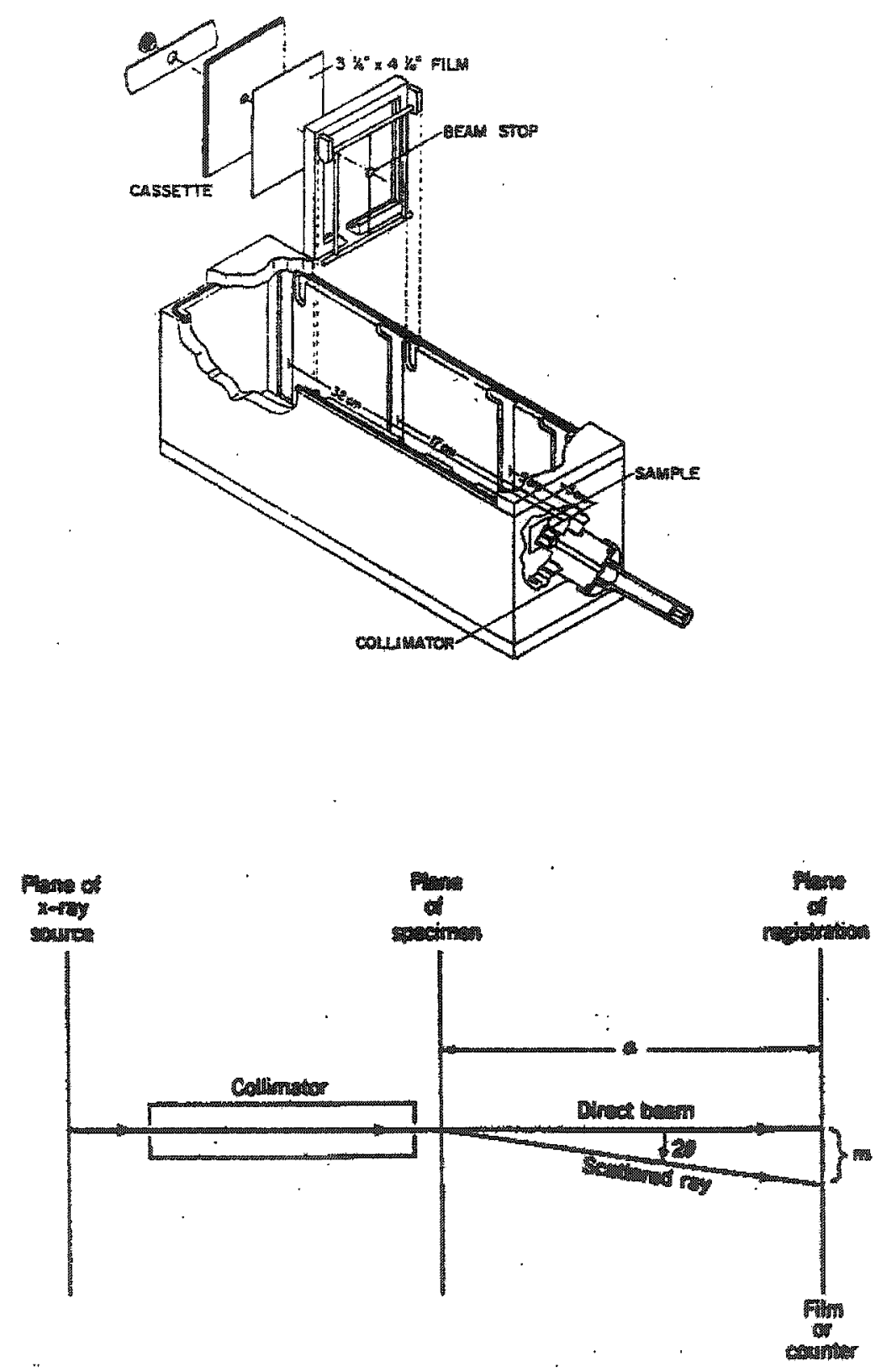

Figure 2.12 Schematic of a Statton-type Warhus flat film camera (top) and the Bragg diffraction (bottom) [from Alexander ${ }^{13}$ ] 


\subsubsection{Small Angle Light Scattering (SALS)}

This method provides information about structures having a size of the order of the wavelength of visible light, of around $1000-100000 \AA^{14}$. Small angle light scattering can be used to study the growth and structure of the spherulites ${ }^{15,16}$. In order to obtain the light scattering pattern, a thin sample containing spherulites is irradiated with polarized monochromatic light from a laser source. The light is scattered by the spherulites and then passes through an analyzer. The scattering pattern can be recorded on a photographic plate or by some other suitable means. Two types of scattering patterns are obtained depending on the polarization conditions ${ }^{17}$. When the polarization of the incident beam and that of the analyzer are both vertical, it is called a $V_{v}$ type pattern. When the incident radiation is vertical in polarization but the analyzer is horizontal (polarizers crossed), an $H_{v}$ pattern is obtained. The $H_{v}$ pattern resembles a four-leaf clover. $V_{v}$ pattern arises due to the fluctuations in density and anisotropy of the scattering material, whereas $H_{v}$ pattern arises due to the fluctuations in anisotropy or refractive index. These two types of scattering patterns are illustrated in Figure 2.13.
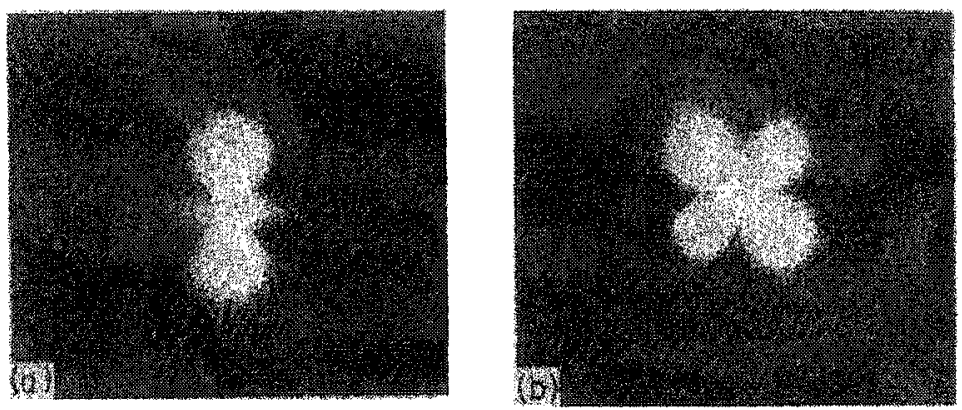

Figure 2.13 Small angle light scattering patterns from spherulitic polyethylene using (a) $\mathrm{V}_{\mathrm{v}}$ and (b) $\mathrm{H}_{\mathrm{v}}$ polarization ${ }^{18}$. 
Small angle light scattering can measure spherulites in the size range which are too small to be easily measured using the light microscope ${ }^{10}$. Another advantage of SALS is that the average size of the spherulites in a restricted area can be calculated from one SALS pattern.

Since spherulites are optically anisotropic, SALS was used in the $\mathrm{H}_{\mathrm{v}}$ mode in this study, to detect the spherulitic crystalline morphology. The setup is similar to the one described by Jabarin and $\operatorname{Stein}^{19}$, which includes a $10 \mathrm{~mW}$ He-Ne laser with $\lambda=0.6328 \mu \mathrm{m}$, a rotatable analyzer, and a photographic setup for Polaroid $4 \times 5$ Land film (Fig. 2.13). The vertically polarized incident laser beam was passed through a $2 \mathrm{~mm}$ pinhole to avoid stray radiation and the pattern was recorded with the optical axis of the analyzer kept horizontal $\left(H_{\mathrm{v}}\right.$ mode). The average size of the spherulite is given by ${ }^{20}$ :

$$
4 \pi(R / \lambda) \sin (\theta / 2)=4
$$

with

$$
\theta=\tan ^{-1}(\mathrm{r} / \mathrm{D})
$$

Here $\mathrm{R}$ is the radius of the spherulite, $\lambda$ is the wavelength of the laser beam, $\mathrm{r}$ is the distance on the $H_{\mathrm{v}}$ photograph from the centre of the incident beam to the point of maximum intensity on the four-leaf clover pattern and $D$ is the sample to film distance. 


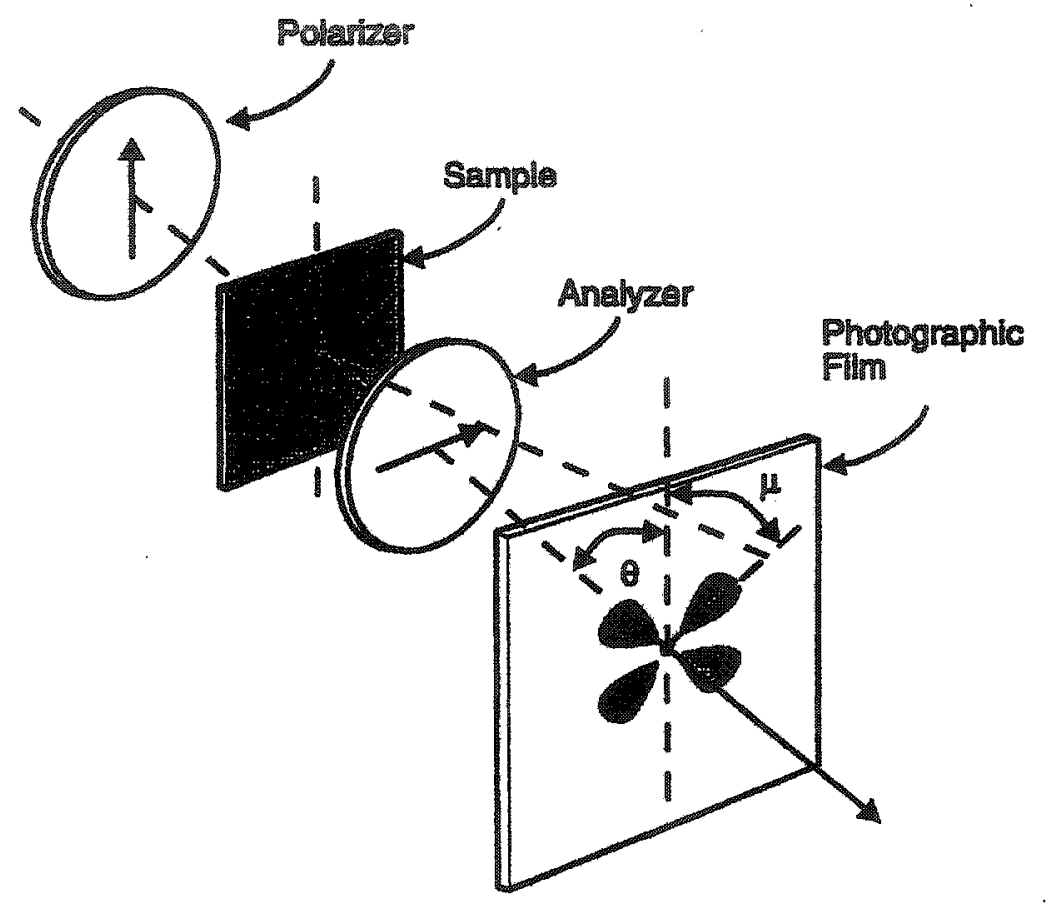

Figure 2.14 Schematic of the experimental arrangement for small angle light scattering (from Stein and Rhodes ${ }^{20}$ ).

\subsubsection{FTIR Spectroscopy}

IR spectroscopy is one of the most widely used techniques for the determination of molecular structure and for the identification of compounds. It can also provide valuable information regarding the molecular level interactions between the chemical components in the blends. This technique causes molecules to undergo changes in vibrational energy state by radiating the sample with a broad-band source of radiation in the infrared region. The necessary condition for absorption or emission of radiation to take place is that the 
dipole moment of the molecule should change during the vibration. The theory of $\mathbb{R}$ transitions has been discussed by Herzberg ${ }^{21}$ and Steinfeld ${ }^{22}$ in detail.

Organic applications of infrared spectroscopy are almost entirely concerned with the range of $650-4000 \mathrm{~cm}^{-1}(15.4-2.5 \mu \mathrm{m})$ (the mid infrared) ${ }^{23}$. The wavenumber measured in reciprocal centimeter $\left(\mathrm{cm}^{-1}\right)$ is related to the wavelength, $\lambda$ by the following equation:

$$
\bar{v}=\frac{1}{\lambda}(\text { with } \lambda \text { in } \mathrm{cm})
$$

The region of frequencies lower than $650 \mathrm{~cm}^{-1}$ is called the far infrared, and that of frequencies higher than $4000 \mathrm{~cm}^{-1}$ is called the near infrared. The regions from $4000-$ $1400 \mathrm{~cm}^{-1}$ gives information about the functional groups present in the structure. The regions from $600 \mathrm{~cm}^{-1}-1400 \mathrm{~cm}^{-1}$ is called the fingerprint region because the pattern of absorption in this region is unique to any particular compound ${ }^{24}$. The bands in this region can be used with great utility to assign the aromatic ring substitution pattern ${ }^{25}$.

In our study, FTIR spectroscopic measurements were carried out at ambient conditions using a Michelson M129 BOMEM Fourier Transform Infrared (FTIR) spectrometer. The data were collected using BOMEM GRAMS/386 software. Five mg of sample were sandwiched between two $\mathrm{NaCl}$ disks and were melted at $110^{\circ} \mathrm{C}$ and then either slowcooled or quenched. In some cases, the FTIR spectra of the samples were taken in the form of transparent $\mathrm{KBr}$ pellets (described in section 2.2.1.1). A background FTIR spectrum was taken for each experiment with the identical sample holder. 


\subsubsection{Molecular Modeling}

Simple molecular modeling was performed using HyperChem (from Hypercube Inc.)

software (version 6.01). Geometry optimization of the molecular structures was done using the $\mathrm{MM}+$ force field. 


\subsection{References}

1 Stevens, M.P. Polymer Chemistry, an Introduction, $3^{\text {rd }}$ ed.; Oxford University Press: New York, 1999; p 380.

2 Kim, K.; Plass, K.E.; Matzger, A.J. Langmuir, 2003, 19, 7149.

3 Furer, V.L. J. Mol. Struct. $2000,520,117$.

4 Lin-Vien, D.; Colthup, N.B.; Fateley, W.G.; Grasselli, J.G. The Handbook of Infrared and Raman Characteristic Frequencies of Organic Molecules, Academic Press Inc.: Boston, 1991; p 14.

5 Kalsi, P. Spectroscopy of Organic Compounds, $4^{\text {th }}$ ed.; New Age International Ltd: New Delhi, 2000; p 255.

6 http://www.arizonachemical.com/AppGuide/TSB/stearic+acids.pdf

7 http:/www.chembuyersguide.com/partners/crompton.html

8 Wendlandt, W.W. Thermal Analysis, Wiley Interscience: New York, 1986; p. 667.

9 Stevens, M.P. Polymer Chemistry an Introduction, $3^{\text {rd }}$ ed.; Oxford University Press: New York, 1999; Chap. 5.

10 Saville, B.P. in Applied Polymer Light Microscopy; Homsley, D.A., Ed; Elsevier Science Publishers Ltd.: New York, 1989; Chap. 4.

11 Billmeyer, F.W. Textbook of polymer science, $3^{\text {rd }}$ ed.; Wiley-Interscience : New York, 1984; Chap. 9.

12 Curson, A.D. in Applied Polymer Light Microscopy, Hemsley, D.A., Ed.; Elsevier Science Publishers Ltd.: New York, 1989; Chap. 1. 
13 Alexander, L.E. X-Ray Diffraction Methods in Polymer Science, WileyInterscience: New York, 1969.

14 Stein, R. S. in Structure and Properties of Polymer Films, Lenz, R.W.; Stein, R.S., Eds.; Plenum Press: New York, 1973; Chap. 1.

15 Stein, R.S.; Misra, A. J. Polym. Sci. Polym. Phys. Ed., 1980, 18, 327.

16 Stein, R.S. in Rheology, Theory and Applications, Vol 5, F.R. Eirich, ed.; Academic Press: New York, 1969; Chap. 6.

17 Stein, R.S. J. Chem. Ed., 1973, 50, 748.

18 Sperling, L.H. Introduction to Physical Polymer Science, Wiley-Interscience, New York, 1969; p 170.

19 Jabarin, S.A.; Stein, R.S. J. Phys. Chem. 1973, 77, 399.

20 Stein, R.S.; Rhodes, M.B. J. Appl. Phys. 1960, 31, 1873.

21 Herzberg, G. Molecular Spectra and Molecular Structure, $2^{\text {nd }}$ ed.; van Nostrand Reinhold Company: New York, 1950.

22 Steinfeld, J.I. Molecules and Radiation, An Introduction to Molecular Spectroscopy; The MIT Press : Cambridge, 1985.

23 Kemp, W. Organic Spectroscopy, $3^{\text {rd }}$ ed.; Macmillan Education Ltd.: London, 1991.

24 Kalsi, P.S. Spectroscopy of Organic Compounds, $4^{\text {th }}$ ed.; New Age International Ltd: New Delhi, 2000; pp. 60-63.

25 Pavia, D.L.; Lampman, G.M.; Kris, G.S. Introduction to Spectroscopy, $3^{\text {rd }}$ ed.; Harcourt College Publisher, 2001; p. 41. 
Chapter 3

Morphology and Thermal Behaviour of Self-Assembling Carbamates and Their Blends*

* J. Phys. Chem. B 2003, 107, 8416-8423 


\subsection{Introduction}

In chapter 2 , we reported the synthesis of some long-chain monocarbamates which have alkyl side chains of different lengths. Because of the presence of the polar urethane group and alkyl moiety, they can be considered as model compounds for high molecular weight polyurethanes. This chapter discusses the dependence of morphology and related properties (heat of fusion, crystallinity, crystallite size etc.) on the structure of these carbamates. As mentioned in Chapter 1, due to their low melt viscosity and semicrystalline nature, long chain carbamates are attractive candidates for printing applications $^{1-3}$. Understanding the structure and morphology relationship is essential for successful industrial applications of these carbamates.

It is common practice in industry to incorporate plasticizers or clarifiers as nucleating agents to control the crystallinity and spherulite size and to improve the optical properties of materials. In this study, we attempted to control the morphology by blending two homologous carbamates with different compositions. The difference between the use of the clarifiers and the blends as studied here is that the latter involves a homologous series of molecules. Since the self-assembling process in the carbamates is facilitated by $\mathrm{N}-\mathrm{H} \cdots \mathrm{O}=\mathrm{C}$ hydrogen bonding, it is of interest to study the extent to which the selfassembly would be interrupted by blending a second component. When used in the printing process, naturally the melt will be quenched instantly upon transfer to the substrate. Hence, the differences in morphology behaviour between samples that were slowly cooled and quenched from the melt were also investigated in this study. 


\subsection{Preparation of the Blends}

Binary blends of carbamates were prepared according to the procedure described in chapter 2 with 80/20,60/40,50/50, 40/60 and 20/80 (wt\%) compositions. Three types of binary blends were prepared, with $\mathrm{C}_{12} / \mathrm{C}_{16}$ (see Table 2.1 and 3.1 for sample identification), $C_{7} / C_{16}$ and $C_{4} / C_{16}$. The first series was used for most of the study. The other two were used to rationalize the miscibility behavior.

\subsection{Results and Discussion}

The melting points and the melt viscosities of the carbamates and the lengths of the geometrically optimized structures of these carbamates, calculated using HyperChem Pro 6 molecular visualization and simulation software, are listed in Table 3.1.

Table 3.1 Molecular lengths, melting points $\left(\mathrm{T}_{\mathrm{m}}\right)$ and melt viscosities of different carbamates

\begin{tabular}{ccccc}
\hline Carbamate & & $\begin{array}{c}\text { Length of the } \\
\text { Formula }\end{array}$ & $\mathrm{T}_{\mathrm{m}}\left({ }^{\circ} \mathrm{C}\right)$ & $\begin{array}{c}\text { Melt viscosity } \\
\text { molecule }(\AA)\end{array}$ \\
\hline $\mathrm{C}_{18} \mathrm{H}_{37} \mathrm{NHCOOC}_{4} \mathrm{H}_{9}$ & $\mathrm{C}_{4}$ & 30.0 & 61 & (cps) \\
$\mathrm{C}_{18} \mathrm{H}_{37} \mathrm{NHCOOC}_{7} \mathrm{H}_{15}$ & $\mathrm{C}_{7}$ & 34.0 & 66 & - \\
$\mathrm{C}_{18} \mathrm{H}_{37} \mathrm{NHCOOC}_{8} \mathrm{H}_{17}$ & $\mathrm{C}_{8}$ & 35.2 & 66 & 2.2 \\
$\mathrm{C}_{18} \mathrm{H}_{37} \mathrm{NHCOOC}_{12} \mathrm{H}_{25}$ & $\mathrm{C}_{12}$ & 40.4 & 74 & 3.2 \\
$\mathrm{C}_{18} \mathrm{H}_{37} \mathrm{NHCOOC}_{16} \mathrm{H}_{33}$ & $\mathrm{C}_{16}$ & 45.4 & 83 & 3.4 \\
$\mathrm{C}_{18} \mathrm{H}_{37} \mathrm{NHCOOC}_{18} \mathrm{H}_{37}$ & $\mathrm{C}_{18}$ & 48.0 & 86 & 3.1 \\
\hline
\end{tabular}




\subsubsection{Optical microscopy}

The spherulitic morphology depends on the length of the alkyl chain as well as whether the sample was slowly cooled or quenched. The slow cooled and the quenched samples of $\mathrm{C}_{4}$ showed spherulitic morphology (Figure $3.1 \mathrm{a}, \mathrm{c}$ ) with a classical Maltese cross. They exhibited negative birefringence indicating that the crystallites are oriented tangentially within the spherulite ${ }^{4}$. The intensity of the birefringence was low.
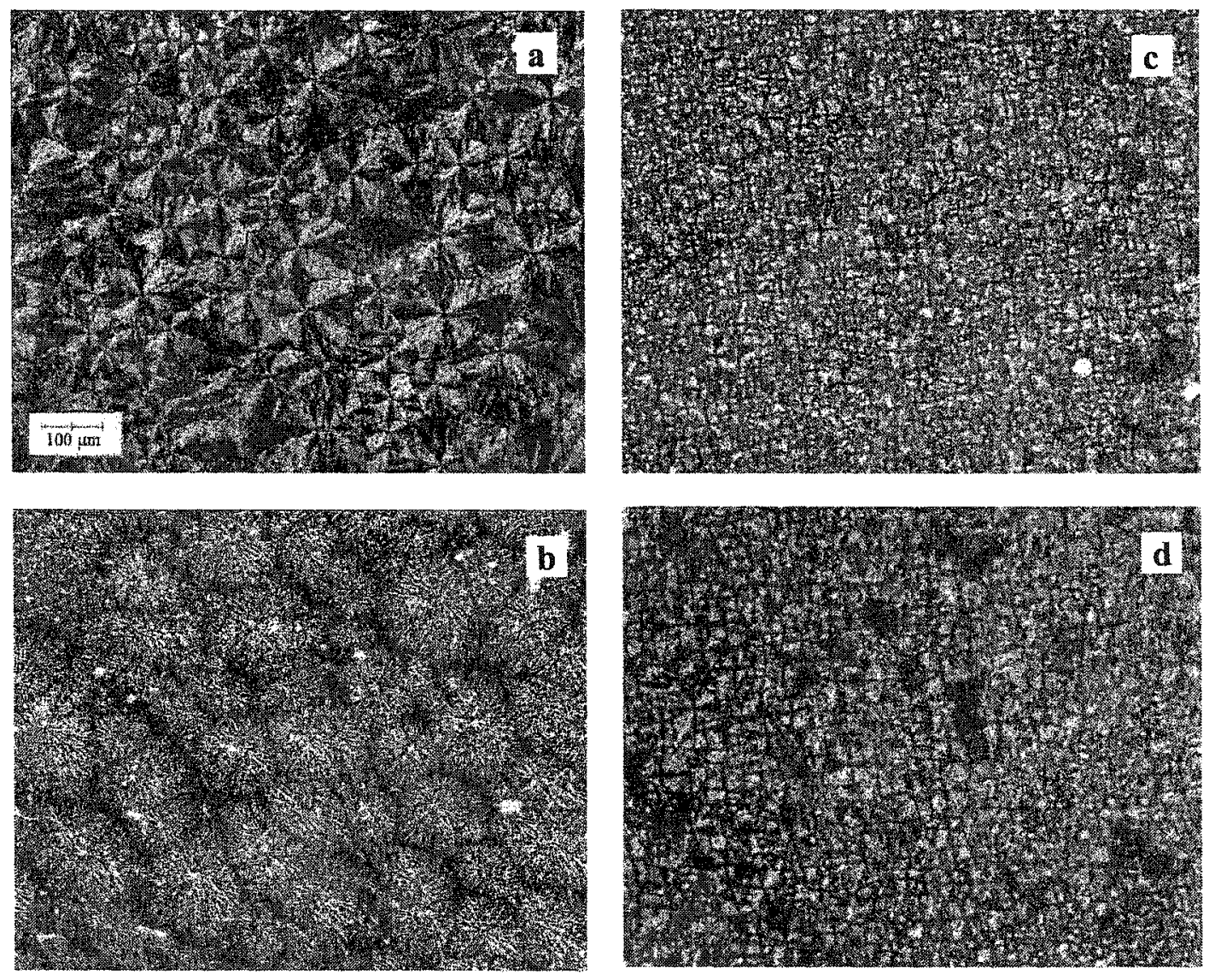

Figure 3.1 Optical micrographs of different carbamates: slow cooled samples of $\mathrm{C}_{4}$ and $\mathrm{C}_{8}$ ( $\mathrm{a}$ and $\mathrm{b}$ respectively); quenched samples of $\mathrm{C}_{4}$ and $\mathrm{C}_{8}$ ( $\mathrm{c}$ and $\mathrm{d}$ respectively). 
The optical micrographs of the slow-cooled and quenched samples of $\mathrm{C}_{8}$ are shown in Figure 3.1 (b) and (d) respectively. $\mathrm{C}_{7}$ and $\mathrm{C}_{8}$ showed similar negatively birefringent spherulites. While the Maltese cross was well defined in the quenched samples of $\mathrm{C}_{7}$ and $\mathrm{C}_{8}$, it was not with the slow cooled sample.

The slow-cooled samples of $\mathrm{C}_{12}$ showed highly coarse spherulites with positive birefringence (Figure 3.2a). It is likely that in these spherulites also the crystallites grow in a tangential direction (as in normal negative spherulites) but many branches grow perpendicular to this principal growth direction, exhibiting positive birefringence ${ }^{4}$. Another interesting feature is that these spherulites showed a Maltese cross at $45^{\circ}$ to the polarizing direction, which are known as an unusual type of spherulite. (Note that in Figure $3.2 \mathrm{~d}$, the extinction is along the vertical and horizontal directions of the page, while it is at an angle of about $45^{\circ}$ in Figure 3.2a). This unusual type is a characteristic of spherulites whose optical axis lies at an angle of approximately $45^{\circ}$ to the spherulitic axis $^{5-7}$. The quenched sample of $C_{12}$ still exhibited positive birefringence, but the Maltese cross was found to appear along the polarizers $\left(0^{\circ}\right.$ and $\left.90^{\circ}\right)$ (Figure 3.2d) indicating that the optic axis is now parallel to the spherulite axis. The slow-cooled and quenched samples of $\mathrm{C}_{16}$ exhibited needle-shaped crystallites (Figure $3.2 \mathrm{~b}, \mathrm{e}$ ). In most cases, these crystallites were found to aggregate surrounding a centre. Slow-cooled and quenched samples of $\mathrm{C}_{18}$ formed fibrillar spherulites with negative birefringence (Figure 3.2c,f). Thus, only the $\mathrm{C}_{12}$ sample showed positive birefringence and unusual type of spherulites. But for this, there was no effect seen due to odd- even nature of the alkyl chains or the

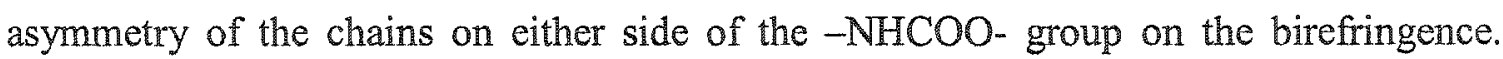
However, progressive fibrillation is seen with an increase in the length of the alkyl chain. 

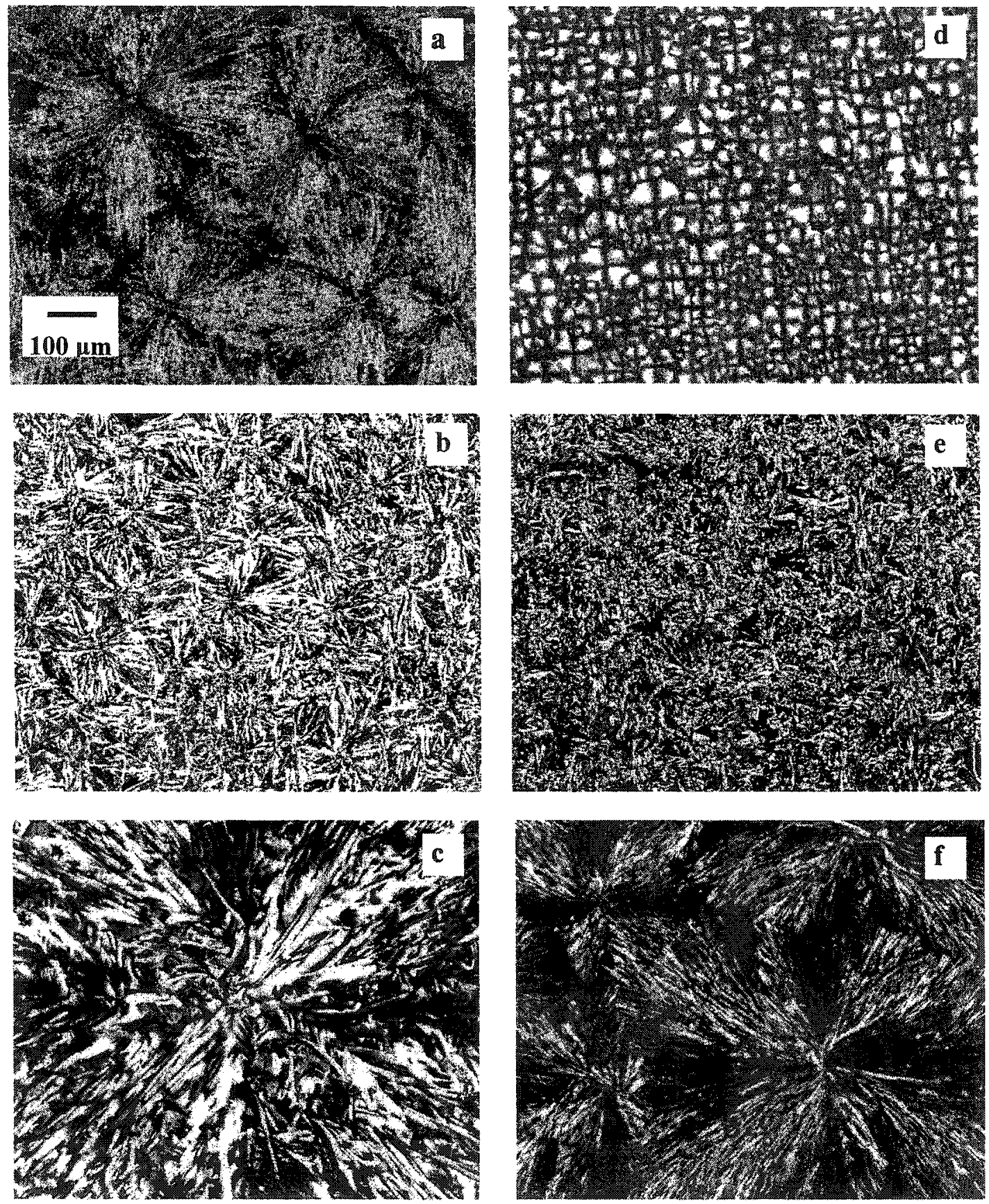

Figure 3.2 Optical micrographs of different carbamates: slow cooled samples of $\mathrm{C}_{12}$, $C_{16}$ and $C_{18}$ ( $a, b$ and $c$ respectively); quenched samples of $C_{12}, C_{16}$ and $C_{18}$ (d, e and $f$ respectively) 
The spherulites from the slow cooled and the quenched samples were large enough to measure their radius from the optical micrographs. The spherulite size increases gradually from $C_{4}$ to $C_{12}$ and then there is a sharp increase of spherulite size for $C_{18}$ (Figure 3.3). The size of the spherulites decreases significantly when the samples were quenched instead of slow-cooled. For example, when $\mathrm{C}_{18}$ was slowly cooled from the melt, the average spherulite size was $1170 \mu \mathrm{m}$ whereas in the quenched sample, it decreased to 220 $\mu \mathrm{m}$.

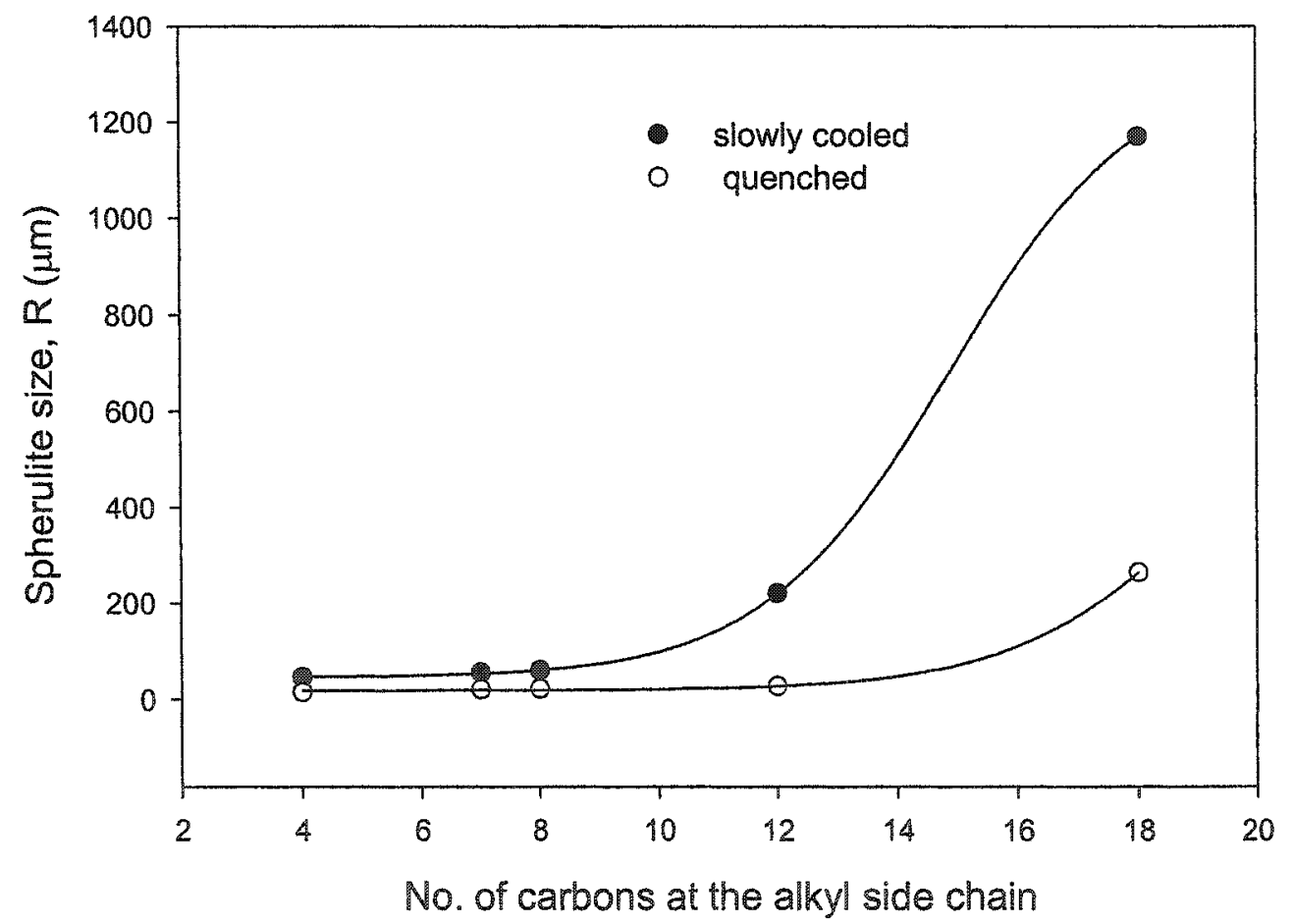

Figure 3.3 Spherulite size as a function of number of carbons at the alkyl side chain derived from alcohol. 

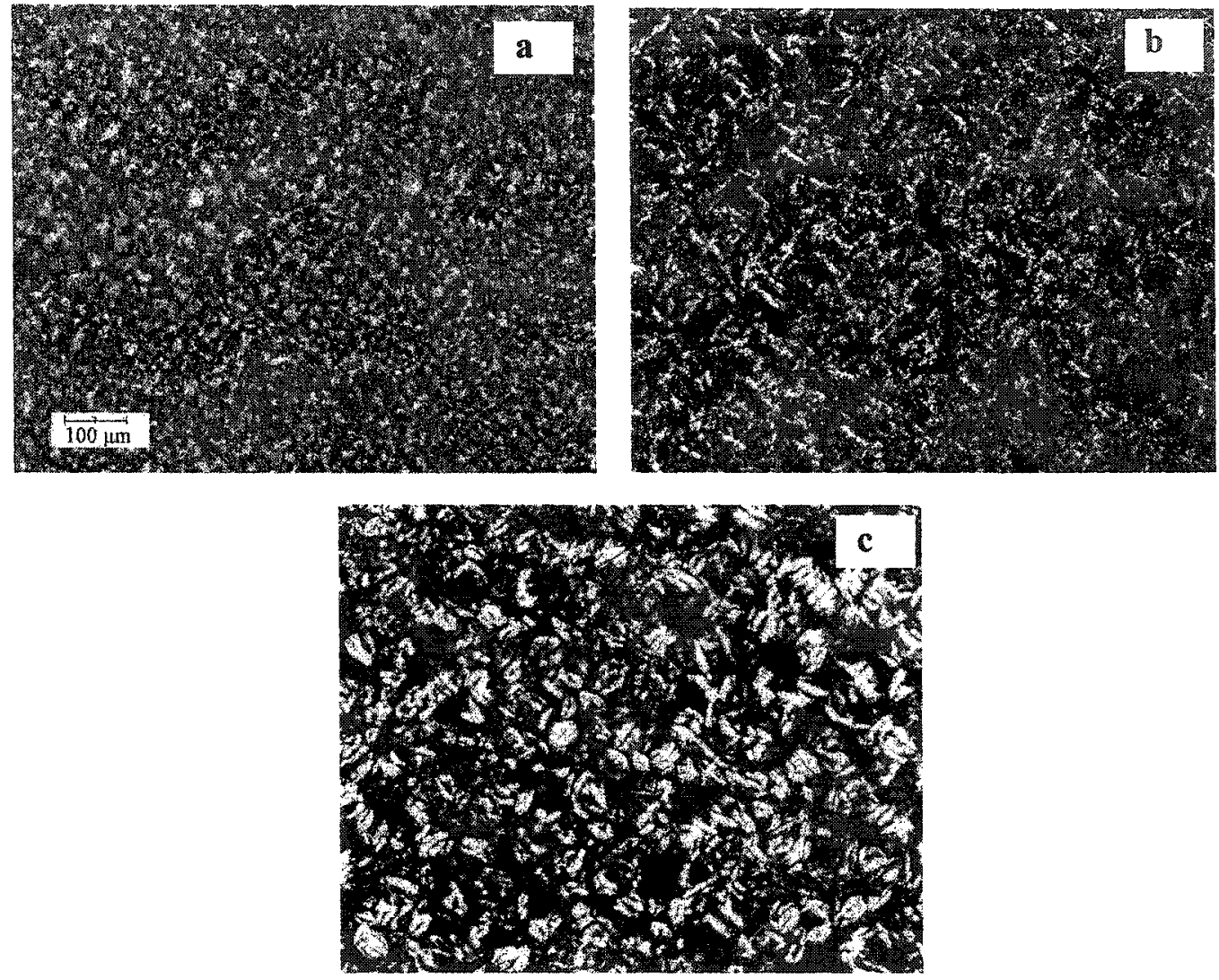

Figure 3.4 Optical micrographs of the slow cooled samples of $\mathrm{C}_{12} / \mathrm{C}_{16}$ blends (a) $80 / 20$ (b) $60 / 40$ (c) $50 / 50$.

Blending affects the morphology significantly, as expected. The $80 / 20$ blend of $\mathrm{C}_{12} / \mathrm{C}_{16}$ showed tiny spherulites under the optical microscope (Figure 3.4a). With an increase in the fraction of $\mathrm{C}_{16}$, the blends showed a mixture of crystals, some of which were needle shaped while the others were spherulitic (Figure $3.4 \mathrm{~b}, \mathrm{c}$ ). These can be compared with the micrographs exhibiting large spherulites for the individual components, shown in Figure $3.2 \mathrm{a}$ and $\mathrm{b}$. The spherulites in the blends exhibited very low birefringence. The sign of the 
birefringence could not be determined. In most cases, the size of the spherulites was not large enough to determine reliably from the optical microscope, but small angle light scattering could be used in some cases. It is noteworthy that the transparency of the $80 / 20,60 / 40$ and $50 / 50$ blends was found to improve significantly as compared to pure $\mathrm{C}_{12}$ or $\mathrm{C}_{16}$. This is shown in Figure 3.5. To take the photographs shown in Figure 3.5, samples of $\mathrm{C}_{12}, \mathrm{C}_{16}$ and $80 / 20$ blend of $\mathrm{C}_{12} / \mathrm{C}_{16}$ were melted individually between two microscope slides and then slowly cooled. The graphic on a transparency slide containing the logo and the text was covered with the microscope slides and was projected on a screen. The photographs clearly show the improvement in transparency in the blend as compared to that of $\mathrm{C}_{12}$ and $\mathrm{C}_{16}$.
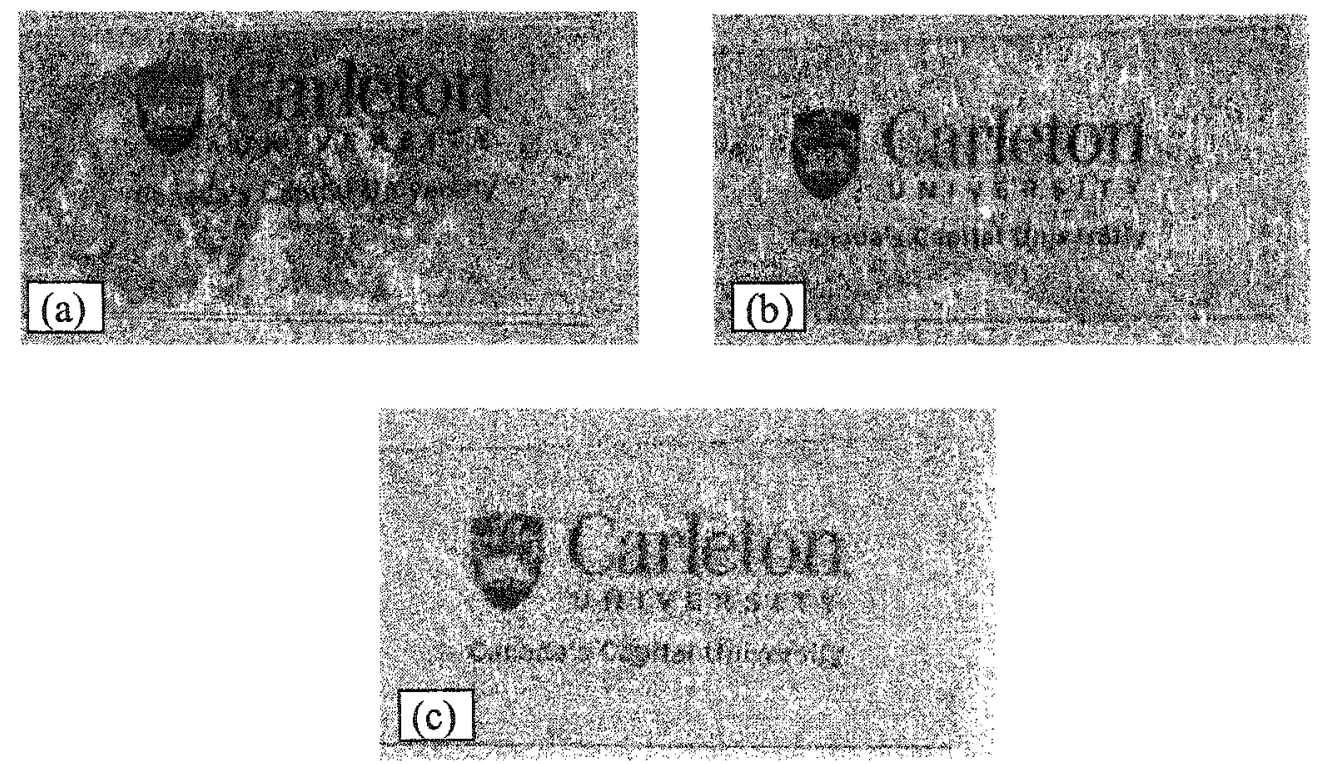

Figure 3.5 Transparency of (a) $\mathrm{C}_{12}$ (b) $\mathrm{C}_{16}$ and (c) $80 / 20$ blend of $\mathrm{C}_{12} / \mathrm{C}_{16}$. All the samples are slowly cooled. 


\subsubsection{Small Angle Light Scattering}

The $\mathrm{H}_{V}$ scattering patterns were recorded with the same sample-film distance for all cases. Those arising from spherulites of slow cooled samples of $\mathrm{C}_{4}, \mathrm{C}_{7}$ and $\mathrm{C}_{8}$ showed the characteristic four-leaf clover pattern, having $45^{\circ}$ intensity maximum. The slow cooled sample of $\mathrm{C}_{12}$ showed intensity maximum at $0^{\circ}$ and $90^{\circ}$ (Figure $3.6 \mathrm{a}$ ) but the quenched sample showed the more common $45^{\circ}$ intensity maximum (Figure 3.6b). This is consistent with the observation in the optical microscope: the observed $\mathrm{H}_{\mathrm{v}}$ scattering pattern for the slow cooled sample of $C_{12}$ is characteristic of the spherulite having an angle between the optic axis and the spherulite axis.
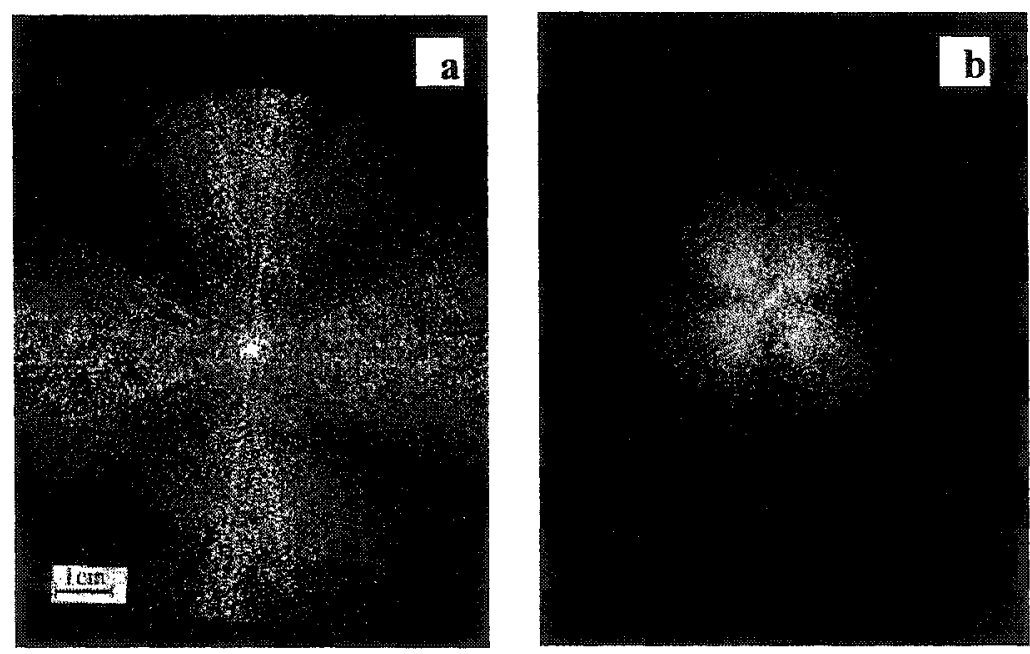

Figure 3.6 $\quad \mathrm{H}_{\mathrm{v}}$ scattering pattern for $\mathrm{C}_{12}$ (a) slowly cooled (b) quenched

Both the slow cooled and quenched samples of $C_{16}$ also exhibited an $H_{v}$ pattem with intensity maxima at $0^{\circ}$ and 90 i.e., the unusual type. However, $\mathrm{C}_{18}$ exhibited the usual 
four-leaf clover pattern. Figure 3.7 shows the $H_{v}$ patterns obtained from the slow cooled samples of the blends of $\mathrm{C}_{12}$ and $\mathrm{C}_{16}$ at different compositions. The four-leaf clover pattern was found to become larger with increasing incorporation of $\mathrm{C}_{16}$ in the blend, indicating a decrease in the size of the spherulites.
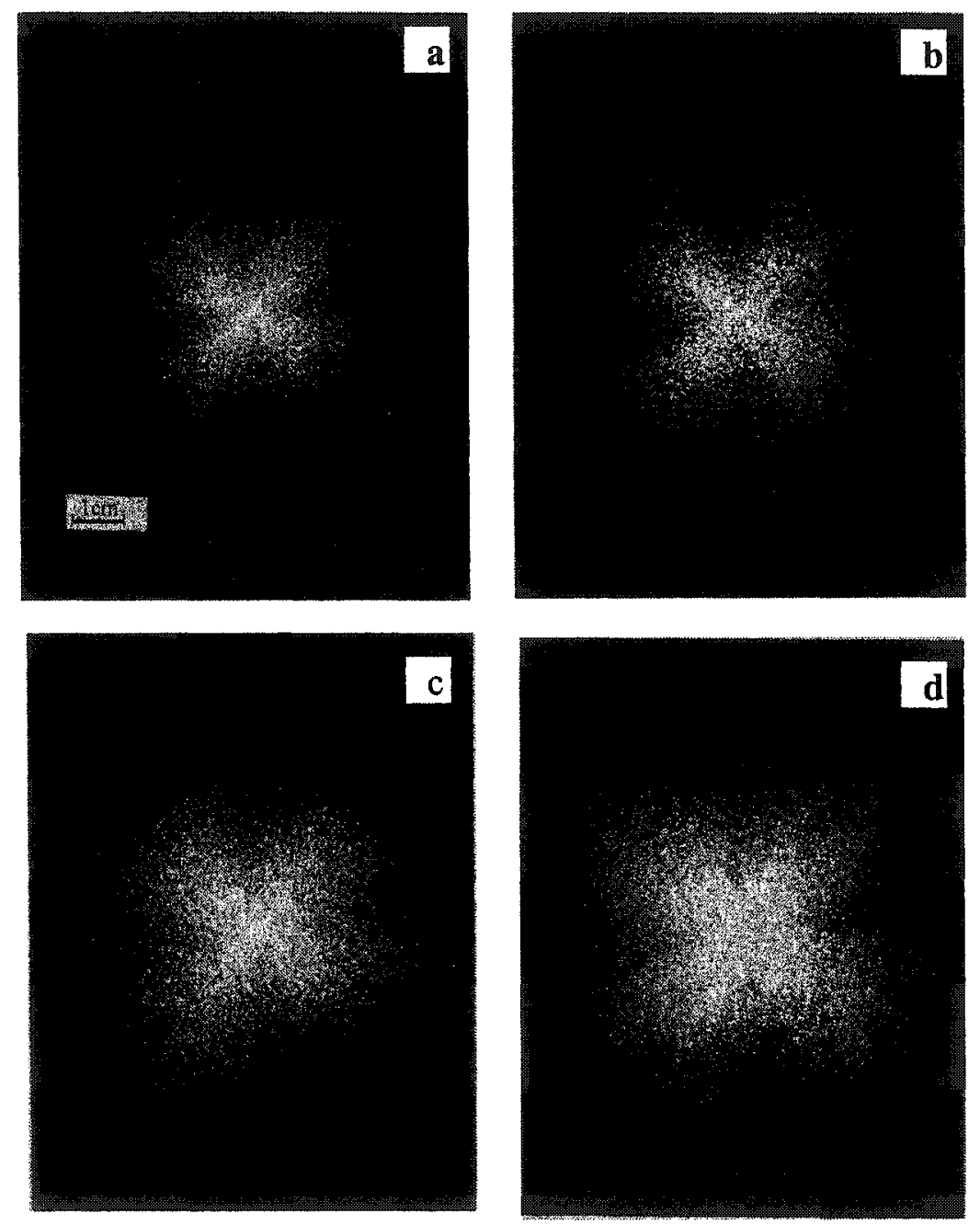

Figure 3.7 $\mathrm{H}_{\mathrm{v}}$ scattering pattern for blends of $\mathrm{C}_{12} / \mathrm{C}_{16}$ at composition of (a) $80 / 20$ (b) $60 / 40$ (c) $50 / 50$ (d) 40/60; all the samples are slowly cooled. 
As seen in Figure 3.8, the size of the spherulites in the blend calculated from the SALS pattern decreases with an increase in the fraction of $C_{16}$. This decrease in spherulite size can be attributed to the heterogeneous nucleation and less ordered state of the blend compared to the pure materials. Thus, the effect of blending these two carbamates is similar to the role of clarifiers to reduce the spherulite size. As mentioned above, the transparency of the films improves significantly with the blends. The four leaf clover patterns obtained from the quenched samples of the blends were not perfect, probably due to the size of the spherulites being too small. Hence, they were not used to calculate the spherulite size.

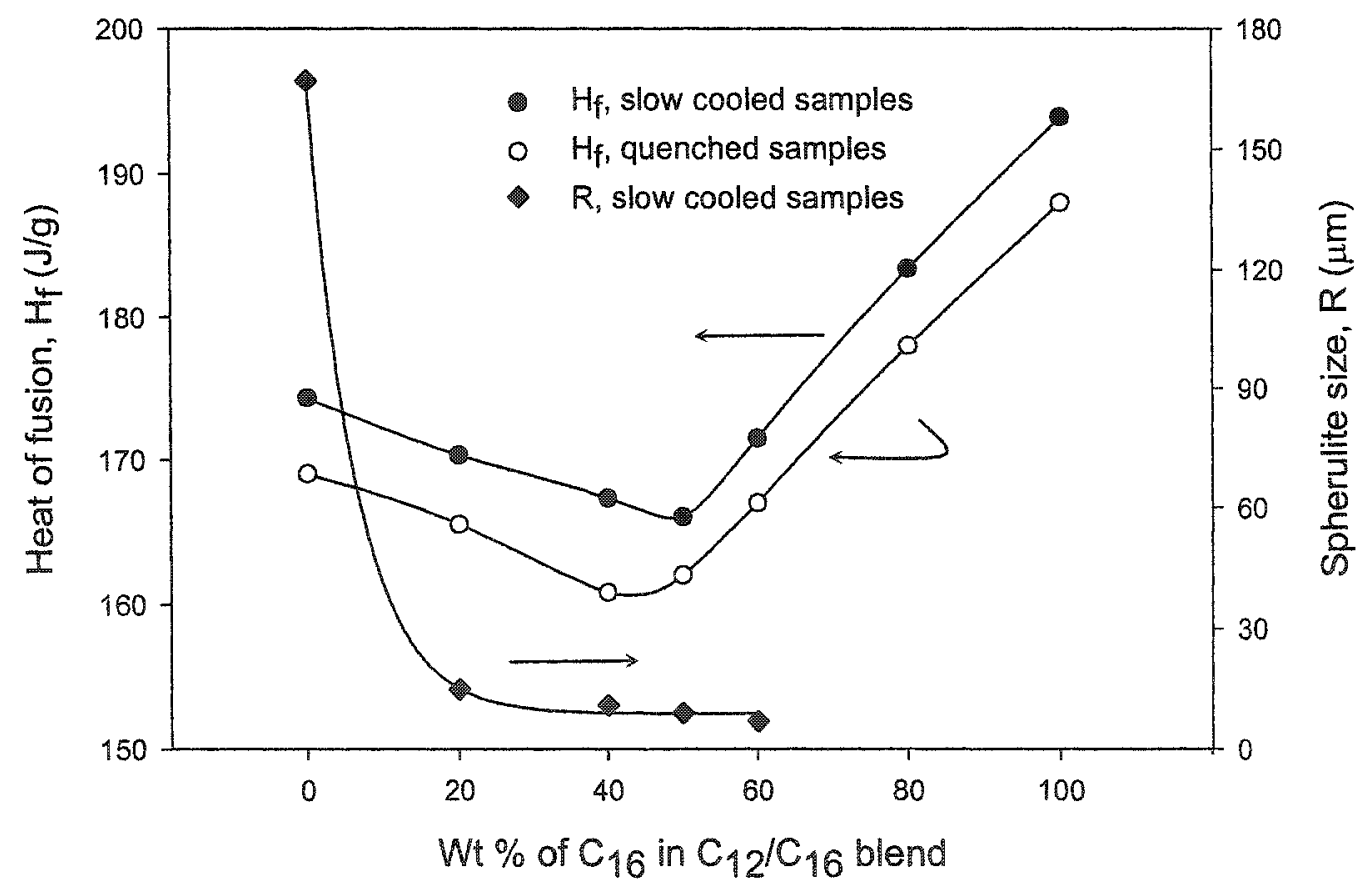

Figure 3.8 Spherulite size and heat of fusion as a function of wt $\%$ of $\mathrm{C}_{16}$ in the binary blends of $\mathrm{C}_{12}$ and $\mathrm{C}_{16}$ 


\subsubsection{Thermal analysis}

In the DSC thermograms of all the carbamates, only one phase transition from solid to liquid was observed. This indicates the absence of any detectable impurity or any polymorphic transition prior to melting. Figure 3.9 shows the DSC thermogram and the TG curve for $\mathrm{C}_{16}$. The DSC thermogram shows a sharp transition. The nonisothermal TG analysis shows $5 \%$ weight loss of the carbamates at around $270{ }^{\circ} \mathrm{C}$. However, when the sample was heated isothermally at $200^{\circ} \mathrm{C}$, it shows $5 \%$ weight loss after half an hour of heating.

Krol et al..$^{8}$ reported $5 \%$ weight loss of $\mathrm{N}$-butylcarbamateoctyl ester at $159^{\circ} \mathrm{C}$ during the nonisothermal TG experiment. They attributed the mass loss of the carbamate to the conservative evaporation of the compound. However, our study indicates that the mass loss is due to decomposition rather than conservative evaporation. This is evident from the X-ray diffractograms and the $\mathbb{R}$ spectra shown in Figure 3.10. Two grams of the carbamate $\mathrm{C}_{16}$ were taken into a $10 \mathrm{ml}$ beaker and were heated at $200{ }^{\circ} \mathrm{C}$ for 1 hour and the evaporated sample was condensed on a microscope slide as well as on a $\mathrm{NaCl}$ disk. The condensed sample showed a completely different diffraction pattern (Figure 3.10a) and IR spectrum (Figure 3.10b) as compared to those of the original sample. 


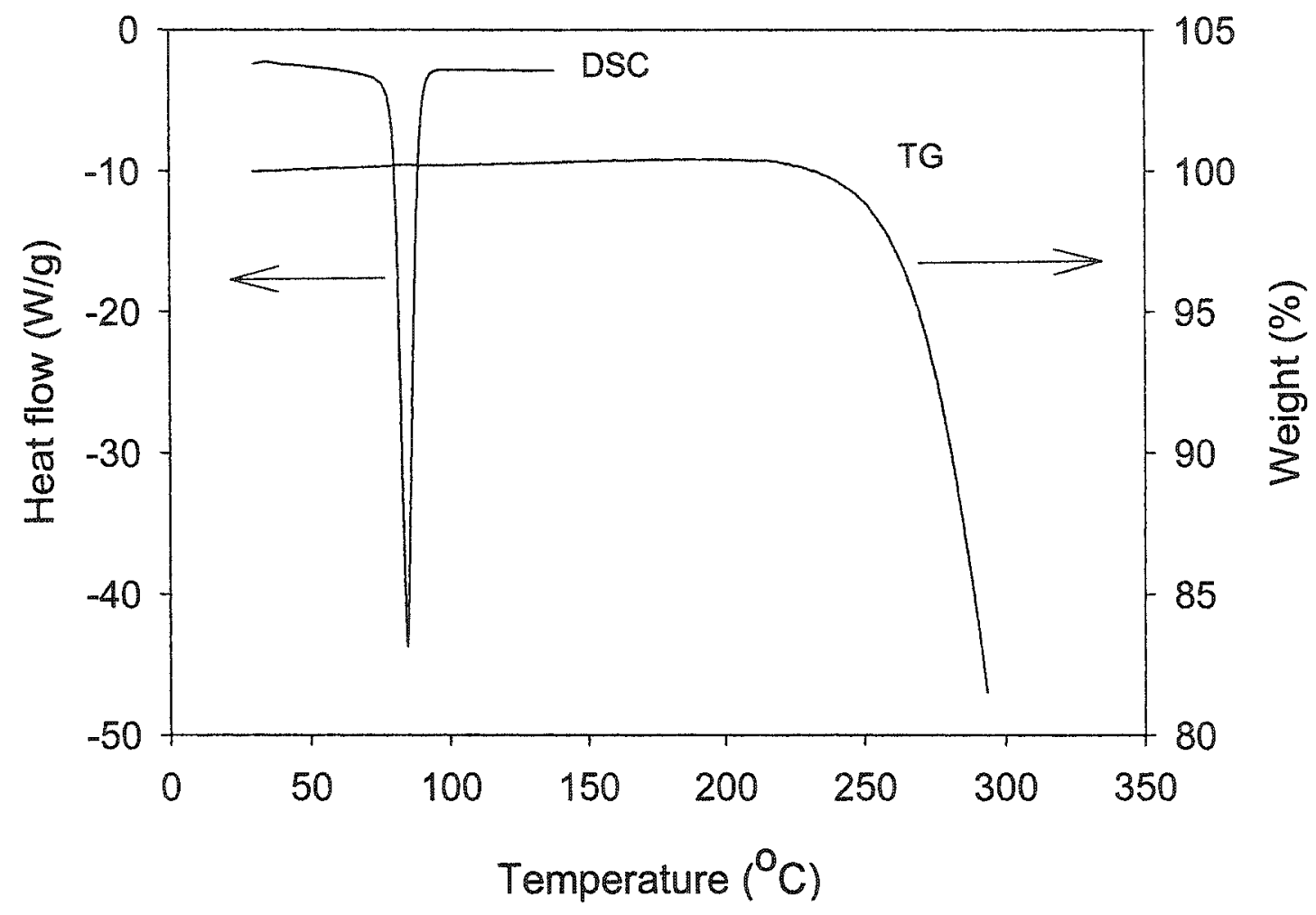

Figure 3.9 TG and DSC curves for $\mathrm{C}_{16}$ 

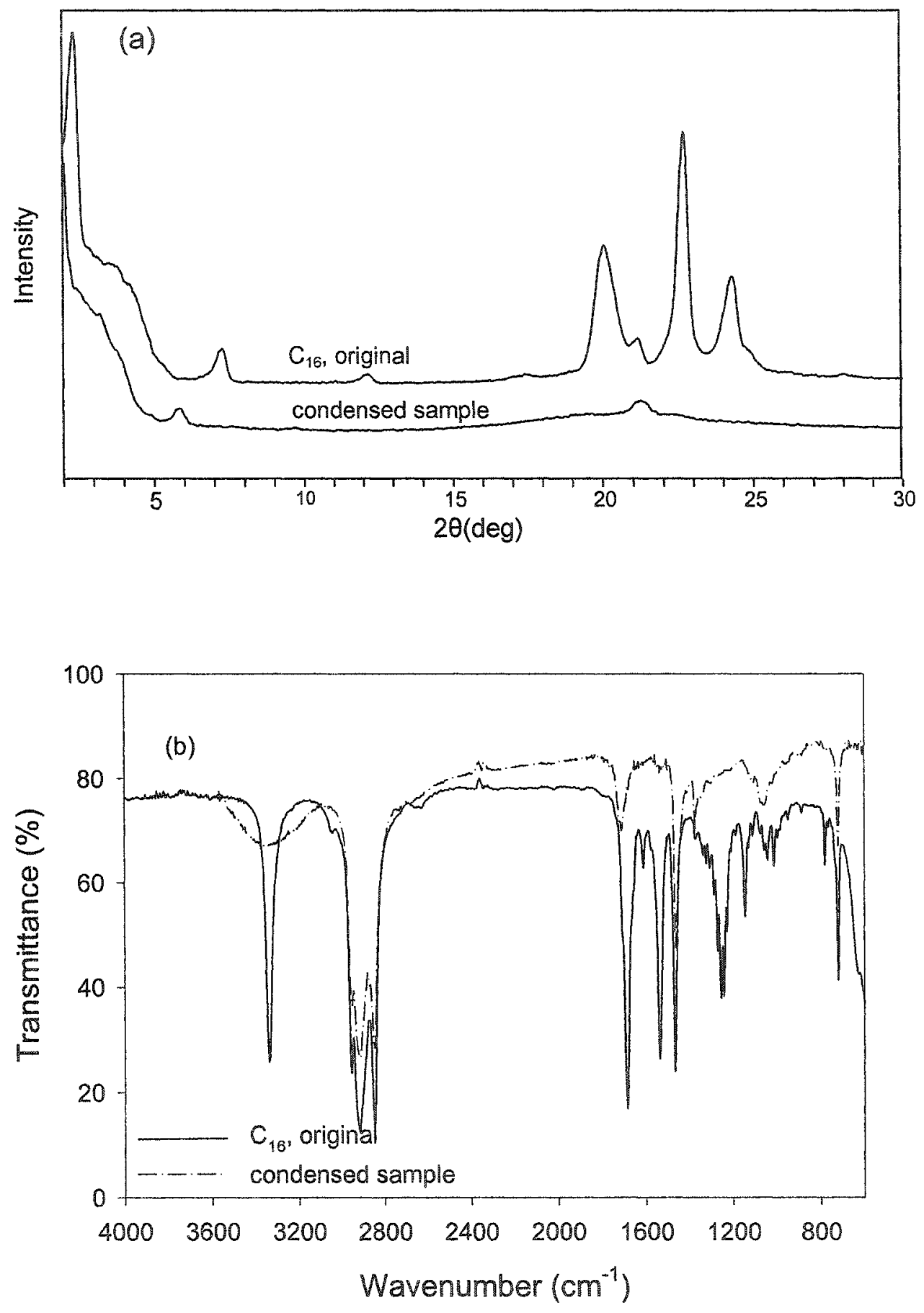

Figure 3.10 (a) X-ray diffractograms and (b) $\mathbb{R}$ spectra of original $\mathrm{C}_{16}$ and the sample evaporated at $200^{\circ} \mathrm{C}$ and condensed on a microscope slide. 
The melting points of the carbamates as determined by DSC are shown in Table 3.1, column 3. There was a linear increase of the melting point with the length of the alkyl side chain (Figure 3.11). The melting points of the slow cooled and the quenched samples did not differ significantly. Heat of fusion data showed sigmoidal characteristics as the length of the alkyl side chain increases (Figure 3.11). Up to $C_{12}$, the heat of fusion did not change significantly, but after that it increased linearly. The heat of fusion of the slow cooled samples was found to be higher than the quenched samples, consistent with the Xray crystallinity measurements.

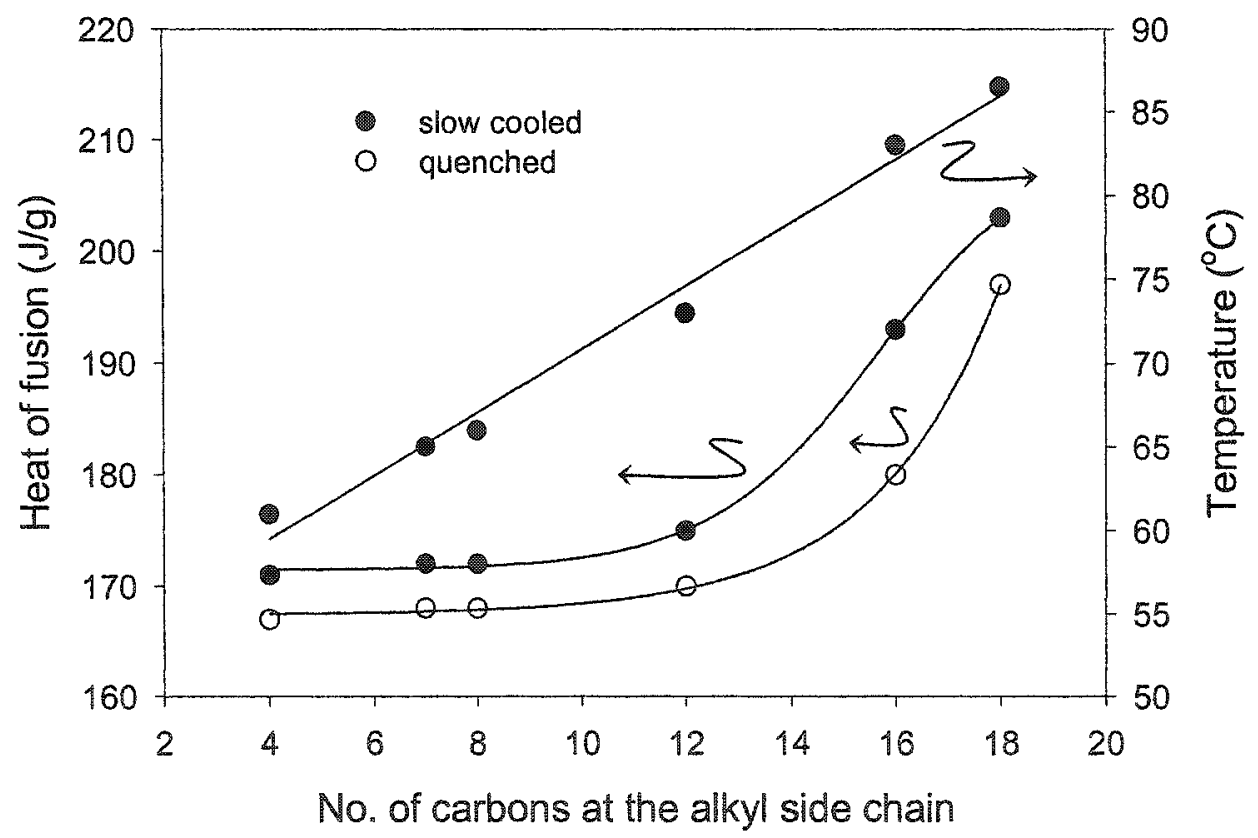

Figure 3.11 Heat of fusion and melting points as a function of number of carbons at the alkyl side chain derived from alcohol. 
Let us now consider the themal characteristics of the blends. Figure 3.8 shows the heat of fusion as a function of the blend composition for the binary blends prepared from $\mathrm{C}_{12}$ and $\mathrm{C}_{16}$. It is seen that initially there is a decrease in the heat of fusion with the incorporation of $\mathrm{C}_{16}$ in the blend. It passes through a plateau at the weight fraction of 0.4 of $\mathrm{C}_{16}$ and then increases with an increase in the content of $\mathrm{C}_{16} . \mathrm{A}$ similar behavior was found with the $\mathrm{C}_{4} / \mathrm{C}_{16}$ and $\mathrm{C}_{7} / \mathrm{C}_{16}$ blends. In all these cases, the heat of fusion of the slow cooled samples was higher than that of quenched samples.

The DSC thermographs of the blends of $C_{12}$ and $C_{16}$ are shown in Figure 3.12. These are shown in three diagrams in order to provide clarity. It is seen from Figure $3.12 \mathrm{a}$ that $80 / 20$ and $60 / 40$ blends of $C_{12}$ and $C_{16}$ show a single peak in DSC indicating the possibility that they are completely miscible with each other. However, it is seen not to be the case, as discussed below. The $50 / 50$ blend still shows a broad single peak with a shoulder (Figure 3.12b). Splitting of peaks occurs with $40 / 60$ and $20 / 80$ blends.

The melting points of blends of different compositions of $\mathrm{C}_{12}$ and $\mathrm{C}_{16}$ along with the melting points of the pure carbamates are summarized in Table 3.2. Note that the melting temperature of $\mathrm{C}_{16}$ is higher than that of $\mathrm{C}_{12}$ by about $10^{\circ}$. Surprisingly, although the $80 / 20$ and $60 / 40$ blends of $C_{12}$ and $C_{16}$ exhibited a single peak in DSC, their melting points were found to be less than the melting point of pure $\mathrm{C}_{12}$. 


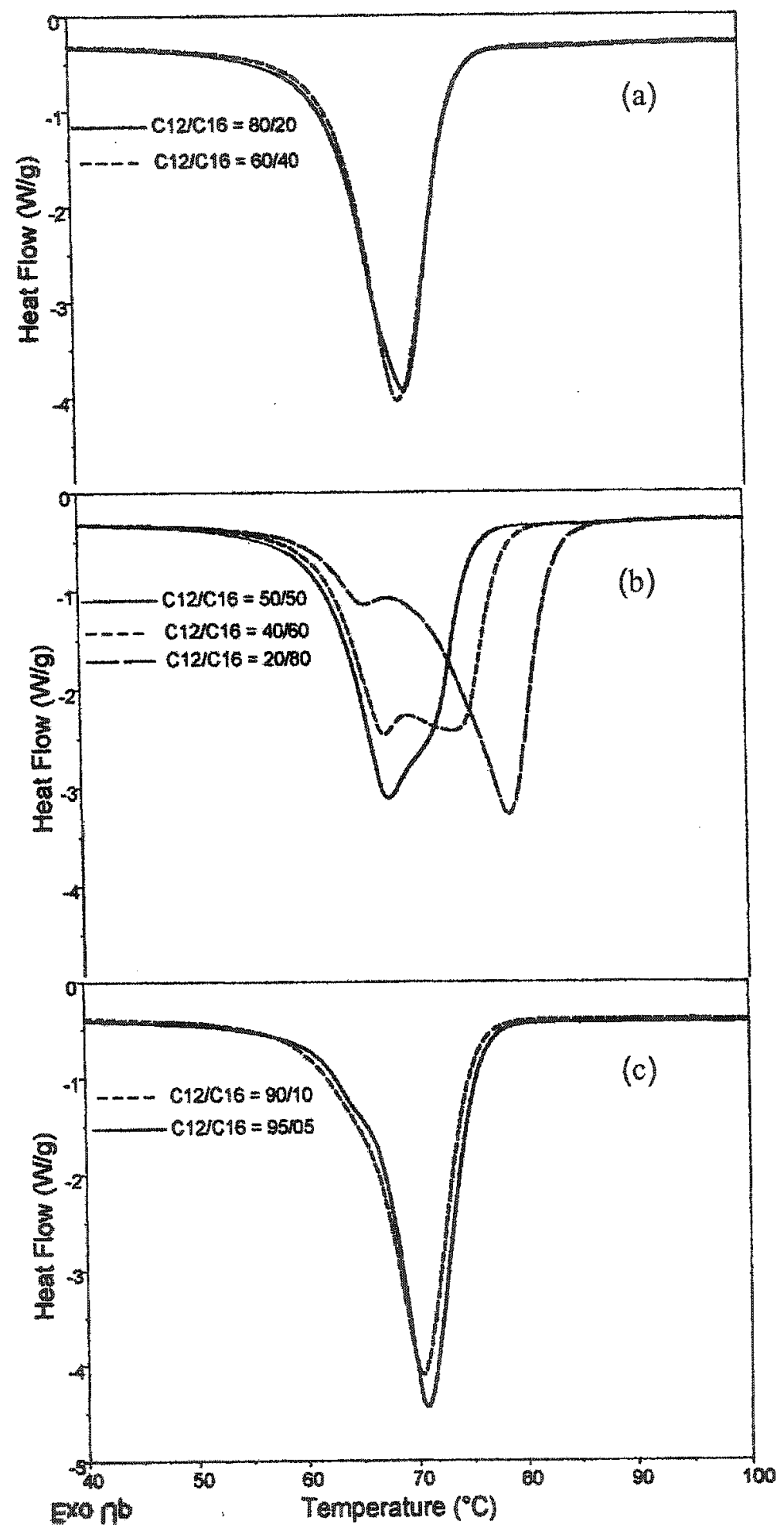

Figure 3.12 DSC thermographs of binary blends of $\mathrm{C}_{12} / \mathrm{C}_{16}$ at (a) $80 / 20$ and $60 / 40$ (b) $50 / 50,60 / 40$ and $20 / 80$ (c) $90 / 10$ and $95 / 05$ compositions. 
If the single peak in $80 / 20$ and $60 / 40$ blends were due to the complete miscibility of $\mathrm{C}_{12}$ and $\mathrm{C}_{16}$ at these compositions, we would expect the melting point of the blends to be in between the melting points of the components. To examine this anomaly, another two series of blends were prepared with $C_{16}$, but with $C_{4}$ or $C_{7}$ as the other member, to see its effect on the melting points of the blends. The difference in the lengths of the alkyl chains is large in the blend of $\mathrm{C}_{16}$ and $\mathrm{C}_{4}$. The $\mathrm{C}_{16} / \mathrm{C}_{7}$ blend provides an example of mixing even-odd components. The results are summarized in Table 3.2.

Table 3.2 Melting Points of the binary blends of carbamates

\begin{tabular}{clcccc}
\hline & \multicolumn{2}{c}{$\mathrm{C}_{12} / \mathrm{C}_{16}$} & \multicolumn{2}{c}{$\mathrm{C}_{7} / \mathrm{C}_{16}$} & \multicolumn{2}{c}{$\mathrm{C}_{4} / \mathrm{C}_{16}$} \\
\hline Sample & \multicolumn{1}{c}{ Melting } & Sample & Melting & Sample & Melting \\
& point/s $\left({ }^{\circ} \mathrm{C}\right)$ & & point $/ \mathrm{s}\left({ }^{\circ} \mathrm{C}\right)$ & & point/s $\left({ }^{\circ} \mathrm{C}\right)$ \\
\hline $100 / 0$ & 72.8 & $100 / 0$ & 65.5 & $100 / 0$ & 61.2 \\
$80 / 20$ & 69.5 & $80 / 20$ & 62.7 & $80 / 20$ & 58.2 \\
$60 / 40$ & 68.9 & $60 / 40$ & 62.4 & $60 / 40$ & $57.5 \& 67.1$ \\
$50 / 50$ & 68.5 & $50 / 50$ & $62.1 \& 72.2$ & $50 / 50$ & $57 \& 69.6$ \\
$40 / 60$ & $67.2 \& 73.8$ & $40 / 60$ & $61.7 \& 74.7$ & $40 / 60$ & $57 \& 72.7$ \\
$20 / 80$ & $65.5 \& 78.7$ & $20 / 80$ & $60.6 \& 79$ & $20 / 80$ & $56.4 \& 72.7$ \\
$0 / 100$ & 83 & $0 / 100$ & 83 & $0 / 100$ & 83 \\
\hline
\end{tabular}


Table 3.2 shows that when there was a splitting in DSC thermograms of the AB blends (A denotes the carbamate with shorter alkyl side chain), two melting points were observed, the first melting point was lower than that of pure carbamate $A$, the second one was lower than that of pure carbamate B. As the fraction of A was decreased in the blend, the second melting point increased, whereas the first melting point decreased. From these observations, it seems that the carbamates A and B exert a mutual plasticizer effect on each other in the blend, resulting in a depression of melting points of both. At high concentrations of $\mathrm{A}$, it depresses the melting point of $\mathrm{B}$ to such extent that these two melting peaks overlap resulting in one peak

If this rationale is valid, a further increase of the amount of $\mathrm{A}$ in the blend should either give a single peak (because of overlap) or it should depress the melting point of $B$ to such extent that the melting peak of $B$ should be at a position lower than that of $A$. To confirm this, two binary blends with $90 / 10$ and $95 / 5$ compositions were prepared from $\mathrm{C}_{12}$ and $\mathrm{C}_{16}$. Their DSC thermograms are shown in Figure 3.12(c). There is still a single peak observed for the $90 / 10$ composition. With $95 / 05$ composition of $\mathrm{C}_{12}$ and $\mathrm{C}_{16}$, a shoulder below the melting point of $\mathrm{C}_{12}$ was observed, which indicated that the single peak at some compositions was not due to miscibility, but because of the mutual plasticizer effect of the carbamates.

\subsubsection{X-ray diffraction}

The X-ray diffraction patterns of different carbamates are presented in Figure 3.13 and the $d$-spacings and relative intensities are listed in Table 3.3 . 


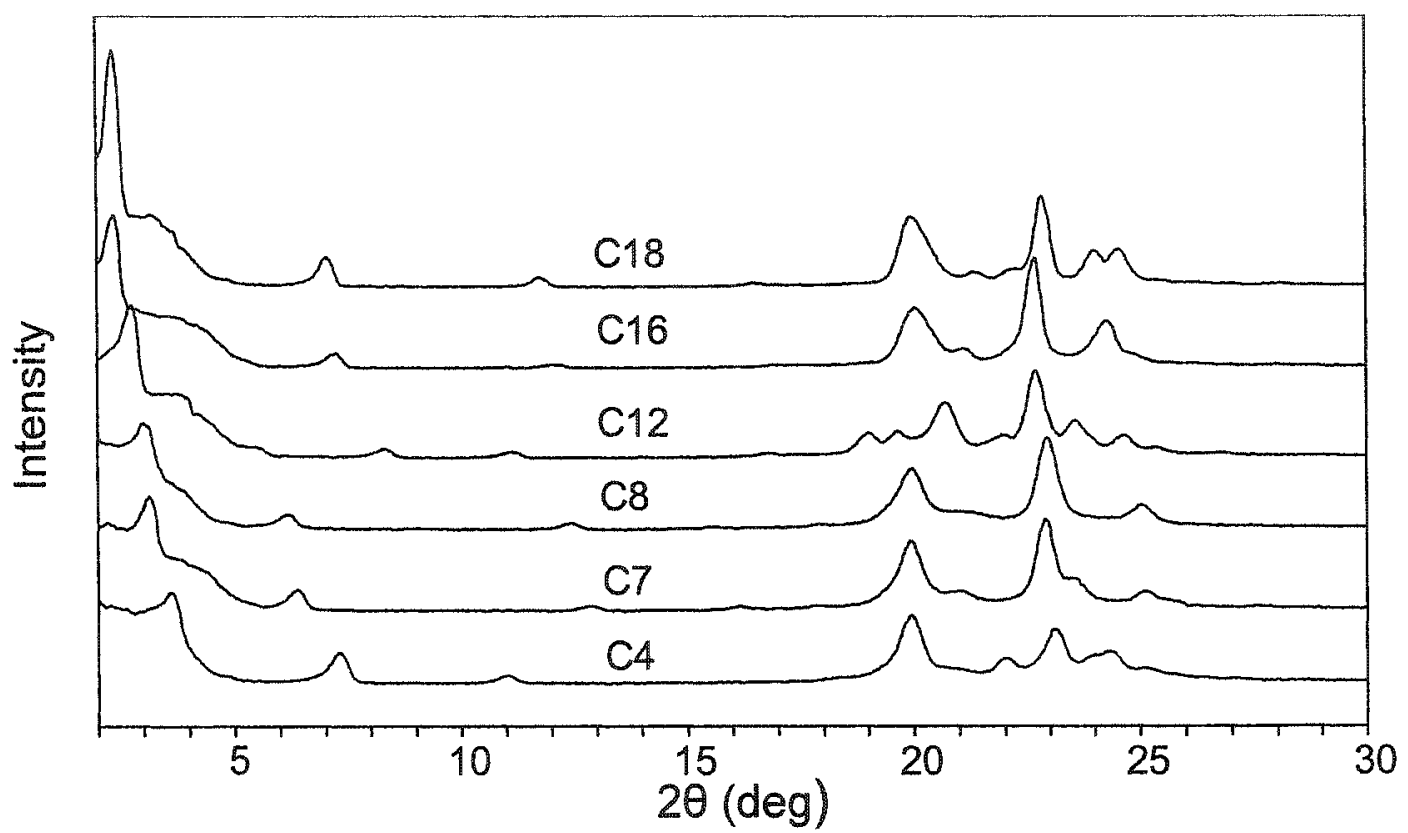

Figure 3.13 X-ray diffraction patterns of different carbamates.
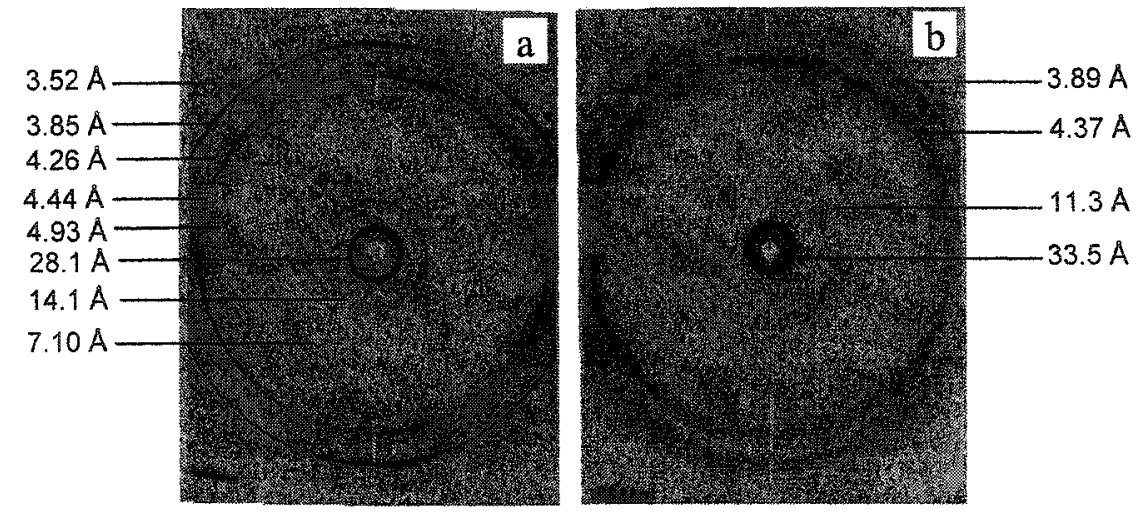

Figure 3.14 Diffraction patterns obtained from (a) $\mathrm{C}_{8}$ (b) $80 / 20$ blend of $\mathrm{C}_{12} / \mathrm{C}_{16}$. The $d$-spacings are marked. 
Table 3.3 Interplanar spacings $d(\AA)$ and relative intensities (\%) of X-ray diffraction maxima for the various carbamates.

\begin{tabular}{|c|c|c|c|c|c|c|c|c|c|c|c|}
\hline \multicolumn{2}{|c|}{$\mathrm{C}_{4}$} & \multicolumn{2}{|c|}{$\mathrm{C}_{7}$} & \multicolumn{2}{|c|}{$\mathrm{C}_{8}$} & \multicolumn{2}{|c|}{$\mathrm{C}_{12}$} & \multicolumn{2}{|c|}{$\mathrm{C}_{16}$} & \multicolumn{2}{|c|}{$C_{18}$} \\
\hline$d$ & $I$ & $d$ & $I$ & $d$ & $I$ & $d$ & 1 & $d$ & $I$ & $d$ & $I$ \\
\hline 42.5 & $\mathrm{~m}$ & 42.6 & $\mathrm{~m}$ & 42.8 & $\mathrm{~m}$ & 64.7 & $\mathrm{~m}$ & 62.4 & $\mathrm{~m}$ & 64.7 & $\mathrm{~m}$ \\
\hline 29.9 & $\mathrm{~m}$ & 33.4 & $\mathrm{~m}$ & 35.1 & $\mathrm{~m}$ & 51.4 & $\mathrm{w}$ & 52.1 & $\mathrm{~m}$ & 52.4 & $\mathrm{~m}$ \\
\hline 26.8 & $\mathrm{~m}$ & 30.2 & $\mathrm{~m}$ & 31.6 & $\mathrm{~m}$ & 44.7 & $\mathrm{~m}$ & 46.1 & $\mathrm{~m}$ & 46.4 & $\mathrm{~m}$ \\
\hline 24.5 & $100(s)$ & 28.1 & $100(\mathrm{~s})$ & 29.4 & $100(s)$ & 39.6 & $\mathrm{~m}$ & 42.3 & $\mathrm{~m}$ & 42.3 & $\mathrm{~m}$ \\
\hline 14.2 & W & 20.9 & 39.7 & 22.6 & 39.0 & 32.0 & $100(\mathrm{~s})$ & 35.9 & $100(\mathrm{~s})$ & 38.1 & $100(\mathrm{~s})$ \\
\hline 13.5 & w & 16.4 & w & 15.6 & w & 23.7 & 23.7 & 20.6 & 30.2 & 26.9 & 35.8 \\
\hline 12.1 & 36.8 & 15.3 & $\mathrm{~m}$ & 14.3 & 18.0 & 16.2 & 10.0 & 13.3 & $\mathrm{~m}$ & 22.4 & $\mathrm{w}$ \\
\hline 8.84 & w & 13.8 & 21.6 & 9.1 . & w & 13.3 & $\mathrm{~m}$ & 12.1 & 13.9 & 19.1 & w \\
\hline 8.02 & 12.4 & 11.5 & $w$ & 7.12 & 9.7 & 12.0 & $\mathrm{~m}$ & 10.6 & $\mathrm{w}$ & 14.8 & w \\
\hline 4.96 & $\mathrm{~m}$ & 9.8 & $\mathrm{w}$ & 5.67 & 6.4 & 10.6 & 8.3 & 9.82 & $\mathrm{~m}$ & 14.0 & $\mathrm{w}$ \\
\hline 4.63 & w & 9.1 & w & 4.94 & 9.0 & 7.93 & 6.9 & 7.25 & 6.1 & 13.0 & $\mathrm{~m}$ \\
\hline 4.44 & 74.9 & 6.88 & 7.7 & 4.61 & $\mathrm{~m}$ & 5.24 & 5.6 & 4.41 & 43.5 & 12.5 & 16.5 \\
\hline 4.24 & w & 5.49 & w & 4.44 & 58.8 & 4.67 & 18.3 & 4.29 & $\mathrm{~m}$ & 10.4 & $\mathrm{~m}$ \\
\hline 4.03 & 30.8 & 4.97 & 8.5 & 4.26 & $\mathrm{~m}$ & 4.52 & 19.5 & 4.18 & 15.7 & 9.20 & $\mathrm{~W}$ \\
\hline 3.84 & 61.3 & 4.60 & W & 4.01 & $\mathrm{w}$ & 4.29 & 37.8 & 4.05 & w & 7.94 & $\mathrm{~W}$ \\
\hline 3.66 & 38.3 & 4.44 & 62.0 & 3.87 & 86 & 4.05 & w & 3.90 & 81.7 & 7.52 & 6.7 \\
\hline 3.46 & w & 4.21 & 20.2 & 3.56 & 26.1 & 3.91 & 58.1 & 3.64 & 33.1 & 5.37 & 4.2 \\
\hline & & 4.01 & $\mathrm{~m}$ & 3.25 & 8.5 & 3.77 & 26.5 & & & 4.93 & W \\
\hline & & 3.88 & 80.1 & & & 3.61 & 17.0 & & & 4.66 & $\mathrm{w}$ \\
\hline & & 3.69 & $\mathrm{~m}$ & & & 3.50 & 9.3 & & & 4.44 & 35.8 \\
\hline & & 3.54 & 20.5 & & & 3.33 & 6.2 & & & 4.28 & $\mathrm{~m}$ \\
\hline & & 3.36 & $\mathbf{w}$ & & & & & & & 4.16 & 9.4 \\
\hline & & 3.23 & w & & & & & & & 4.00 & $\mathrm{w}$ \\
\hline & & & & & & & & & & 3.89 & 45.6 \\
\hline & & & & & & & & & & 3.68 & w \\
\hline & & & & & & & & & & 3.58 & 20.3 \\
\hline & & & & & & & & & & 3.17 & 4.1 \\
\hline
\end{tabular}


It is seen from Figure 3.13 that all the carbamates exhibit the most intense peak below $2 \theta$ $=5^{\circ}(d>17.7 \AA)$. No significant diffraction maximum was observed at $2 \theta>30^{\circ}(d<2.97$ $\AA$ ). Some diffraction maxima below $5^{\circ}$ were not well resolved and in those cases the $d$ spacings were calculated from the pattern recorded on film and their intensity is reported in Table 3.3 in terms of strong (s), medium (m) and weak (w). As an illustration, Figure 3.14(a) shows the diffraction pattern obtained from $\mathrm{C}_{8}$.

Although it is not our intent here to determine the crystal structure of these carbamates, some general observations could be made from the diffraction data. Table 3.3 shows that the $d$-spacing of the most intense peak increases with the length of the alkyl side chain, from 24.5 for $\mathrm{C}_{4}$ to $38.1 \AA$ for $\mathrm{C}_{18}$. The patterns recorded on film also show reflections with much larger spacings. The largest spacing recorded for $\mathrm{C}_{4}, \mathrm{C}_{7}$ and $\mathrm{C}_{8}$ is about 42.5 $\AA$, and this reflection does not show variation with the length of the alkyl side chain in these three samples. Similarly, the reflection with a spacing of $62 \AA$ does not show a systematic variation between $\mathrm{C}_{12}, \mathrm{C}_{16}$ and $\mathrm{C}_{18}$. A medium intensity reflection with $\mathrm{d}$ spacing corresponding to the molecular length (see column 3, Table 3.1) was observed for all the carbamates.

In all the diffractograms, there is a strong diffraction maximum at $2 \theta \cong 22.8^{\circ}(d=3.9 \AA)$. Using HyperChem simulation software, two molecules of e.g., $\mathrm{C}_{12}$ were placed in proximity and the energy minimized. With the hydrogen bond between the two molecules, the distance between the alkyl chains was found to be $3.9 \AA$. Thus, the above $d$-spacing corresponds to the plane of hydrogen bonding (Figure 3.15). The crystallite 
size corresponding to this diffraction maximum was calculated for these carbamates, and the results are shown in Figure 3.16a as a function of the alkyl side chain length. The crystallite size is found to increase linearly with the increase of the length of the alkyl side chain. Figure $3.16 \mathrm{~b}$ illustrates the crystallinity calculated from the X-ray diffractograms as a function of the number of carbons at the alkyl side chain derived from alcohol. Like the heat of fusion, the plot of X-ray crystallinity showed sigmoidal characteristic. The crystallinity increases significantly only after $C_{12}$. In all cases, the crystallinity of the slow cooled samples was found to be higher than that of quenched samples.

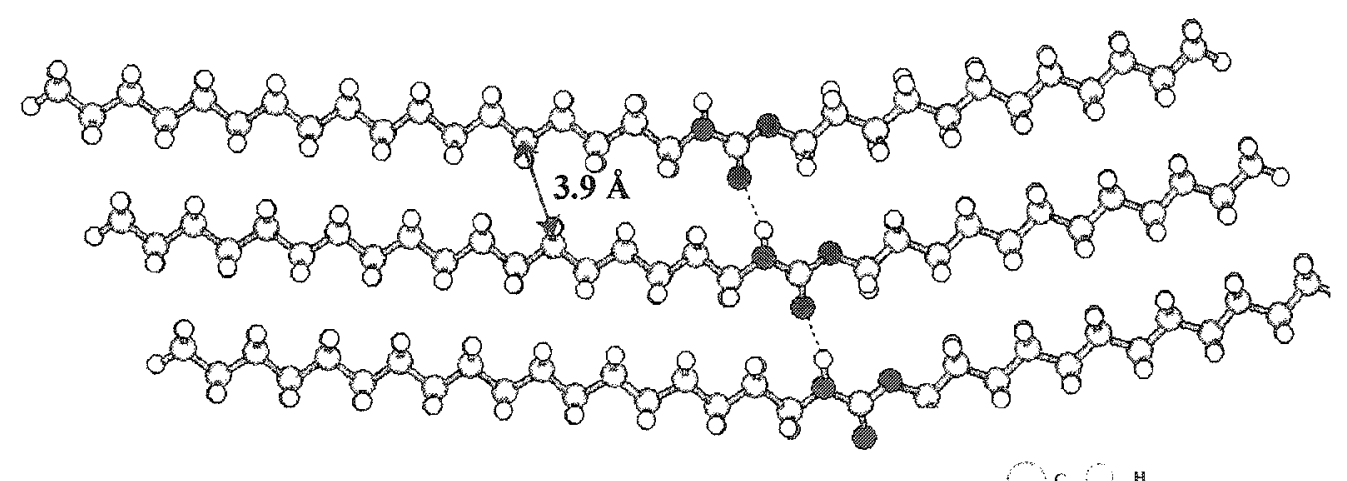

W

Figmre 3.15 The distance between the alkyl chains in the hydrogen bonded network of carbamates 

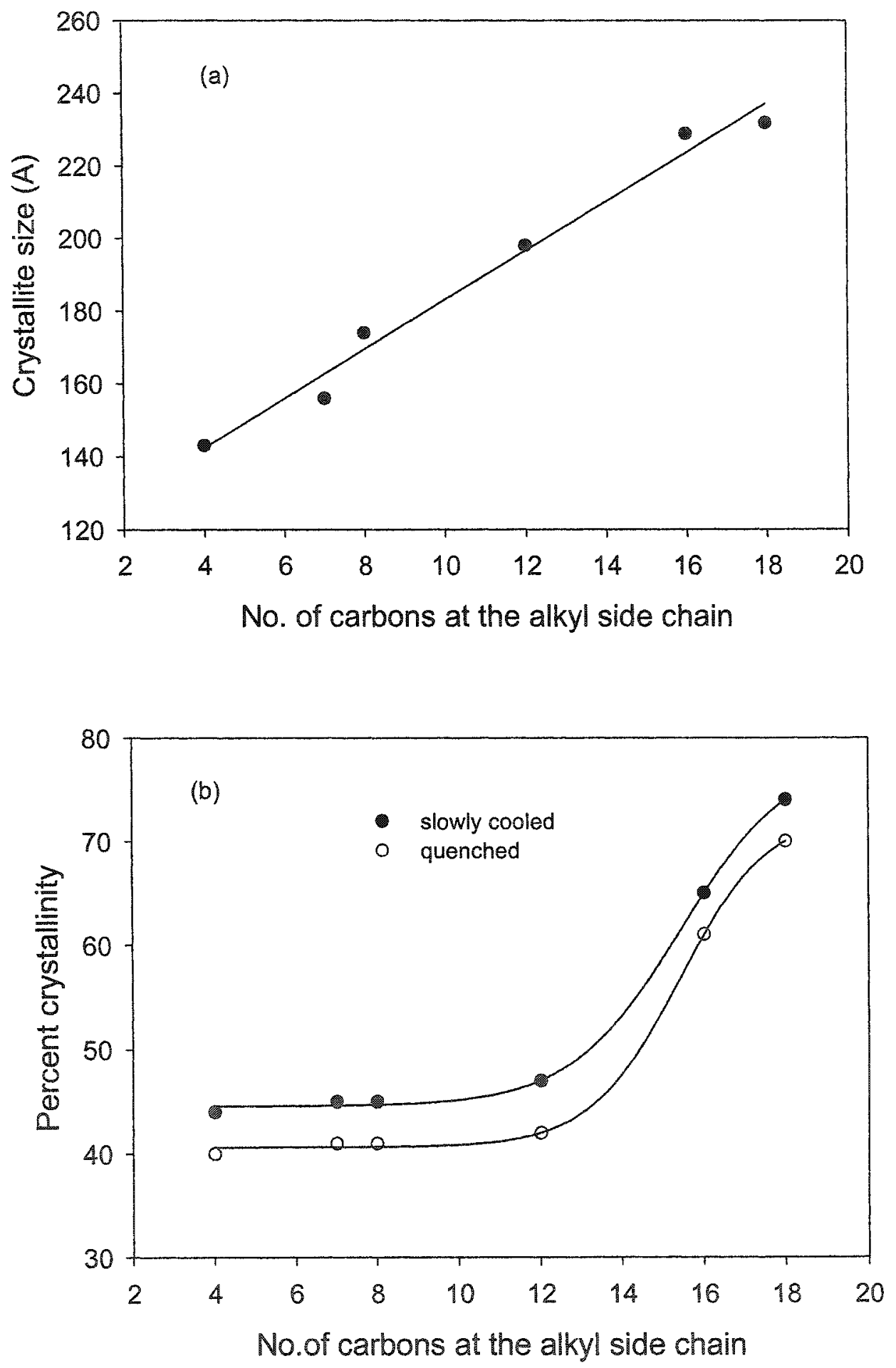

Figure 3.16 (a) Crystallite size corresponding to the reflection at $22.8^{\circ}$ and (b) Crystallinity as a function of number of carbon atoms at the alkyl side chain derived from alcohol. 
Figure 3.17 presents the X-ray diffractograms of binary blends of $\mathrm{C}_{12}$ and $\mathrm{C}_{16}$ along with the diffractograms of the pure carbamates. These diffractograms show several characteristics. At 80/20 composition of $\mathrm{C}_{12}$ and $\mathrm{C}_{16}$, there is a reduction of number of peaks. The relative intensity of most of the peaks reduces compared to $\mathrm{C}_{12}$. For example, the intensity of the diffraction maximum at $2 \theta \cong 22.8^{\circ}$, relative to the most intense peak, reduces from 58 to $37 \%$, the full width at half maximum (fwhm) increases from 0.366 to 1.108 radians in the $2 \theta$ scale, and the crystallite size decreases from $230 \AA$ to $73 \AA$. Having in mind the possibility that reduction of peak in the $80 / 20$ blend might be simply because the instrument was not sensitive enough to record some weak peaks, this diffractogram was compared with the diffraction rings obtained from the film $\mathrm{x}$-ray as shown in Figure 3.14b. The film shows several additional peaks with very low intensity. The decrease in crystallite size is supported from the broadening of diffraction rings in Figure $3.14 \mathrm{~b}$. As the fraction of $\mathrm{C}_{16}$ increases in the blend, the relative intensity of the peaks gradually increases. However, for all the blends, the crystallite size corresponding to the reflection at $2 \theta \cong 22.8^{\circ}$ was found to be significantly lower than those of pure $\mathrm{C}_{12}$ and $\mathrm{C}_{16}$. 


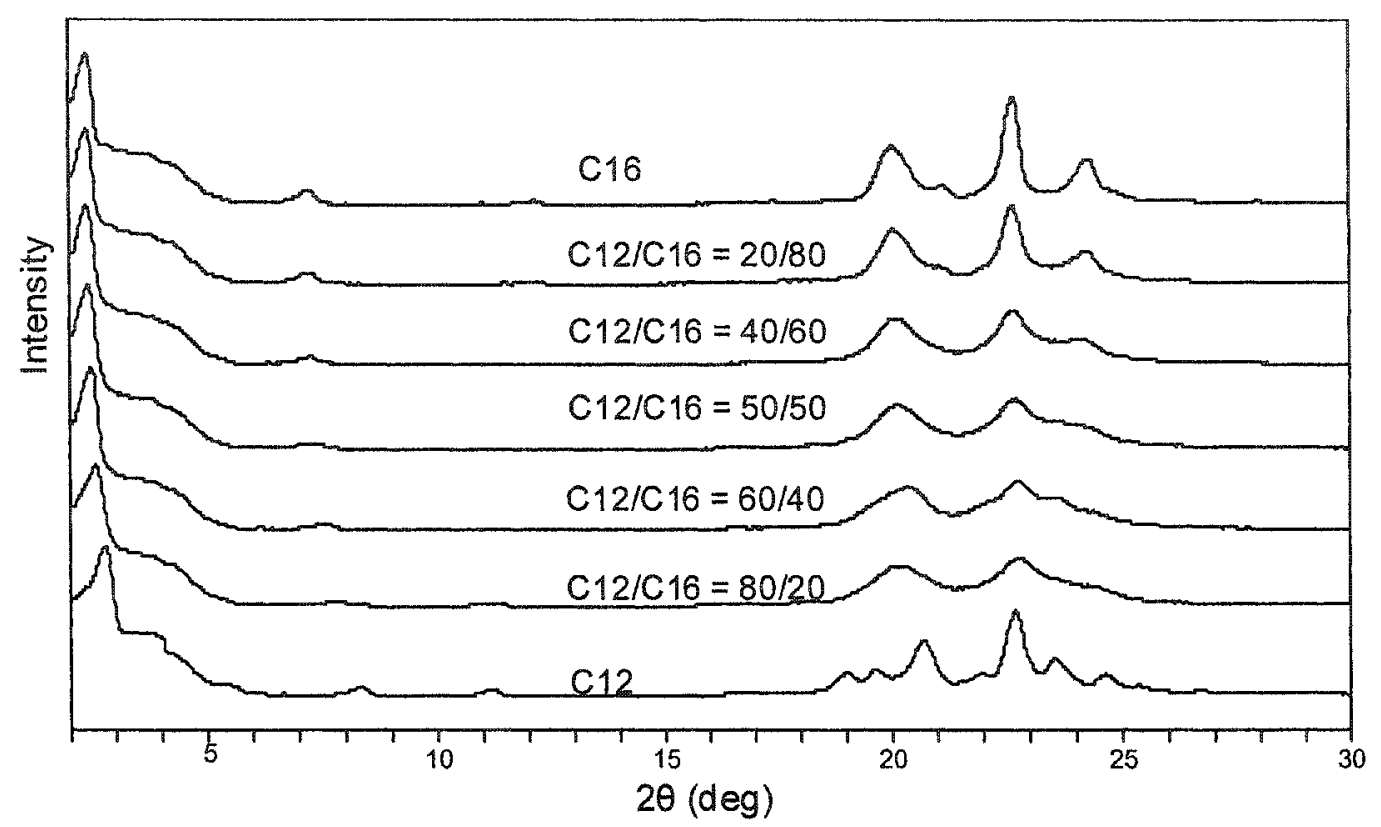

Figure 3.17 X-ray diffractograms of the binary blends of $\mathrm{C}_{12} / \mathrm{C}_{16}$ along with those of $\mathrm{C}_{12}$ and $\mathrm{C}_{16}$

Figure 3.18 shows the $\mathrm{X}$-ray crystallinity as a function of the blend compositions. As shown in the figure, there is a decrease in the X-ray crystallinity with the incorporation of $C_{16}$ in the blend. It passes through a plateau at the weight fraction of 0.4 of $C_{16}$, similar to the heat of fusion shown in Figure 3.8. Again the crystallinities of the slow cooled samples were found to be higher than that of quenched samples. 


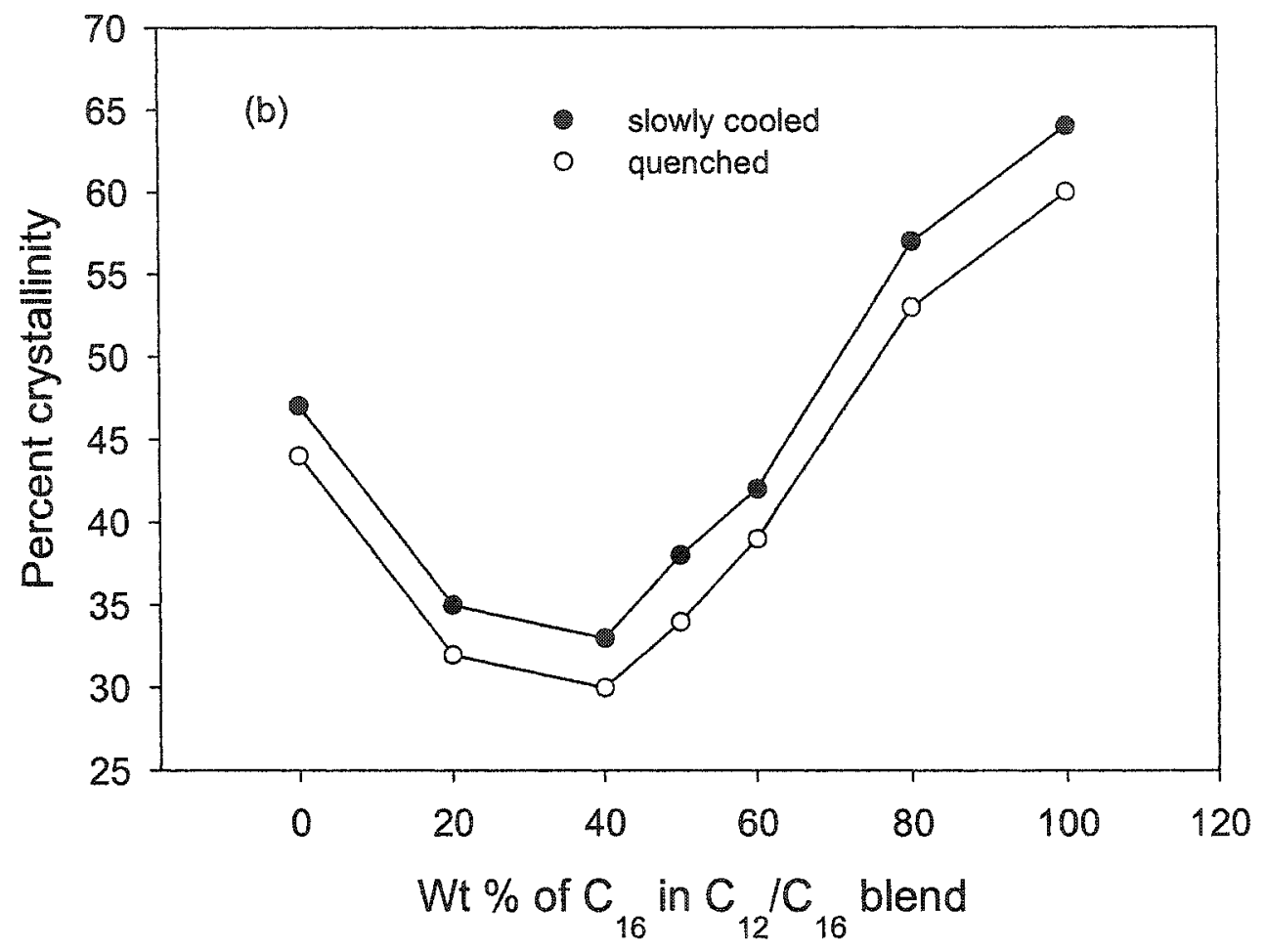

Figure 3.18 Percent X-ray crystallinity as a function of $w t \%$ of $\mathrm{C}_{16}$ in the binary blends of $\mathrm{C}_{12}$ and $\mathrm{C}_{16}$

The question arises as to whether the decrease in the crystallinity of the blend can be attributed to the disruption of hydrogen bond leading to less efficient self-assembly and the less ordered state of the blend compared to the pure carbamates. FTIR spectra of all the carbamates studied here showed bands at $1686 \mathrm{~cm}^{-1}$ and $3337 \mathrm{~cm}^{-1}$ corresponding to hydrogen bonded $\mathrm{C}=\mathrm{O}$ and $\mathrm{N}-\mathrm{H}$ stretching vibrations, and there was no absorption peak corresponding to free $\mathrm{C}=\mathrm{O}$ or $\mathrm{N}-\mathrm{H}$. Thus all the $\mathrm{C}=\mathrm{O}$ and $\mathrm{N}-\mathrm{H}$ groups are hydrogen bonded. Another interesting aspect is that neither the frequency nor the intensity of the 
bands showed any change in the case of the blends, indicating that the extent of hydrogen bonding is unaffected with blending. Thus, the changes in the morphology are caused by the differences in the packing of the alkyl chains in the blends, rather than by the disruption of the hydrogen bonds.

\subsection{Conclusions}

It was found that the length of alkyl side chain of the carbamates has an influence on the morphology, heat of fusion, crystallinity and crystallite size. Most of the long chain carbamates exhibit spherulitic morphology; the size of the spherulites increases with the increase of the length of the alkyl side chain. Most of the carbamates exhibit negative birefringence indicating the tangential orientation of chains within the spherulite. While the melting point increases linearly, the heat of fusion and crystallinity shows a sigmoidal trend. The crystallite size corresponding to the diffraction maximum along the hydrogenbonding plane increases linearly with the increase of the alkyl side chain length.

The morphology can be controlled by the cooling rate as well as by blending. The crystal/spherulite size, heat of fusion and crystallinity of the slow cooled samples are higher than those of quenched samples. In some cases, cooling rate can alter the optic axis with respect to the spherulite axis. Blending reduces the crystal/spherulite size, heat of fusion and crystallinity. Blending also improves the transparency of the sample significantly.

The carbamates exert mutual plasticizer effect in the blend resulting in the depression of 
melting point of the parent compounds. The single point at some compositions of the blend is probably due to the overlap of the two peaks rather than due to the complete miscibility of the parent compounds. This work shows the dependence of morphology and related properties on the structure of the carbamates and the blend compositions. It is interesting that blending of any two of the carbamates does not affect the self assembling process itself, as indicated by the absence of any change in the IR spectra. Thus the morphological changes upon blending are not due to the disruption of the hydrogen bonds, but due to the poor packing of the alkyl chains. This shows that one could control the morphology of a self-assembling system, by tailoring alkyl segments, and without reducing the extent of the hydrogen bond network.

As mentioned in the Introduction, it is a common practice to use clarifiers as nucleating agents to control the morphology. We have shown here that blends of like molecules could be used for the same purpose. Although it is difficult to assess if such blends are used currently in printing inks, there are examples in the patent literature to this effect ${ }^{9}$. 


\subsection{References}

1. Jpn. Kokai Tokkyo Koho JP 58201758 (1983). Chem. Abstr. 100,174289z.

2. Tanaka, T.; Yoshitomi, T.; Hanada, Y.; Ohashi, M.; Takeda, Y. Jpn. Kokai Tokkyo Koho JP 6290 289. Chem. Abstr. 107, 20896b.

3. Goodbrand, B.; Boils, D.; Sundararajan, P. R.; Wong, R.; Malhotra, S. U. S. Patent 6,187,082 (2001).

4. Bodor, G. Structural Investigation of Polymers; 1st ed.; Ellis Harwood Ltd.: New York, 1991; pp 163.

5. Stein, R.S.; Misra, A. J. Polym. Sci. Polym. Phys. Ed. 1980, 18, 327.

6. Stein, R.S. in Structure and Properties of Polymer Films; Lenz, R.W., Stein, R.S., Eds., Plenum: New York, 1973.

7. Park, C.-S.; Lee, K.-J.; Kim, S.W.; Lee, Y.K.; Nam, J.-D. J. Appl. Polym. Sci. $2002,86,478$.

8. Krol, P.; Wietrzynska-Lalak, Z. Eur. Polym. J. 1995, 31, 689.

9. Goodbrand, B.; Boils, D. C.; Sundararajan, P. R.; Wong, R. W. US Patent $6,414,051(2002)$ 
Chapter 4

Hydrogen-Bonding in Heterogeneous Blends : Blends of Carbamate and Stearic Acid*

*Pure Appl. Chem. 2004, 76, 1353-1363. 


\subsection{Introduction}

This chapter discusses the changes in the morphology of the blends of a carbamate with another hydrogen-bonded system. A comparison between these blends and the blends discussed in chapter 3 could provide a molecular basis of the relative efficiency of the blends in controlling the morphology.

The carbamate used for this study was N-octadecylcarbamate octadecyl ester having the molecular formula $\mathrm{C}_{18} \mathrm{H}_{37}(\mathrm{NHCOO}) \mathrm{C}_{18} \mathrm{H}_{37}$. This carbamate was blended with stearic acid $\left(\mathrm{C}_{17} \mathrm{H}_{35} \mathrm{COOH}\right)$. This carbamate and the stearic acid will be referred to as $\mathrm{C}_{18}$ and SA respectively, henceforth. These are shown in Figure 4.1.

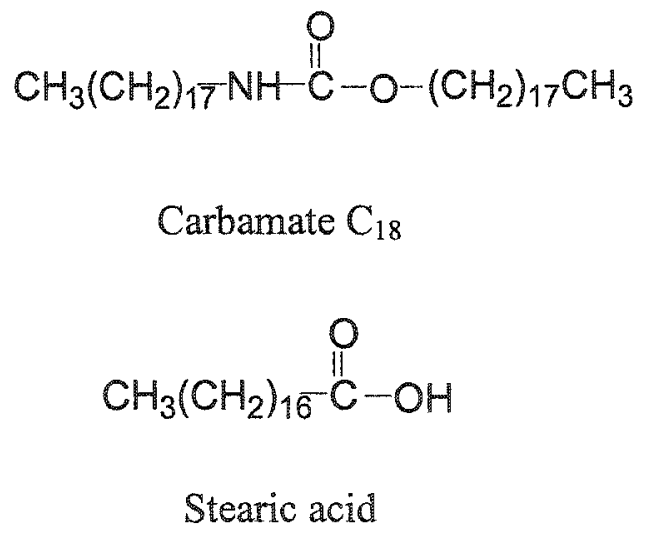

Figure 4.1 Structures of $\mathrm{C}_{18}$ and $\mathrm{SA}$

With the carbamates, the hydrogen bondable group is symmetrically positioned between the $\mathrm{C}_{18}$ alkyl chains on either side. On the other hand, it forms the head group in SA. 


\subsection{Polymorphic Forms of Stearic Acid}

There are four known polymorphic forms of stearic acid: A, B, C and E. The A, B and E forms occur only by solution crystallization, whereas the $\mathrm{C}$ form is formed by both solution and melt crystallization ${ }^{1}$. The $\mathrm{A}$ form is rare and unstable, whereas the $\mathrm{B}$ form is stable at room temperature ${ }^{2}$. The $\mathrm{C}$ polymorph is considered to be the most stable because both $\mathrm{A}$ and $\mathrm{B}$ undergo solid-state phase transition to $\mathrm{C}$ upon heating ${ }^{3}$. The $\mathrm{E}$ form is metastable and transforms to the $\mathrm{B}$ and $\mathrm{C}$ forms through solid state phase transitions under certain conditions $\mathrm{s}^{4,5}$. For example, Kaneko et al found that the $\mathrm{E}$ form transformed to the $\mathrm{C}$ form irreversibly around $45^{\circ} \mathrm{C}$ when heated.

\subsection{Structural Similarities between $\mathrm{C}_{18}$ and SA}

There are some structural similarities between the carbamate $\mathrm{C}_{18}$ and the stearic acid. Both of these compounds contain a long alkyl chain and carbonyl group. Intermolecular $\mathrm{H}$-bonds exist in both. The single crystal structure of the carbamate $\mathrm{C}_{18}$ is not available. However, some similarities could be derived from the powder $\mathrm{x}$-ray data and the molecular modeling of $\mathrm{C}_{18}$. X-ray diffraction shows that the long spacing for stearic acid Form $C$ is $39.5 \AA^{6}$; in $C_{18}$ the long spacing is $38.1 \AA^{7}$. The length of the $c$ axis of the unit cell of stearic acid Form $C$ is $46.6 \AA$, which is equal to the length of two molecules. Molecular modeling shows that the length of one molecule of $C_{18}$ is $47.99 \AA$ and the $X$ ray diffractogram of $C_{18}$ shows a medium intensity peak at $d=46.4 \AA$. Because of the similarities in alkyl moiety and the long spacing of these two H-bonded systems, we studied the morphology of their blends, to examine if the crystalline morphology and the extent of hydrogen bonding are affected. 


\subsection{Preparation of the Blends}

Binary blends of $\mathrm{SA}$ and $\mathrm{C}_{18}$ were prepared by melt mixing, with $90 / 10,80 / 20,70 / 30$, $60 / 40,50 / 50,30 / 70$ and $10 / 90$ (wt $\%$ ) $\mathrm{SA} / \mathrm{C}_{18}$ compositions. The detailed procedure for the preparation of the blends is discussed in chapter 2 .

\subsection{Results and Discussion}

\subsubsection{Optical microscopy}

Figure 4.2 shows the optical micrographs of $\mathrm{C}_{18}$ and $\mathrm{SA}$. The slow cooled and the quenched samples of $\mathrm{C}_{18}$ show fibrillar spherulites (Figs. 4.2a and 4.2b). The average radii of the spherulites of the slow cooled and the quenched samples of $\mathrm{C}_{18}$ are 1170 and $220 \mu \mathrm{m}$, respectively. The slow cooled and quenched samples of stearic acid show very large crystals (Figs. $4.2 \mathrm{c}$ and $4.2 \mathrm{~d}$ ), which can be easily seen with the naked eye. Compared to $\mathrm{C}_{18}$, the SA sample was more opaque when it was cooled from the melt on the microscope slide.

The optical micrographs for the slow cooled and quenched blends show similar trends in morphology except for the fact that the spherulite/ crystal size of the slow cooled samples is much larger than that of quenched samples. The micrographs of the quenched blends (Figure 4.3), show that an addition of 10 to $50 \% \mathrm{SA}$ to $\mathrm{C}_{18}$ causes phase separation, disrupted spherulites of $\mathrm{C}_{18}$ and the crystals of stearic acid are clearly visible under the optical microscope. There was no improvement in the transparency of the samples compared to that of pure $\mathrm{C}_{18}$. When the carbamate is the minor component in the blend, 
there is a significant reduction of the crystal size as compared to that of pure SA (compare Figs. $4.2 \mathrm{~d}$ and $4.3 \mathrm{f}$ ). Compared to pure stearic acid, these blends provide better transparency. Thus, it would seem that the carbamate is effective in improving the morphology (e.g., the transparency) of the stearic acid but not vice versa.
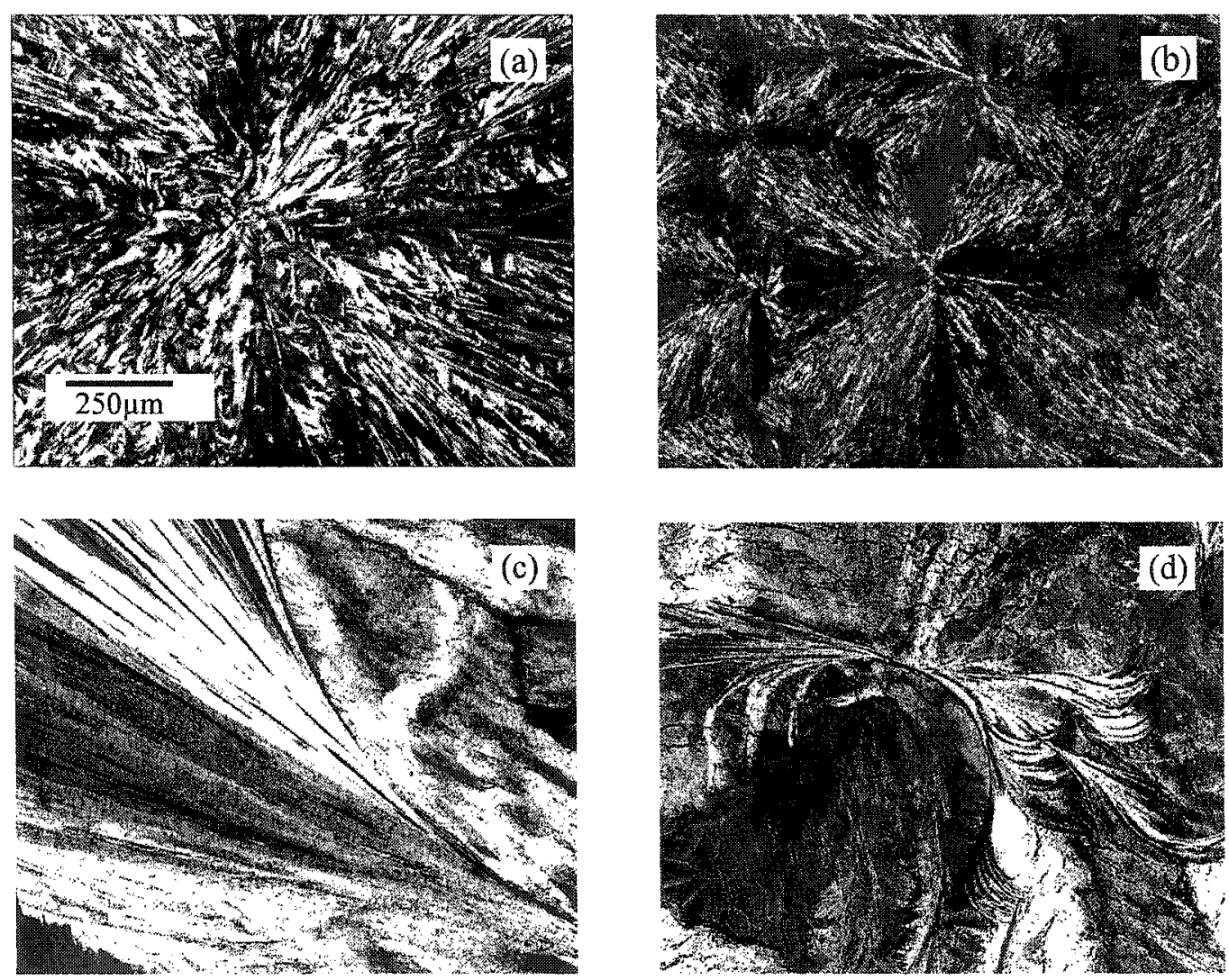

Figure 4.2 Optical micrographs of $\mathrm{C}_{18}$ ( $\mathrm{a}$ and $\mathrm{b}$ ) and SA (c and d). (a) and (c): slow cooled; (b) and (d): quenched. 

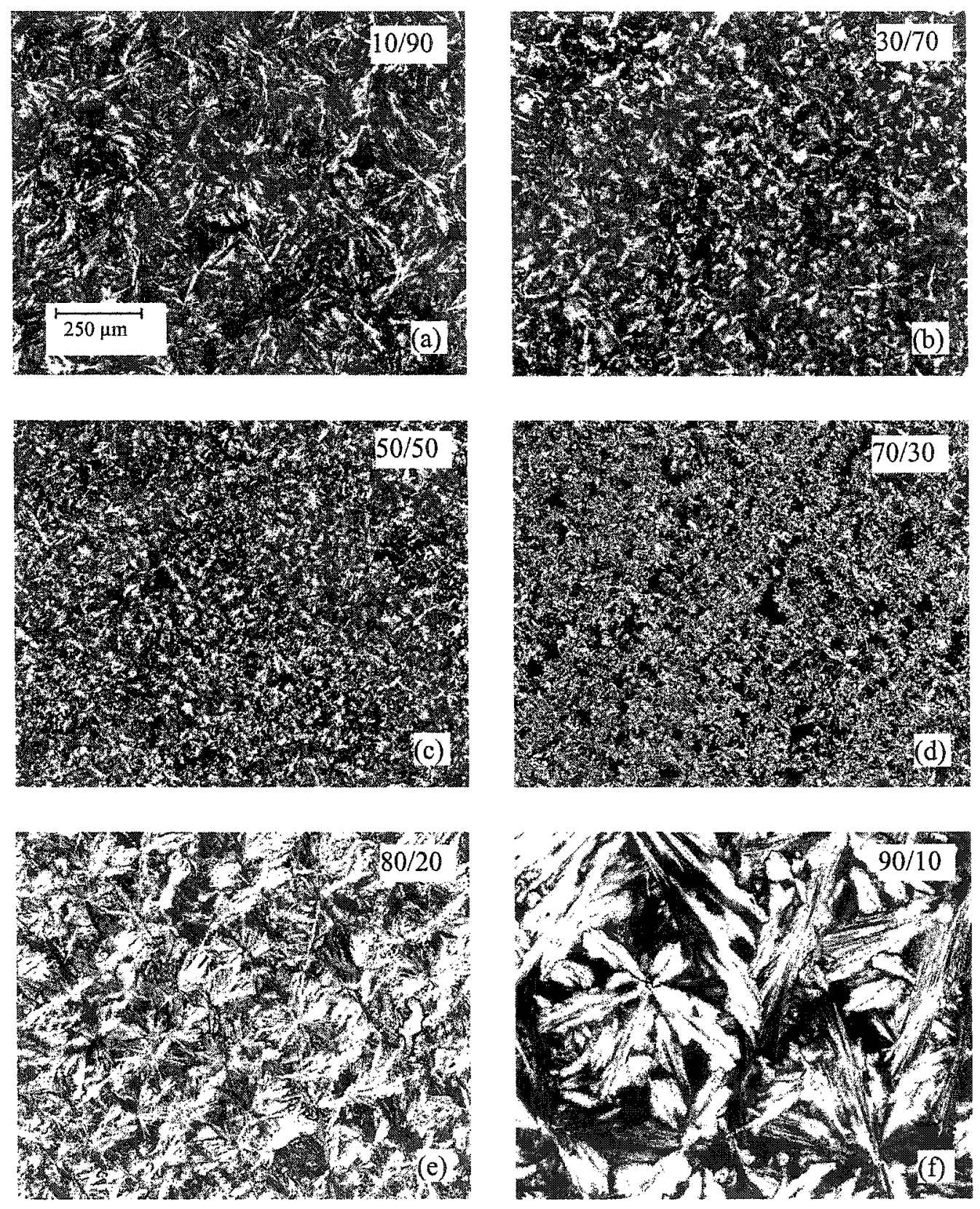

Figure 4.3 Optical micrographs of $\mathrm{SA} / \mathrm{C}_{18}$ blends. All the samples were quenched from the melt. 
A comparison of the morphology and transparency of these blends with those prepared with the homologous carbamates ${ }^{7}$ (chapter 3 ) shows that the latter is more effective in reducing the spherulite size and enhancing the transparency. At some compositions, the spherulite size was reduced to a few microns ${ }^{7}$.

\subsubsection{Thermal amalysis}

The melting points obtained from DSC for the slow cooled and the quenched samples of $\mathrm{SA}$ and $\mathrm{C}_{18}$ as well as of their blends are shown in Table 4.1. The melting points of the slow cooled and quenched samples did not differ significantly. Although the melting point of $\mathrm{C}_{18}$ is higher than that of $\mathrm{SA}$ by about $17^{\circ}$, the $90 / 10,80 / 20,70 / 30$, and $60 / 40$ compositions of $\mathrm{SA} / \mathrm{C}_{18}$ exhibit single peaks in the $\mathrm{DSC}$ for both the slow cooled and quenched blends. The $50 / 50$ composition shows a single peak with a shoulder whereas the $30 / 70$ and $10 / 90$ compositions show two peaks. The melting points of these blends show trends similar to that discussed previously ${ }^{7}$ (chapter 3 ) for the blends of $C_{12}$ and $C_{16}$ carbamates. The melting points of $90 / 10,80 / 20,70 / 30$, and $60 / 40$ blends are lower than those of either of the parent compounds. In the DSC thermograms of $30 / 70$ and $10 / 90$ $\mathrm{SA}_{18}$ compositions, which exhibit two melting peaks, the first melting point is lower than that of pure SA and the second one is lower than that of pure $\mathrm{C}_{18}$. As the fraction of SA decreases in the blend, the temperature corresponding to the second melting point increases whereas that of the first melting point decreases. In chapter 3 we observed this type of melting behavior with several series of blend compositions and concluded that such a behavior is due to the components of the blends exerting a mutual diluent effect, thereby reducing the melting temperatures. 
Table 4.1 Melting point(s) of $\mathrm{SA} / \mathrm{C}_{18}$ blends

\begin{tabular}{|c|c|c|c|}
\hline \multirow[t]{2}{*}{ Wt $\%$ of $C_{18}$} & Slow cooled sample & \multicolumn{2}{|c|}{ Quenched sample } \\
\hline & $\begin{array}{c}\text { Melting point(s) } \\
\left({ }^{\circ} \mathrm{C}\right)\end{array}$ & $\begin{array}{l}\text { Melting point(s) } \\
\left({ }^{\circ} \mathrm{C}\right)\end{array}$ & $\begin{array}{l}\text { Hump position } \\
\left({ }^{\circ} \mathrm{C}\right)\end{array}$ \\
\hline 0 & 69.9 & 69.9 & - \\
\hline 10 & 68.4 & 68.7 & 61.6 \\
\hline 20 & 67.6 & 67.4 & 61.8 \\
\hline 30 & 67.4 & 67.2 & 59.8 \\
\hline 40 & 67.3 & 66.8 & $58.6 \& 60.7$ \\
\hline 50 & 66.8 & 66.8 & 60.5 \\
\hline 70 & $66.1 \& 77.3$ & $65.5 \& 77.2$ & 61 \\
\hline 90 & $64.5 \& 82.2$ & $64.2 \& 82.4$ & - \\
\hline 100 & 86.7 & 86.7 & - \\
\hline
\end{tabular}


An interesting difference between the DSC thermograms of the slow cooled and quenched blends of $\mathrm{SA} / \mathrm{C}_{18}$ is the appearance of a hump in the latter. Figure 4.4 shows the DSC thermograms of the slow cooled and quenched samples of the $80 / 20$ blend of $\mathrm{SA} \mathrm{C}_{18}$

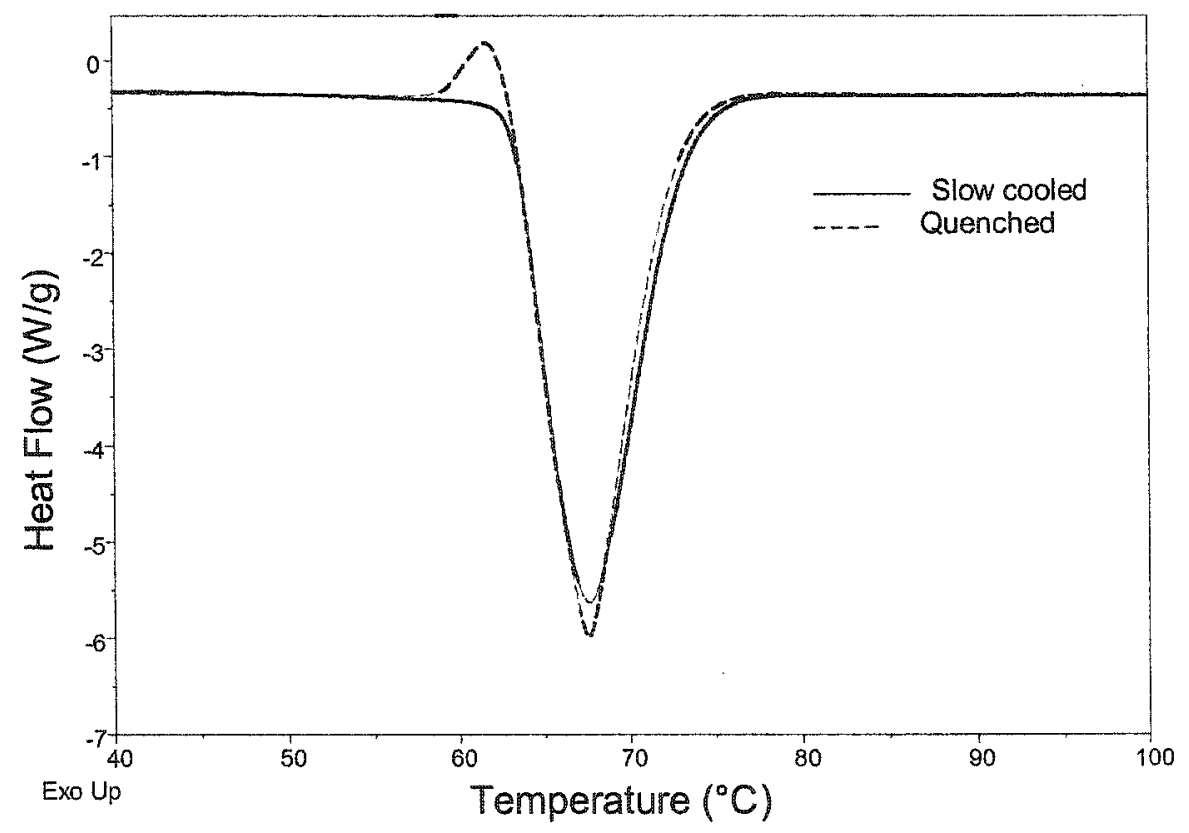

Figure 4.4 DSC thermograms of slow cooled and quenched blends of $\mathrm{SA}_{4} \mathrm{C}_{18}$ with $80 / 20$ composition.

All the quenched blends, except with $10 / 90$ and $90 / 10$ compositions, show a hump in DSC thermograms at about $61^{\circ} \mathrm{C}$. Its exact position for different blend compositions is 
given in Table 4.1. This is an indication of a solid-solid transition between polymorphic forms ${ }^{8}$. Interestingly, the thermogram of the quenched sample of stearic acid does not show any hump, which indicates the possibility that the quenched stearic acid is not in the same polymorphic form as in the quenched blends, i.e., the carbamate is inducing a polymorphic transition in the quenched samples. To determine the effect of the heating rate on the position of the hump, the $80 / 20$ blend was run at a heating rate of $2.5^{\circ} \mathrm{C} / \mathrm{min}$. It did not effect the position of the hump significantly (a small change from 61.8 to 61.3 ${ }^{\circ} \mathrm{C}$ ), whereas the melting peak shifted from 67.4 to $65.3{ }^{\circ} \mathrm{C}$. The identity of the polymorphic form in the quenched blends will be discussed below in the X-ray and Infrared analysis sections.

Figure 4.5 shows the heat of fusion of the slow cooled samples as a function of the blend composition for the $\mathrm{SA} / \mathrm{C}_{18}$ blend system. For comparison, the heat of fusion for the slow cooled samples of the $\mathrm{C}_{12} / \mathrm{C}_{16}$ blend system is also shown in the same figure. For the $\mathrm{C}_{12} / \mathrm{C}_{16}$ blend, there is initially a decrease in the heat of fusion with the incorporation of $\mathrm{C}_{16}$ in the blend. It passes through a plateau and then increases with an increase in the content of $\mathrm{C}_{16}$. For $\mathrm{SA}_{\mathrm{C}} \mathrm{C}_{18}$ blend system, the heat of fusion decreases up to $30 \%$ of $\mathrm{C}_{18}$ in the blend. There is then an increase with $40 \%$ of $\mathrm{C}_{18}$, with no further change with increasing $\mathrm{C}_{18}$ content. Thus, when $\mathrm{C}_{18}$ is the minor component, there is a change in the crystallinity and morphology. The $\mathrm{SA}$, as a minor component, does not cause any change in the morphology of the carbamate. Owing to the hump in the DSC thermograms of the quenched blends, their heats of fusion could not be calculated reliably, and hence they are not shown in Figure 4.5. 


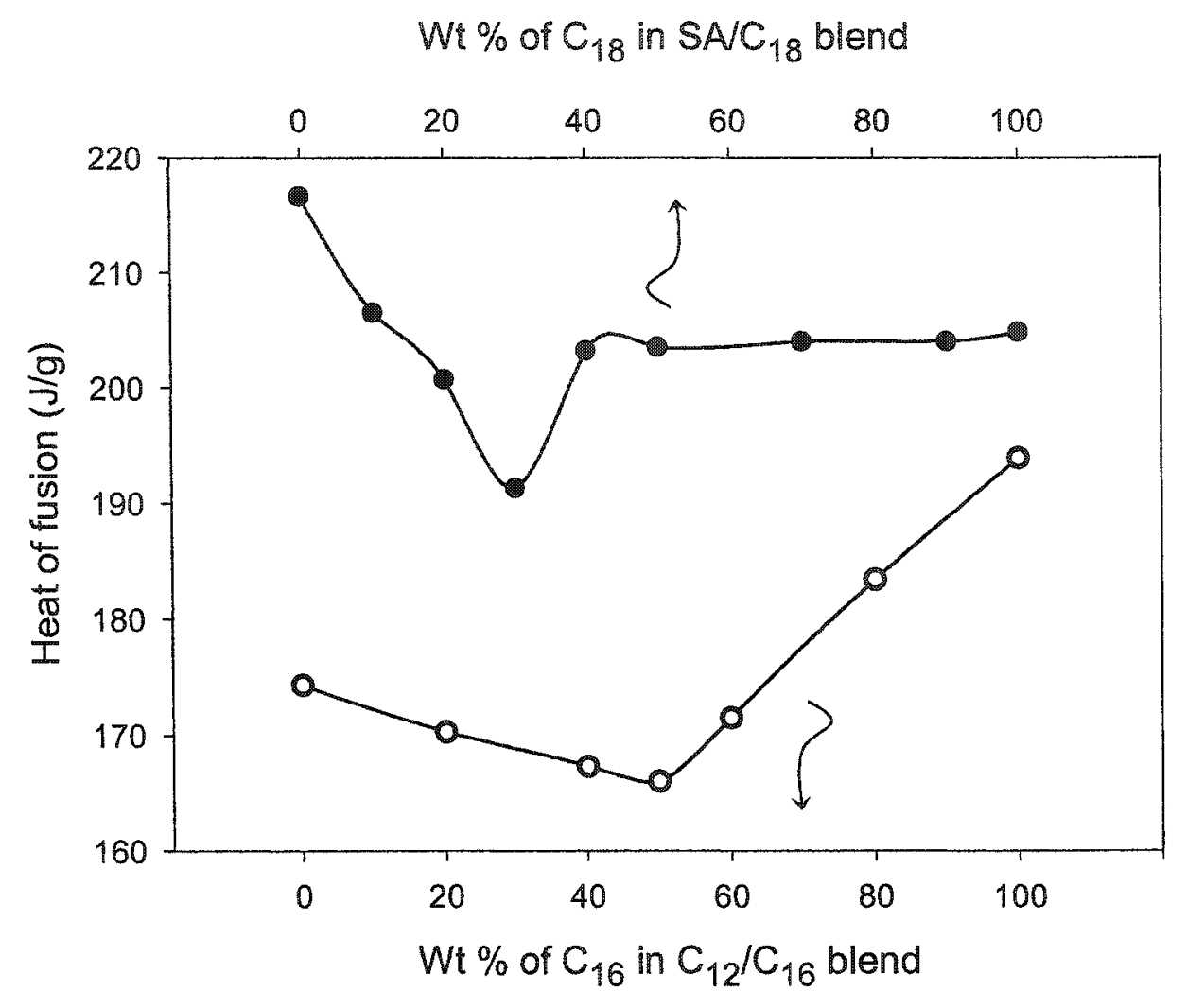

Figure 4.5 Heat of fusion of slow cooled blends of $\mathrm{SA} / \mathrm{C}_{18}(-\bullet-)$ and $\mathrm{C}_{12} / \mathrm{C}_{16}(-\mathrm{o}-)$.

\subsubsection{X-ray Diffraction}

$\mathrm{X}$-ray powder diffractograms of the slow cooled samples of $\mathrm{SA}$ and $\mathrm{C}_{18}$ are shown in Figure 4.6. Comparison of the powder diffraction pattern of SA with the published x-ray pattern of different polymorphic forms of stearic acid ${ }^{9}$ indicates that it is in the $\mathrm{C}$ form in both the slow cooled and the quenched samples. From Figure 4.6, it is seen that some of the reflections from $\mathrm{SA}$ and $\mathrm{C}_{18}$ occur at about the same 20 , due to the similarity of the long spacing and the sub-cell structures mentioned in the Introduction. 
The X-ray diffractograms of the blends do not show any new reflection as compared to those from $\mathrm{SA}$ and $\mathrm{C}_{18}$. However, some closely spaced reflections from $\mathrm{SA}$ and $\mathrm{C}_{18}$ merge and show single peak in the blend. For example, the reflection at $2 \theta=6.60^{\circ}(d=$ $13.38 \AA)$ from SA and the reflection at $2 \theta=7.03^{\circ}(d=12.56 \AA)$ from $\mathrm{C}_{18}$ merges in the $50 / 50$ blend and shows a reflection at $2 \theta=6.57^{\circ}(d=13.45 \AA$ ) (see Figure 4.6). The diffractograms of the slow cooled blends indicate that the stearic acid is still in C crystalline polymorph in the blends.

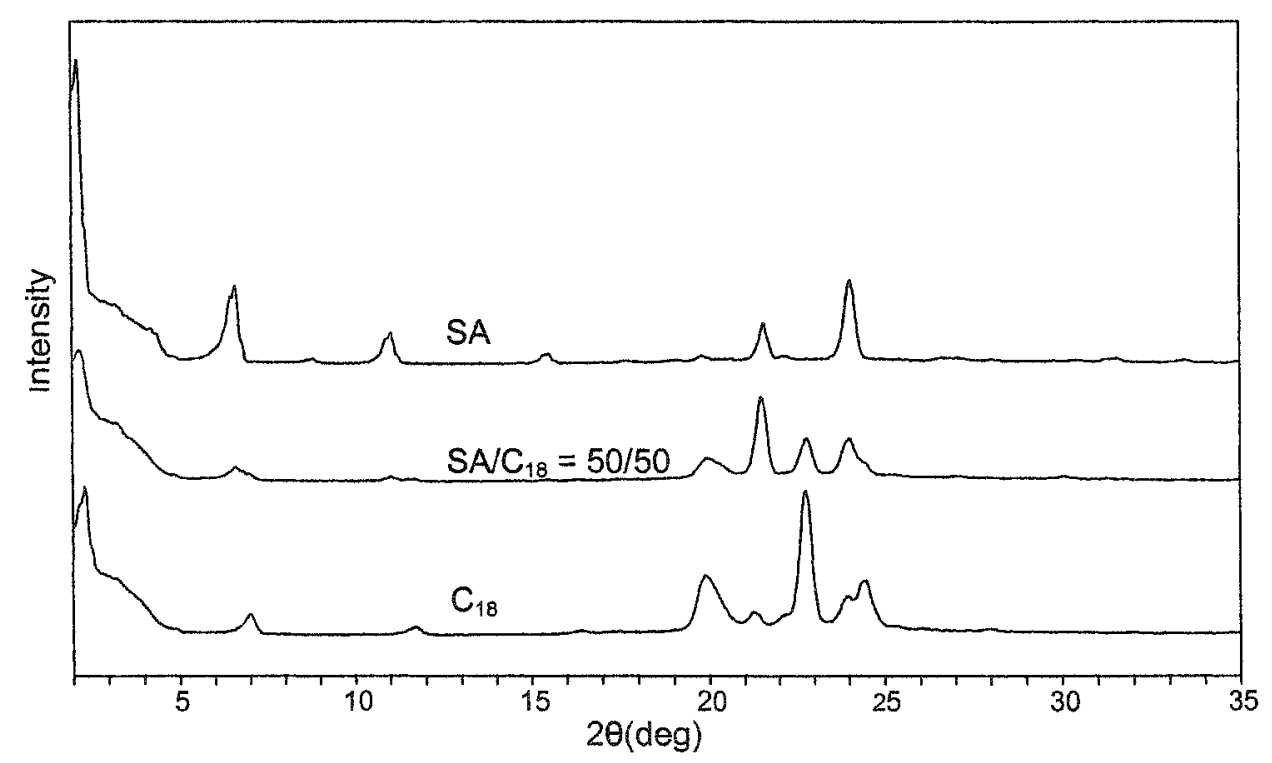

Figure 4.6 X-ray diffractograms of $\mathrm{SA}$ and $\mathrm{C}_{18}$ and of their $50 / 50$ blend. All the samples are slowly cooled.

The relative intensities of the reflections from the slow cooled and quenched blends were found to be different. This might be due to the metastable polymorphic form of stearic acid in the quenched blend. The $d$-spacings of the A form of stearic acid are significantly 
different from those of the $\mathrm{C}$ form ${ }^{9}$. The diffractograms indicate that the stearic acid is not in the A form in the quenched blends. This is also supported by the IR spectra which will be discussed below. However, it cannot be decided unambiguously from the powder diffraction patterns whether stearic acid is in the B or $\mathrm{E}$ forms in the quenched blends, because the long spacings of the two forms are nearly identical. In addition, the presence of $\mathrm{C}_{18}$ in the blends further complicates the situation, since some reflections from $\mathrm{C}_{18}$ merge with those of SA in the blends. However, IR spectra can help us to identify this polymorph (see next section).

The diffractograms of the blends show some interesting features. Figure 4.7a shows the $X$-ray diffractogram of the slow cooled blend, containing $30 \% \quad \mathrm{C}_{18}$ along with the diffractogram of pure SA. It is seen that the addition of $30 \% \mathrm{C}_{18}$ to stearic acid causes a major change in the diffractogram. There is a significant increase in the intensity at $2 \theta=$ $21.6^{\circ}(d=4.1 \AA)$ and a decrease in the intensity at $2 \theta=2.21^{\circ} \quad(d=40 \AA)$. Figure 4.8 shows the intensity ratio of these two reflections for the slow cooled and quenched blends as well as the pure components. It is seen that the intensity ratio changes significantly when $\mathrm{C}_{18}$ is the minor component in the blend. For the slow cooled samples, the maximum change is observed at $70 / 30$ composition of $S A / C_{18}$, whereas in quenched samples, the maximum change is observed at $90 / 10$ composition. Figure $4.7 \mathrm{~b}$ shows that when SA is the minor component in the blend, there is no major change in the diffractogram as compared to that of pure $\mathrm{C}_{18}$, and that the diffractogram is just a combination of the diffractograms of $\mathrm{SA}$ and $\mathrm{C}_{18}$. 

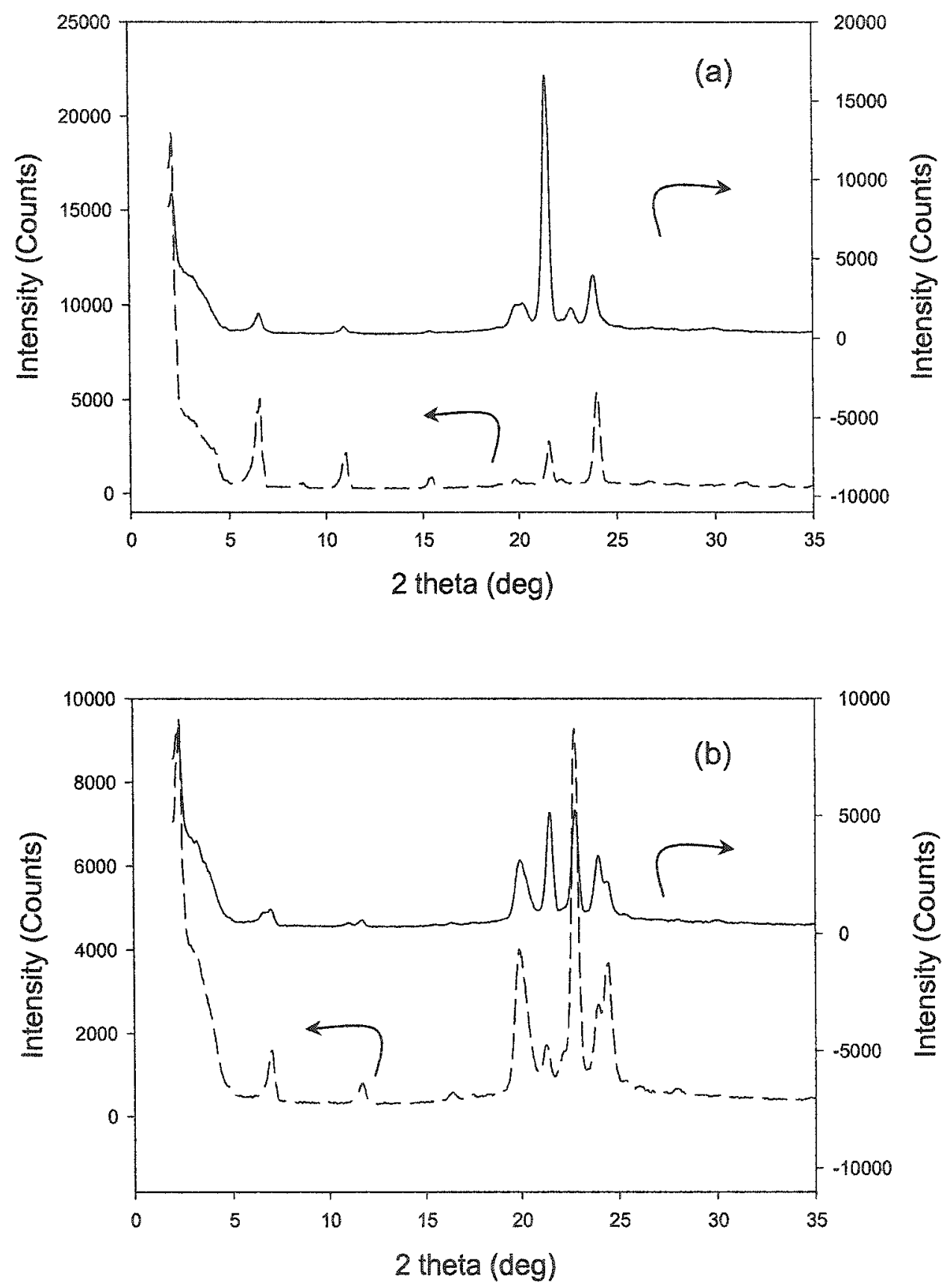

Figure 4.7 X-ray diffractograms of (a) SA and its blend with $30 \% \mathrm{C}_{18}$ (b) $\mathrm{C}_{18}$ and its blends with $30 \% \mathrm{SA}$. All the samples are slowly cooled. 


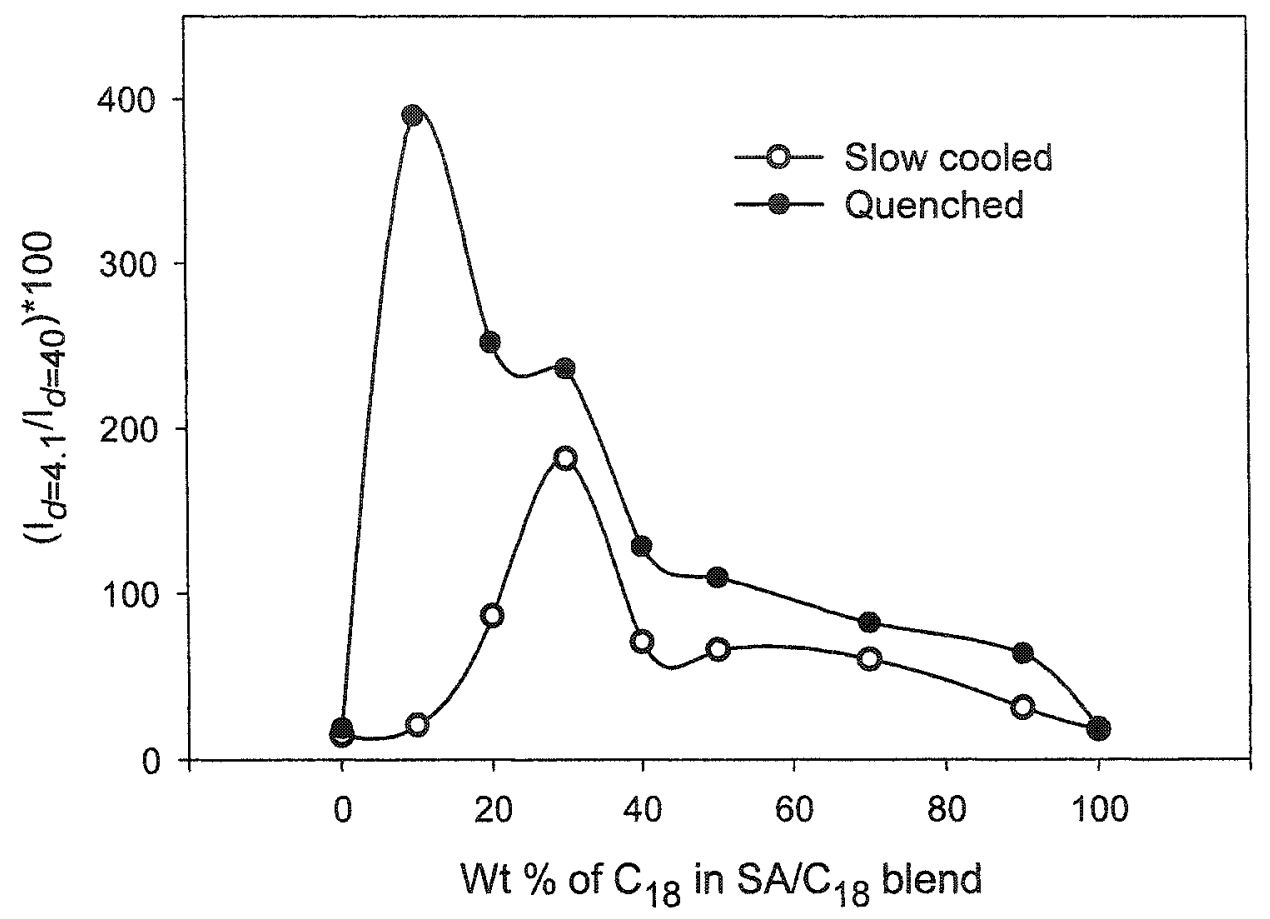

Figure 4.8 Intensity ratio of the diffraction maxima at $d=4.1 \AA$ and $40 \AA$ for the slow cooled and quenched blends.

In the crystal structure of stearic acid, the $d$-spacings of 40.0 and $4.1 \AA$ correspond to [001] and the [110] planes respectively ${ }^{4}$ (Figure 4.9). Further, in stearic acid, the intensity at $d=4.1 \AA$ is very low compared to that of the $40 \AA$ reflection, for both the slow cooled and quenched samples. Reduction of intensity of the long spacing of stearic acid in the blends indicates that $\mathrm{C}_{18}$ disturbs the crystal lattice of stearic acid to some extent. However, none of the pure polymorphs of stearic acid exhibit such a strong reflection at $d=4.1 \AA$, as is observed in the case of the blends of this study. Frede et al. ${ }^{10}$ 
observed a similar decrease in intensity at $40 \AA$ and increase in intensity at $4.1 \AA$ when they melt blended stearic acid with palmitic acid. However, they did not report the polymorphic transition observed in this study with the blends.

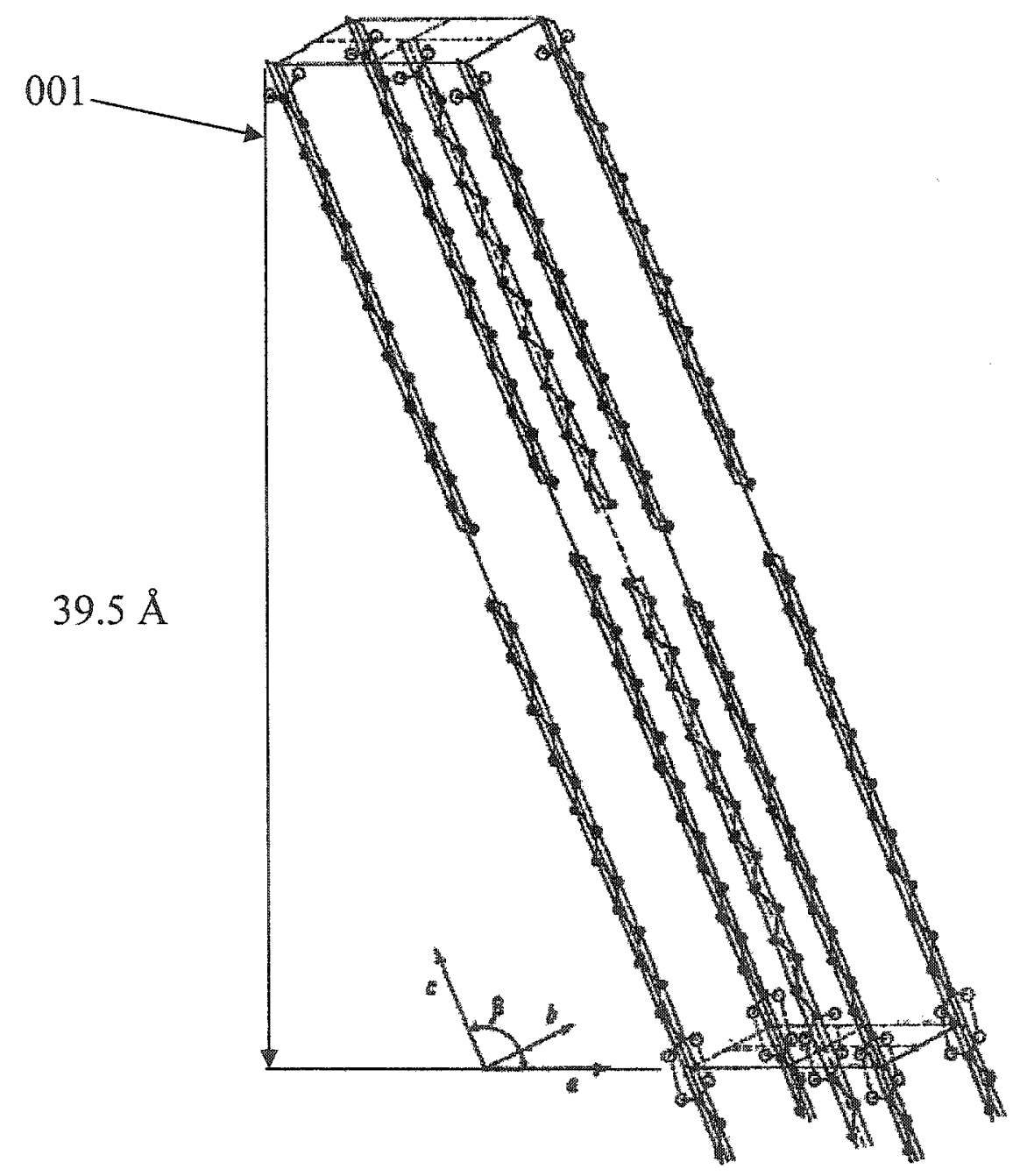

Figure 4.9 Unit cell of stearic acid 


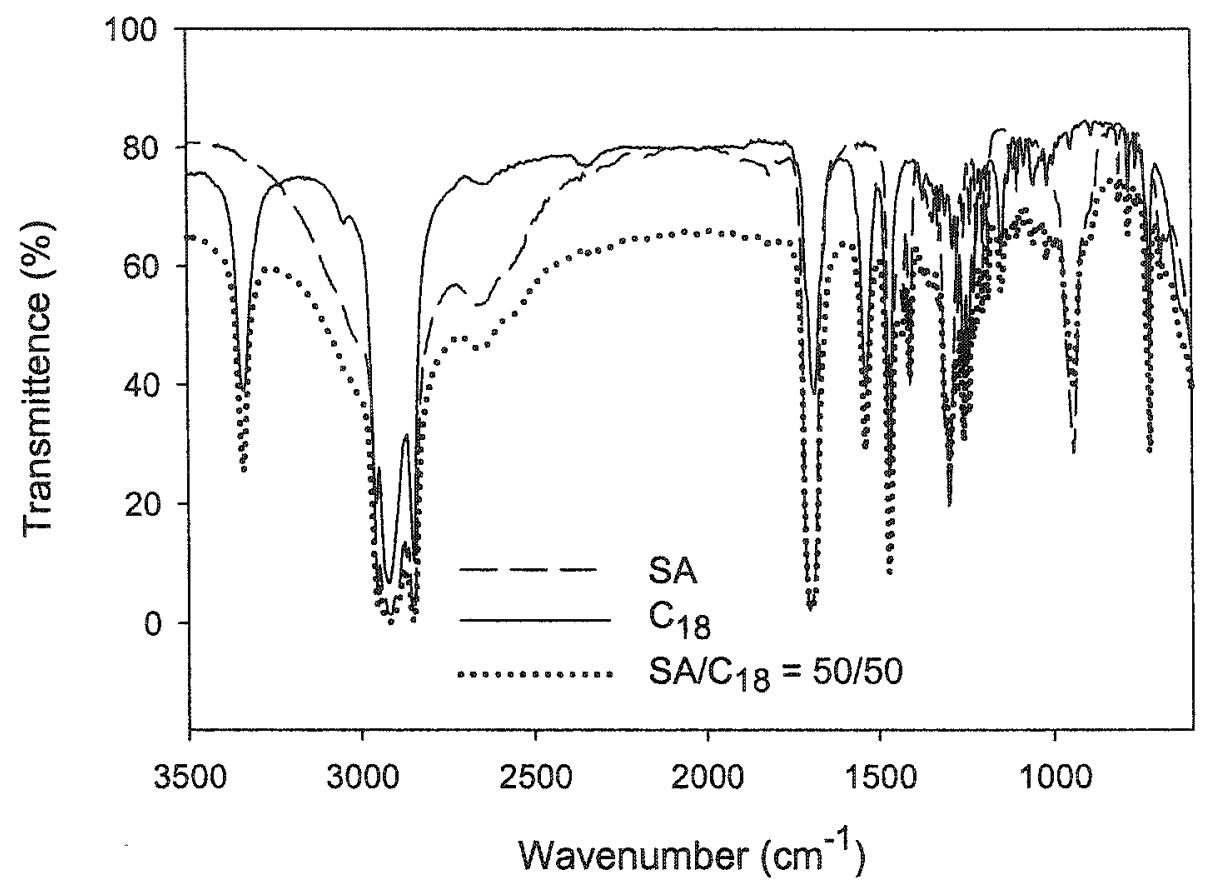

Figure 4.10 IR spectra of SA and $\mathrm{C}_{18}$ and of their $50 / 50$ blend.

\subsubsection{IR analysis}

Figure 4.10 shows the infrared spectra of pure $S A$ and $C_{18}$ and that of the $50 / 50$ blend. No new peak appears in the spectrum of the blends as compared to pure $\mathrm{SA}$ and $\mathrm{C}_{18}$. The carbonyl stretching frequencies for $\mathrm{SA}$ and $\mathrm{C}_{18}$ are 1702 and $1686 \mathrm{~cm}^{-1}$ respectively. In the blends only one $-\mathrm{C}=\mathrm{O}$ stretching is seen at about $1698 \mathrm{~cm}^{-1}$ in both the slow cooled and quenched samples. At first glance this indicates the possibility that an interaction between the components in the blends has affected the type of hydrogen bonding of the system. However, the $\mathrm{C}=\mathrm{O}$ band of $\mathrm{C}_{18}$ is so close to that of stearic acid that even a physical mixing would lead to an apparently single band due to superposition. To this 
end, we made a $50 / 50$ physical mixture of $S A$ and $C_{18}$ and recorded its $\mathbb{R}$ spectrum with a $\mathrm{KBr}$ pellet. This spectrum was compared with the spectra of the slow cooled and quenched blends of the $50 / 50$ composition that were also taken with a $\mathrm{KBr}$ pellet. Only one $-\mathrm{C}=\mathrm{O}$ absorption peak was observed in all the three samples, having similar stretching frequency. Thus the single $\mathrm{C}=\mathrm{O}$ stretching band in the blends might not necessarily indicate an interaction between the components in the blends. Further analysis of the spectra shows that there is no shift in the $-\mathrm{NH}$ stretching frequency of $\mathrm{C}_{18}$ (at $3341 \mathrm{~cm}^{-1}$ ) in any of the blends. Even then, we cannot rule out the possibility of the presence of $\mathrm{H}$-bonds between $\mathrm{C}_{18}$ and the stearic acid in the blends because these $\mathrm{H}$ bonds still involve a carbonyl group so that no significant shift should be expected. Since the unit cells in stearic acid are connected through intermolecular H-bonding between $\mathrm{C}=\mathrm{O}$ and $\mathrm{OH}$ groups of stearic acid, any $\mathrm{H}$-bond between $\mathrm{C}_{18}$ and stearic acid in the blends should result in disruption of the crystal lattice of stearic acid to some extent. This is supported by the decrease in the intensity of the long spacing $(d=40 \AA)$ of stearic acid in the blends. It should be mentioned that in our previous study ${ }^{7}$ (chapter 3 ) of the blend system of homologous carbamates, the extent of hydrogen bonding is unaffected, and yet those systems exhibit excellent transparency, low crystallinity and low heat of fusion, which were attributed to the poor packing of the alkyl chains in the blends.

Finally we tried to get some information from $\mathbb{R}$ spectra regarding the polymorphic forms of stearic acid in the slow cooled and quenched blends. Holland et al ${ }^{11}$ studied the infrared spectra of single crystals of the four forms of stearic acid. Their study revealed that in the spectrum of the C-form, a band at $689 \mathrm{~cm}^{-1}$ can be attributed to the $\mathrm{O}-\mathrm{C}=\mathrm{O}$ 
bond angle deformation. For $\mathrm{A}$ and $\mathrm{E}$ forms, this band appears at $677 \mathrm{~cm}^{-1}$ and $686 \mathrm{~cm}^{-1}$ respectively. In the $B$ form, no band was found between 650 and $700 \mathrm{~cm}^{-1}$, indicating that this vibration has considerably lower frequency. In our study, $\mathrm{SA}$ and its blends with $\mathrm{C}_{18}$ show a band around $688 \mathrm{~cm}^{-1}$ in both slow cooled and quenched samples. This observation rules out the possibility of $\mathrm{A}$ and $\mathrm{B}$ polymorphic forms in these blends. Although there are some differences in the single crystal IR spectra of $\mathrm{C}$ and $\mathrm{E}$ forms, the spectra of polycrystalline samples of the $\mathrm{C}$ and $\mathrm{E}$ forms are not very different ${ }^{11}$, and hence they are difficult to distinguish. X-ray diffraction, along with the IR spectra of SA and of slow cooled blends indicates that stearic acid is in the $\mathrm{C}$ form. This is reasonable on the basis of previous studies, which showed that melt grown SA crystals are usually in the $C$ form, which is the most stable form ${ }^{3}$. Since the quenched blends show polymorphic transition in DSC and their X-ray and IR spectra are not much different from the C form, the only possibility is that the SA is in the $\mathrm{E}$ form in the quenched blends. The transition from the metastable $\mathrm{E}$ form to $\mathrm{C}$ form on heating has been reported earlier ${ }^{5}$.

\subsection{Conclusions}

In this study we found that blending affects the morphology of the carbamate and stearic acid. The spherulites of $\mathrm{C}_{18}$ are disrupted due to blending and the large crystals of stearic acid transform into tiny crystals. This effect is more pronounced when carbamate is the minor component in the blend. At these compositions, the blends show considerable improvement in transparency. As expected, in all cases, the spherulite/crystal size of the slow cooled samples is found to be larger than that of the quenched samples. Comparing with our previous study (chapter 3), it seems that blending of two homologous 
compounds is more efficient in controlling the morphology than the blend system discussed in this chapter. The previous system with homologous molecules provided much better transparency.

$\mathrm{SA}$ and $\mathrm{C}_{18}$ exert a mutual diluent effect, resulting in a depression of the melting points. When the carbamate is the minor component in the blend, there is a decrease in the heat of fusion. A decrease in the intensity of long spacing in X-ray diffractograms at these compositions indicates that the crystal lattice is disturbed to some extent due to blending. Thermal analysis reveals that quenching with the carbamate induces polymorphism in the stearic acid in the blend. A metastable phase is formed which is converted to the most stable $\mathrm{C}$ form on heating.

The analysis of $\mathbb{R}$ spectra along with the $\mathrm{x}$-ray diffractograms indicates the possibility that the type of hydrogen bonding might be affected when the carbamate is present as the minor component in the blend with stearic acid. As mentioned earlier, with the carbamates, the hydrogen bondable group is symmetrically positioned between the $\mathrm{C}_{18}$ alkyl chains on either side. On the other hand, it forms the head group in SA. When the SA is the minor component, it is unable to intercalate with/ interrupt the hydrogen bonded carbamate and hence has no effect on the morphology. Thus, the relative positioning of the hydrogen bonding segment in the molecule has a profound effect.

It seems that blending can be an efficient alternative to the conventional clarifiers or plasticizers to control the morphology. Our present study also indicates that long chain carbamates can be used to control the morphology of stearic acid or homologous fatty acids if their application in any specific system requires controlled morphology. 


\subsection{References}

1 Kaneko, F.; Sakashita, H.; Kobayashi, M. J. Phys. Chem. 1994, 98, 3801-3808.

2 Sato, K.; Boistelle, R. J. Cryst. Growth 1984, 66, 441-450.

3 Garti, N.; Wellner, E.; Sarig S. J. Cryst. Growth 1982, 57, 577.

4 Kaneko, F.; Simofuku, T.; Miyamoto, H.; Kobayashi, M. J. Phys. Chem. 1992, $96,10554-10559$.

5 Kaneko, F.; Kobayashi, M.; Kitagawa, Y.; Matsuura, Y. J. Phys. Chem. 1992, 96,7104 .

6 Sato, K.; Okada, M. J. Cryst. Growth 1977, 42, 259-263.

7 Moniruzzaman, M.; Goodbrand, B.; Sundararajan, P. J. Phys. Chem. B. 2003, $107,8416-8423$.

8 Wendlandt, W. W. Thermal analysis, Wiley-Interscience: New York, 1986; p. 667.

9 Garti, N.; Wellner, E.; Sarig, S. Kristall and Technik, 1980, 15, 1303-1310.

10 Frede, E.; Precht, D. J. Am. Oil Chem. Soc. 1976, 53, 668-670.

11 Holland, F.; Nielsen, J. R. J. Mol. Spectroscopy, $1962,9,436-440$. 
Chapter 5

The Role of Hydrogen Bonds in Controlling the Morphology of Self-Assembling Carbamate Systems 


\subsection{Introduction}

It was found in Chapter 3 that blending of two homologous carbamates is an efficient way to reduce the crystal/spherulite size and crystallinity of self-assembling carbamates 1 . A significant improvement of transparency of the sample was achieved with the blending. These results prompted us to further our study on the changes in morphology of the blends of a carbamate with stearic $\operatorname{acid}^{2}$ (Chapter 4 ), which is another hydrogen-bonded system and which has some structural similarities with the carbamate. However, stearic acid was less effective in controlling the morphology and transparency of the carbamate as compared to the blends of two homologous carbamates. On the other hand, when the carbamate was the minor component in the blend, there was a reduction of crystal size of stearic acid and improvement of transparency as compared to those of pure stearic acid. The powder X-ray diffractograms of the blends showed a significant decrease in the intensity of the long spacing $(d=40 \AA)$ of stearic acid, indicating that the presence of carbamate as a minor component in the blends might result in the disruption of the crystal lattice of stearic acid to some extent. The results of these studies raised the question as to the underlying factor that plays a role in the reduction of spherulite size and crystallinity and the improvement of transparency.

The FTIR spectra of the carbamates indicated that all the $\mathrm{C}=\mathrm{O}$ and $\mathrm{N}-\mathrm{H}$ groups are hydrogen bonded. In case of the blends of homologous carbamates, the IR spectra did not show any change in the intensity or position of the $\mathrm{C}=\mathrm{O}$ and $\mathrm{N}-\mathrm{H}$ stretching frequency of the carbamates as compared to that of the pure components. This led us to conclude that the extent of hydrogen bonding was not affected by blending and that the changes in 
morphology were due to the poor packing of the alkyl chains in the blends. The $\mathbb{R}$ spectra of the carbamate/stearic acid blends showed only one $\mathrm{C}=\mathrm{O}$ stretching which indicated the possibility that an interaction between the components in the blends had affected the type of hydrogen bonding of the system. However, no definite conclusion could be made from that observation, since the $\mathrm{C}=\mathrm{O}$ band of the carbamate was so close to that of stearic acid that even a physical mixing could lead to an apparently single band due to superposition. Some of the questions that arise from the above studies are: (i) if the changes in morphology in the blends are due to the poor packing of the alkyl chains, what is the cause of such packing? Is the H-bond responsible to some extent? (ii) would a similar morphology result if the self-assembling system is blended with a non-hydrogen bonded system having similar alkyl chains? (iii) how is the blending of homologous carbamates comparable with the use of commercial clarifiers in controlling the morphology? This chapter is an attempt to address these questions.

The carbamate used for this study was $N$-octadecylcarbamate dodecyl ester. This was blended with (i) a low molecular weight polyethylene (MW 655), which is a nonhydrogen bonded system having similar alkyl chains like the carbamates; (ii) two commercial clarifiers, Kemamide $\mathbb{S}$ and Kemamide $\mathrm{E} 180$. These two clarifiers have similarities with the carbamate: they have long alkyl chains and they are capable of forming intermolecular hydrogen bond. Figure 5.1 shows the molecular structure of kemamide $\mathrm{S}$, kemamide $\mathrm{E} 180$ and the carbamate $\mathrm{C}_{12}$. For convenience, the carbamate, polyethylene, kemamide $\mathrm{S}$ and kemamide $\mathrm{E} 180$ will be referred to as $\mathrm{C}_{12}, \mathrm{PE}, \mathrm{KemS}$ and KemE respectively throughout this chapter. 
$\mathrm{NH}_{2}-\stackrel{\mathrm{O}}{\mathrm{C}}-\left(\mathrm{CH}_{2}\right)_{16} \mathrm{CH}_{3}$

Kemamide S

$\mathrm{CH}_{3}\left(\mathrm{CH}_{2}\right)_{17}-\mathrm{N}-\stackrel{\mathrm{O}}{\mathrm{C}}-\left(\mathrm{CH}_{2}\right)_{11} \underset{\mathrm{Z}}{\mathrm{Z}}\left(\mathrm{CH}_{2}\right)_{7} \mathrm{CH}_{3}$

Kemamide $\mathbb{E} 180$

$\mathrm{CH}_{3}\left(\mathrm{CH}_{2}\right)_{17}-\mathrm{H}-\stackrel{\mathrm{O}}{\mathrm{C}}-\mathrm{O}-\left(\mathrm{CH}_{2}\right)_{11} \mathrm{CH}_{3}$

Carbamate $\mathrm{C}_{12}$

Figure 5.1

For industrial applications, commercial clarifiers are usually added in a small amount $<<$ $10 \mathrm{wt} \%$ ) to control the morphology. Higher concentration would lead to phase separation as well as increasing the melt viscosity of the system (and hence requiring higher process temperatures). Therefore, concentrations of less than $25 \%$ of the clarifiers or polyethylene were used to prepare the blends with the carbamate.

\subsection{Preparation of the Blends}

Binary blends of $\mathrm{C}_{12} / \mathrm{PE}, \mathrm{C}_{12} / \mathrm{KemS}$ and $\mathrm{C}_{12} / \mathrm{KemE}$ were prepared according to the procedure described in Chapter 2 with $98 / 02,95 / 05,90 / 10,85 / 15$ and $80 / 20$ (wt \%) 
compositions. For $\mathrm{C}_{12} / \mathrm{KemE}$ blends, a few more blend compositions were prepared $(60 / 40,50 / 50,40 / 60,20 / 80)$ to study the shifts of carbonyl stretching frequency in IR.

\subsection{Results and Discussion}

Figure 5.2 shows the optical micrographs of $\mathrm{C}_{12}, \mathrm{KemS}, \mathrm{PE}$ and KemE. The slow cooled sample of $\mathrm{C}_{12}$ shows coarse spherulites (Figure 5.2a) with an average size of $220 \mu \mathrm{m}$ and the quenched sample shows regular spherulites with a classical maltese cross (Figure $5.2 \mathrm{~b}$ ), the average size being $35 \mu \mathrm{m}$. The slow cooled samples of KemS show highly coarse fibrillar morphology (Figure 5.2c) which reduces to irregular shaped large crystals in the quenched sample (Figure 5.2d). Figure 5.2(e) and 5.1(f) show the optical micrographs of the slow cooled samples of PE and KemE. PE shows imperfect spherulites and KemE shows fibrillar spherulites. The average size of the spherulites for the slow cooled samples of PE and KemE were $10 \mu \mathrm{m}$ and $45 \mu \mathrm{m}$ respectively. The size of the spherulites in the quenched samples of PE and KemE could not be determined.

The changes in morphology of $\mathrm{C}_{12}$ upon blending with $\mathrm{PE}, \mathrm{KemS}$ and KemE are discussed below.

\subsection{1 $\mathrm{C}_{12} / \mathrm{PE}$ and $\mathrm{C}_{12} / \mathrm{KemS}$ Blends}

The slow cooled samples of $\mathrm{C}_{12}$ containing $2-5 \% \mathrm{PE}$ show coarse spherulites with sizes that are very similar to those of pure $\mathrm{C}_{12}$; also in the quenched blends, the shape and size of the spherulites are similar to those of the quenched sample of pure $\mathrm{C}_{12}$. As the amount of PE increases further in the blend, the size of the spherulites decreases. 

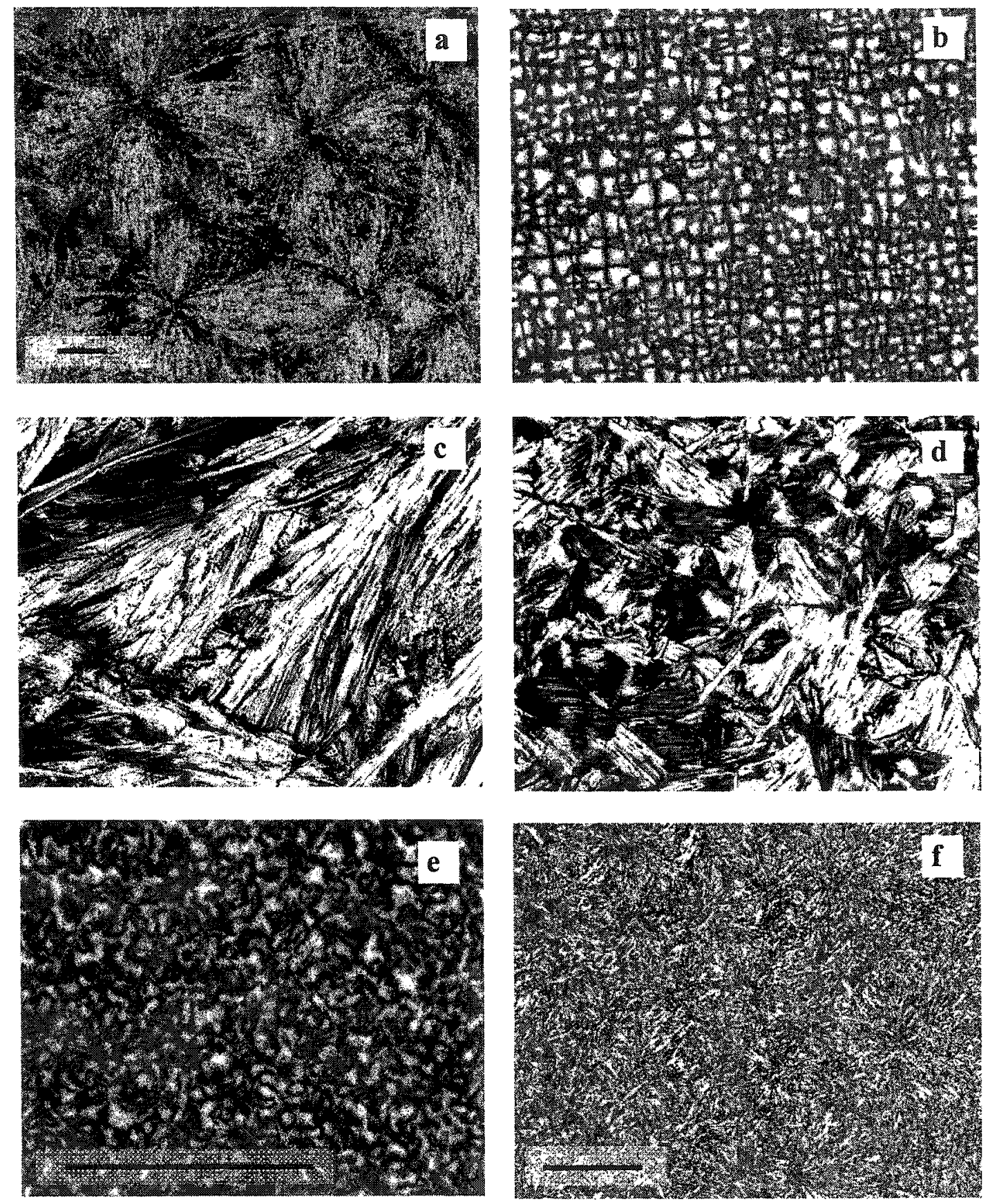

Figure 5.2 Optical micrographs of different samples: (a) $\mathrm{C}_{12}$, slow cooled (b) $\mathrm{C}_{12}$, quenched (c) KemS, slow cooled and (d) KemS, quenched. (e) PE, slow cooled (f) KemE, slow cooled. Note: Scale bars represent $100 \mu \mathrm{m}$. The magnification is same for sample a-d. 

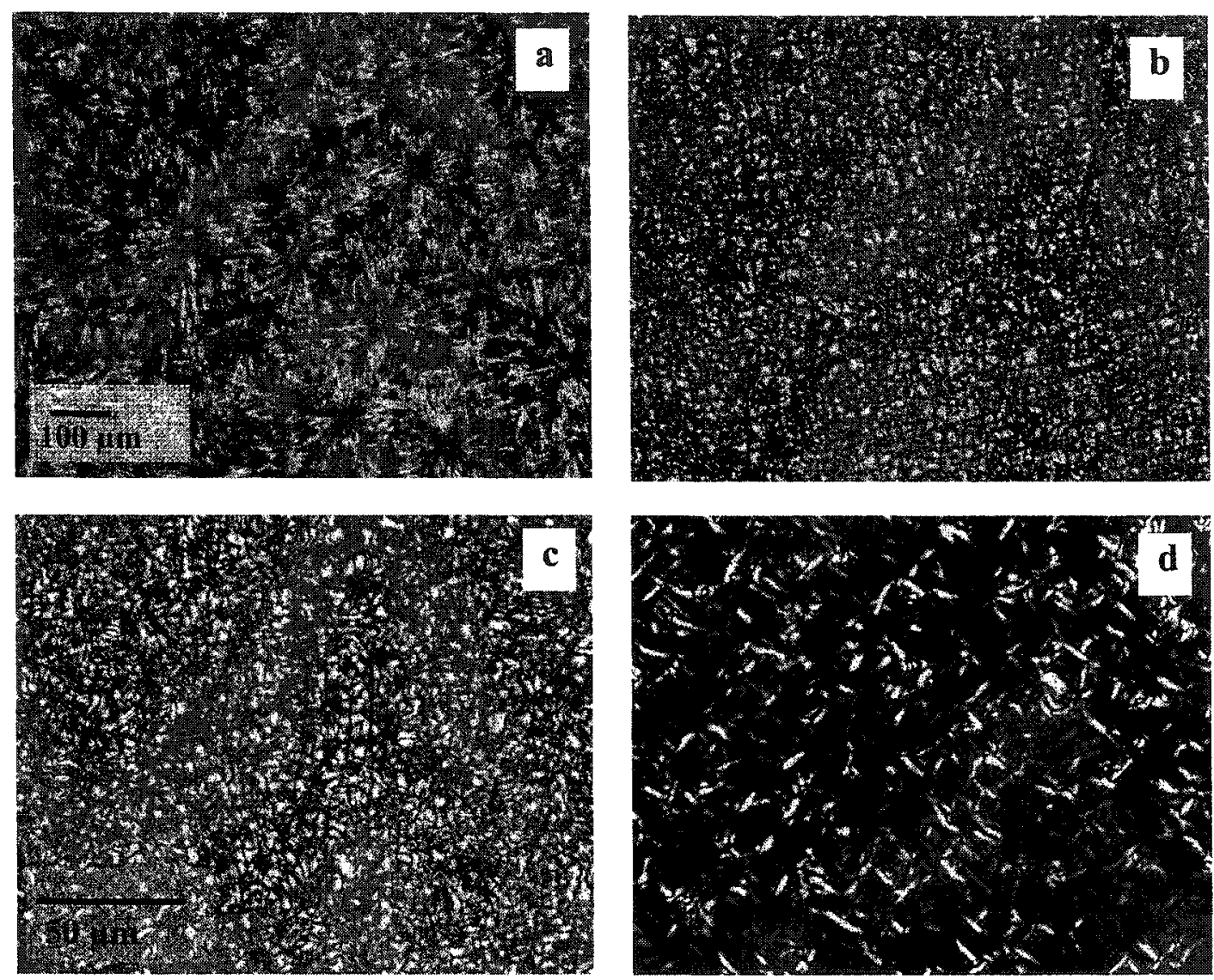

Figure 5.3 Optical micrographs of the $\mathrm{C}_{12} / \mathrm{PE}$ blends (a) $90 / 10$, slow cooled (b) quenched ; (c) 80/20, slow cooled (d) quenched. The magnification is same for a and b. c-f have the same magnification.

The optical micrographs for the slow cooled blends of $\mathrm{C}_{12}$ containing $10 \%$ and $20 \% \mathrm{PE}$ are shown in Figure 5.3a and c respectively and those for the quenched blends are shown in Figure $5.3 \mathrm{~b}$ and $\mathrm{d}$ respectively. The size of the spherulites in the slow cooled blends are plotted in Figure 5.4 as a function of $w t \%$ of PE which shows a decrease in the spherulite size of $\mathrm{C}_{12}$ with increasing concentration of $\mathrm{PE}$ in the blend. It is seen that with 
$10 \% \mathrm{PE}$, the spherulite size reduces from 220 to $60 \mu \mathrm{m}$. In the case of quenched samples, the size reduces even further, to $16 \mu \mathrm{m}$ with $10 \% \mathrm{PE}$. The quenched blends containing 15 and $20 \% \mathrm{PE}$ show only tiny crystals of $c a .6 \mu \mathrm{m}$ size. The spherulites of $\mathrm{C}_{12}$, by itself or in the blends exhibit positive birefringence.

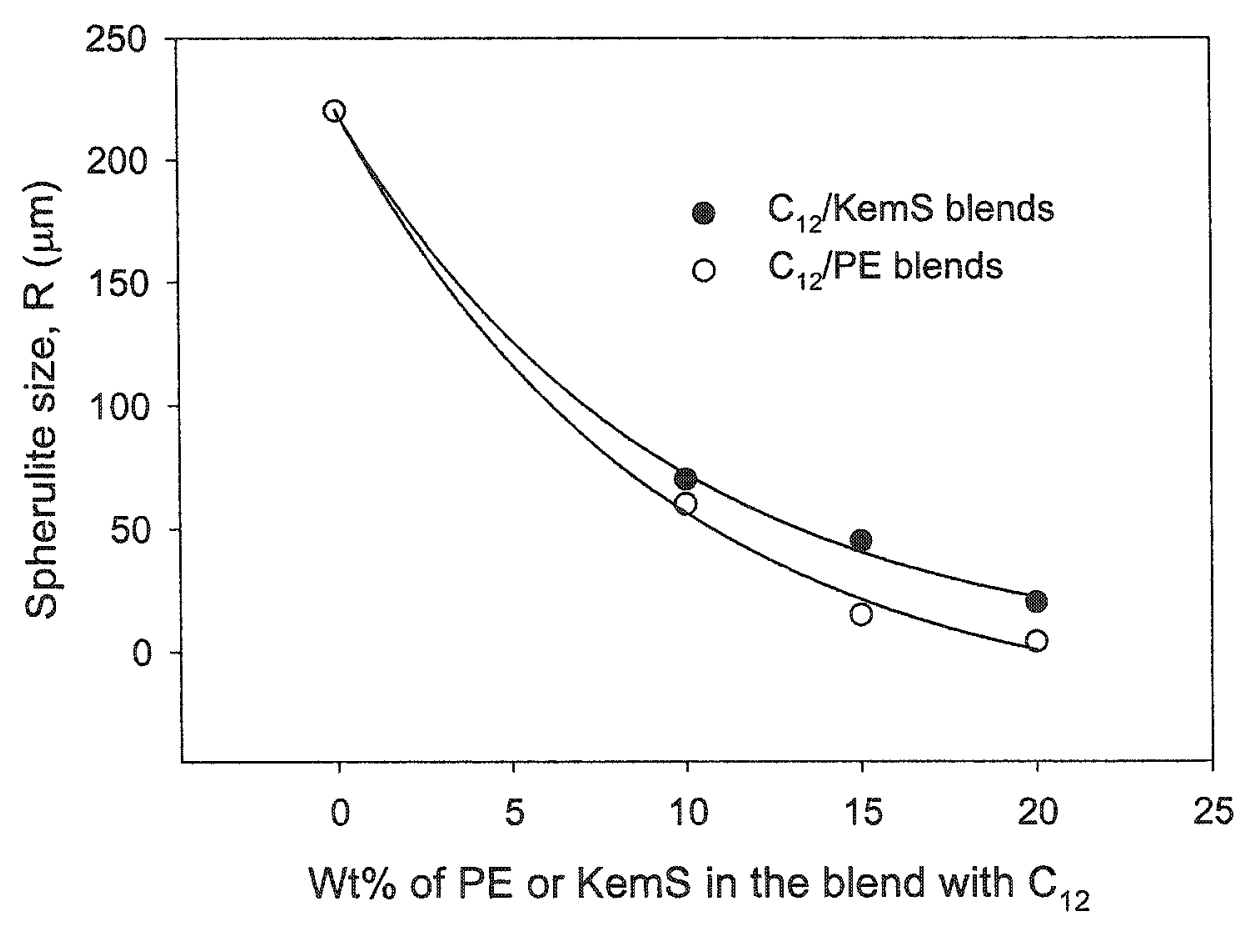

Figure $\mathbf{5 . 4}$ Spherulite size of $\mathrm{C}_{12}$ in the slow cooled blend as a function of wt $\%$ of $\mathrm{PE}$ or KemS.

In the slow cooled and quenched biends of $\mathrm{C}_{12} / \mathrm{KemS}$, the spherulites of $\mathrm{C}_{12}$ as well as the large crystals of KemS are visible at all compositions, indicating phase separation. 
However, similar to $\mathrm{C}_{12} / \mathrm{PE}$ blends, the spherulite size of $\mathrm{C}_{12}$ starts decreasing as the amount of KemS increases to $10 \mathrm{wt} \%$. The optical micrographs for the slow cooled blends containing 10-20\% KemS are shown in Figure 5.5. The phase separation of $\mathrm{C}_{12}$ and KemS in the slow cooled sample containing 20\% KemS are shown at Figure 5.5(c) and 5.5(d); the micrographs were taken from the same sample, but from two different locations.
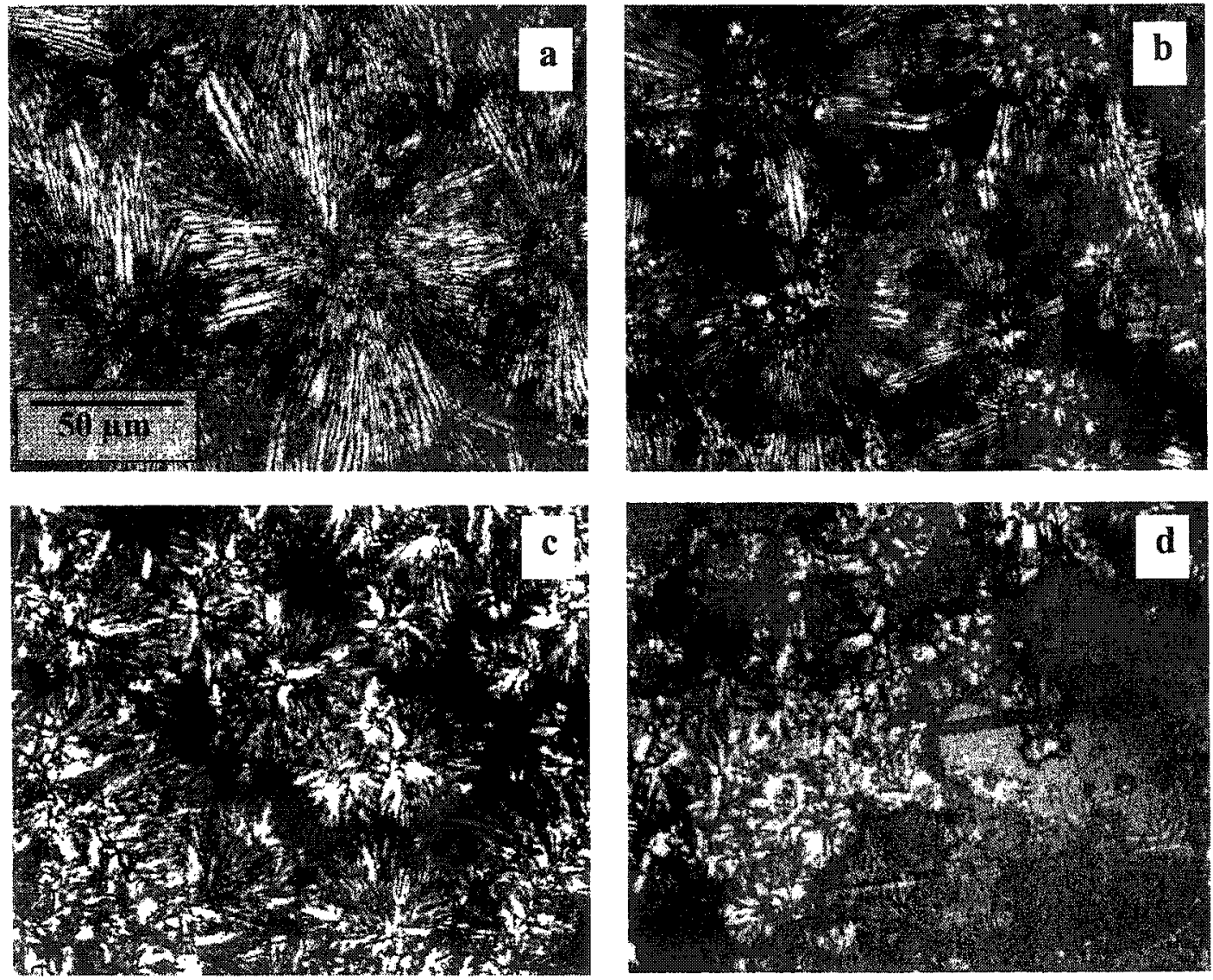

Figure 5.5 Optical micrographs of the slow cooled blends of $\mathrm{C}_{12} / \mathrm{KemS}$ (a) $90 / 10$ (b) $85 / 15(c)$ and $(d) 80 / 20$. 
Figure 5.4 shows a gradual decrease in spherulite size with an increase in the wt\% of KemS in the slow cooled blends. In the quenched blend containing $10 \mathrm{wt} \%$ of KemS, the average size of the spherulites is $15 \mu \mathrm{m}$. The spherulites are not clearly visible in the quenched blends containing $15 \%$ and $20 \% \mathrm{KemS}$, but the phase separated crystals of KemS are clearly visible.

It might be that a similar phase separation occurs in the $\mathrm{C}_{12} / \mathrm{PE}$ blends, but the crystals of $\mathrm{PE}$ could not be distinguished from those of $\mathrm{C}_{12}$ because of their similar size in the blend. However, $\mathrm{PE}$ seems to be more effective in reducing the spherulite size of $\mathrm{C}_{12}$ which is evident from Figure 5.4. For example, for the slow cooled blends, with $20 \% \mathrm{PE}$, the average spherulite size is $4 \mu \mathrm{m}$ as compared to $20 \mu \mathrm{m}$ in case of $20 \% \mathrm{KemS}$ in the blend. It should be mentioned that although the addition of PE and KemS reduced the spherulite size of $\mathrm{C}_{12}$, there was no significant improvement of transparency of the sample. The blending of two homologous carbamates ${ }^{1}$ (Chapter 3 ) resulted in much better transparency.

In the small angle light scattering pattern, the slow cooled sample of $\mathrm{C}_{12}$ showed intensity maxima at $0^{\circ}$ and $90^{\circ}$ but the quenched sample shows more common $45^{\circ}$ intensity maximum (four leaf clover pattern). PE shows imperfect four leaf clover pattern whereas KemS did not show any characteristic pattern in SALS, consistent with the optical microscopy observation. The $\mathrm{H}_{\mathrm{v}}$ scattering patterns for the slow cooled blends containing $2-10 \% \mathrm{PE}$ or $\mathrm{KemS}$ show intensity maxima at $0^{\circ}$ and $90^{\circ}$ (Figure 5.6a), which is similar to the scattering pattern from the slow cooled sample of pure $C_{12}$. The quenched blends 
containing 2-10\% PE or KemS show the usual four leaf clover patterns in SALS (Figure 5.6b). The four leaf clover patterns in the slow cooled and quenched samples containing $15 \%$ and $20 \% \mathrm{PE}$ or KemS were not perfect. This might be due to the imperfect shape of the spherulites or their very small size.
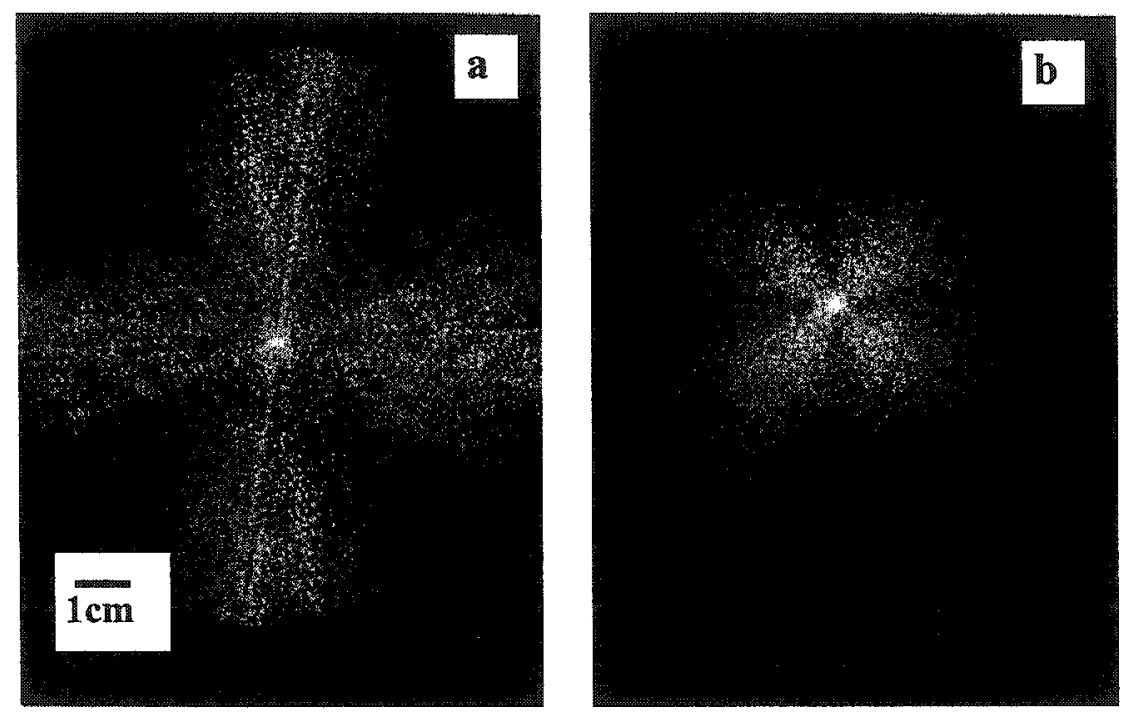

Figure 5.6 $\mathrm{H}_{v}$ scattering pattern for the $90 / 10$ blend of $\mathrm{C}_{12} / \mathrm{PE}$ (a) slowly cooled and (b) quenched.

The melting points of $\mathrm{C}_{12}, \mathrm{PE}$ and $\mathrm{KemS}$ are $74^{\circ} \mathrm{C}, 99^{\circ} \mathrm{C}, 108^{\circ} \mathrm{C}$ respectively, as obtained from DSC. Except for the $98 / 02$ composition, the other compositions of $\mathrm{C}_{12} / \mathrm{PE}$ and $\mathrm{C}_{12} / \mathrm{KemS}$ blends show two melting peaks in the DSC thermograms, one at about $73^{\circ} \mathrm{C}$ which reduces slightly with increasing incorporation of the second component in $\mathrm{C}_{12}$. The second peak appears as a shoulder at a position lower than the melting point of the second component. For example, in the DSC thermogram of the slow cooled blend containing 
$20 \% \mathrm{KemS}$, the melting peak of $\mathrm{C}_{12}$ appears at $72^{\circ} \mathrm{C}$ and the melting peak of $\mathrm{KemS}$ appears as a shoulder at $92{ }^{\circ} \mathrm{C}$. Thus, the components in the $\mathrm{C}_{12} / \mathrm{PE}$ and $\mathrm{C}_{12} / \mathrm{KemS}$ blends exert a mutual diluent effect, resulting in a depression of melting points. Table 5.1 shows the heat of fusion of the slow cooled samples for the pure components and for the blends. For the blends, it represents the cumulative heat of fusion of the components. In all cases, the heat of fusion for the quenched sample was $4-5 \mathrm{~J} / \mathrm{g}$ lower than that of slowcooled samples. Table 5.1 shows that for $\mathrm{C}_{12} / \mathrm{PE}$ and $\mathrm{C}_{12} / \mathrm{KemS}$ blends, the heat of fusion increases with the incorporation of the second component.

Table 5.1 Heat of fusion for the $\mathrm{C}_{12} / \mathrm{PE}, \mathrm{C}_{12} / \mathrm{KemS}$ and $\mathrm{C}_{12} / \mathrm{KemE}$ blends.

\begin{tabular}{cccc}
\hline $\begin{array}{c}\text { Wt \% of } \\
\mathrm{PE} / \mathrm{KemS} / \mathrm{KemE}\end{array}$ & $\mathrm{C}_{12} / \mathrm{PE}$ & $\mathrm{C}_{12} / \mathrm{KemS}$ & $\mathrm{C}_{12} / \mathrm{KemE}$ \\
\hline 0 & 184 & 184 & 184 \\
2 & 190 & 188 & 182 \\
5 & 192 & 189 & 181 \\
10 & 193 & 192 & 179 \\
15 & 194 & 194 & 178 \\
10 & 194 & 194 & 176 \\
\hline
\end{tabular}


Figure 5.7 shows the X-ray diffractograms of slow-cooled samples of $\mathrm{C}_{12} / \mathrm{PE}$ and $\mathrm{C}_{12} / \mathrm{KemS}$ blends along with the diffractograms of the pure components. The quenched blends show similar diffractograms. The diffractograms of the blends are just superposition of those of the parent compounds, which indicates that blending with $\mathrm{PE}$ or $\mathrm{KemS}$ does not affect the crystal structure of $\mathrm{C}_{12}$. This is in contrast with the case of $\mathrm{C}_{18} /$ Stearic acid blend ${ }^{2}$ (Chapter 4).

In the $\mathbb{R}$ spectra of $\mathrm{C}_{12} / \mathrm{PE}$ blends, the positions of $\mathrm{C}=\mathrm{O}$ and $\mathrm{N}-\mathrm{H}$ stretching bands of $\mathrm{C}_{12}$ $\left(1686 \mathrm{~cm}^{-1}\right.$ and $3337 \mathrm{~cm}^{-1}$ respectively) were unaffected which indicates that $\mathrm{PE}$ does not disrupt the intermolecular hydrogen bonded network of $\mathrm{C}_{12}$. In fact, these bands were found to be unaffected even when $\mathrm{C}_{12}$ was blended with $90 \% \mathrm{PE}$. The $\mathrm{C}=\mathrm{O}$ and $\mathrm{N}-\mathrm{H}$ stretching frequencies of Kemamide $S$ are $1646 \mathrm{~cm}^{-1}$ and $3394 \mathrm{~cm}^{-1}$ respectively. The blends show the presence of two $\mathrm{C}=\mathrm{O}$ and two $\mathrm{N}-\mathrm{H}$ bands; there is no shift in the stretching frequencies with respect to the pure components, which indicates that there is neither an exchange of hydrogen bonds between $\mathrm{C}_{12}$ and $\mathrm{KemS}$, nor is there any disruption of hydrogen bonds. 

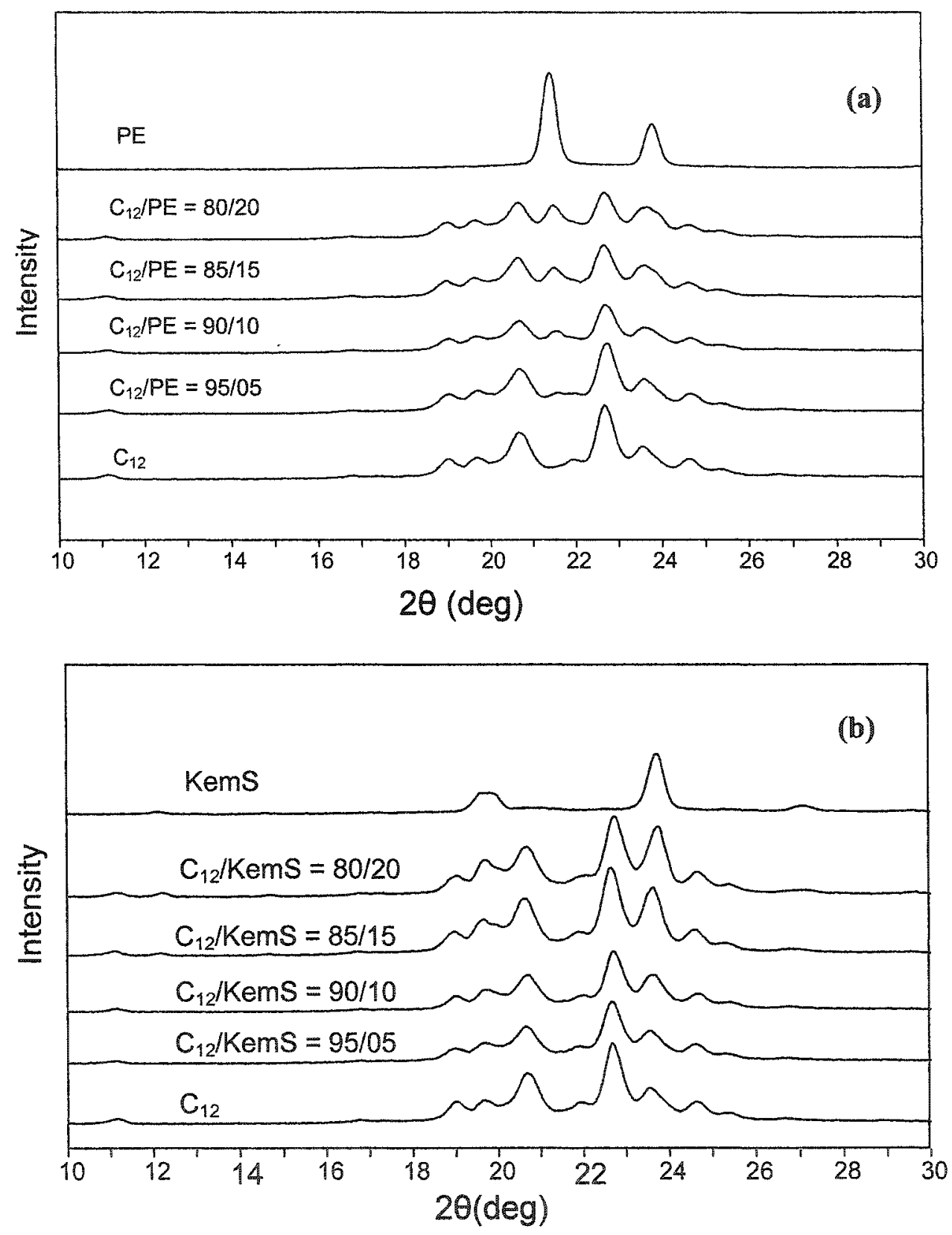

Figure 5.7 X-ray diffractograms of the binary blends of (a) $\mathrm{C}_{12} / \mathrm{PE}$ and (b) $\mathrm{C}_{12} / \mathrm{KemS}$. 

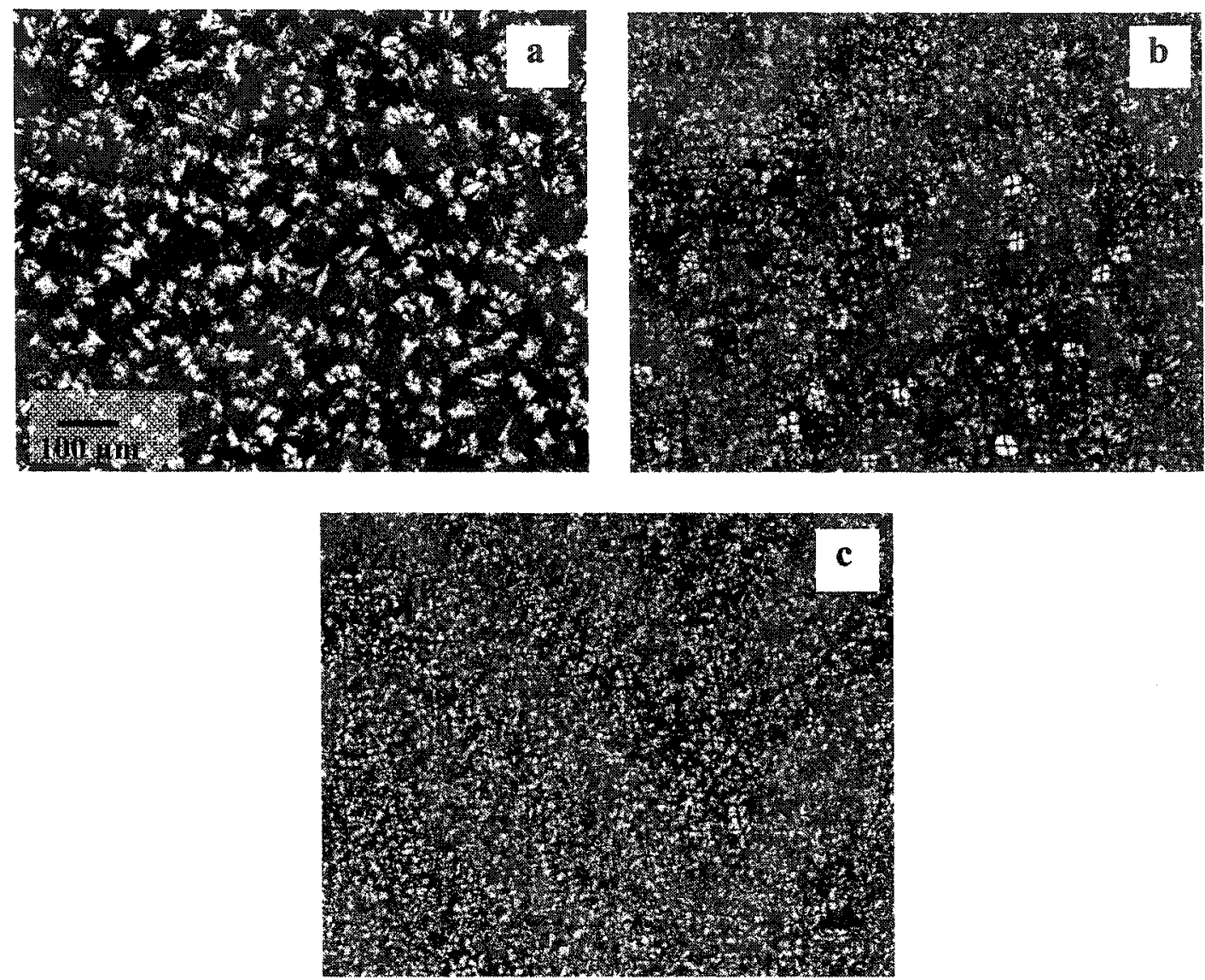

Figure 5.8 Optical micrographs of the slow cooled blends of $\mathrm{C}_{12} / \mathrm{KemE}$ (a) $90 / 10$ (b) $85 / 15$ and (c) $80 / 20$

\subsection{2 $\mathrm{C}_{12} / \mathrm{KemE}$ Blends}

Figure 5.8 shows the optical micrographs of $\mathrm{C}_{12} / \mathrm{KemE}$ blends. The slow cooled samples containing 2-10\% KemE show imperfect spherulites (Figure 5.8a). The slow cooled sample containing $15 \% \mathrm{KemE}$ shows positive spherulites whereas the sample having $20 \%$ KemE shows negative spherulites (Figure $5.8 \mathrm{~b}$ and c respectively). The quenched samples containing 2-15\% KemE show spherulitic morphology with very low 
birefringence. The quenched sample containing $20 \% \mathrm{KemE}$ does not show any crystal/spherulite under optical microscope. Both the slow cooled and quenched blends of $\mathrm{C}_{12} / \mathrm{KemE}$ show excellent transparency which is comparable with what we obtained from the blends of homologous carbamates ${ }^{1}$ (Chapter 3 ). Figure 5.9 shows a comparison in transparency between the slow cooled sample of $\mathrm{C}_{12}$ (Figure $5.9 \mathrm{a}$ ) and its $80 / 20$ blends with $\mathrm{PE}, \mathrm{KemS}$ and $\mathrm{KemE}$ (Figure 5.9b, c and d respectively). The photographs were taken using the same procedure as described in section 3.3 .1 , chapter 3 . The figure clearly shows the significant improvement in transparency in the $80 / 20$ blend of $\mathrm{C}_{12} / \mathrm{KemE}$.
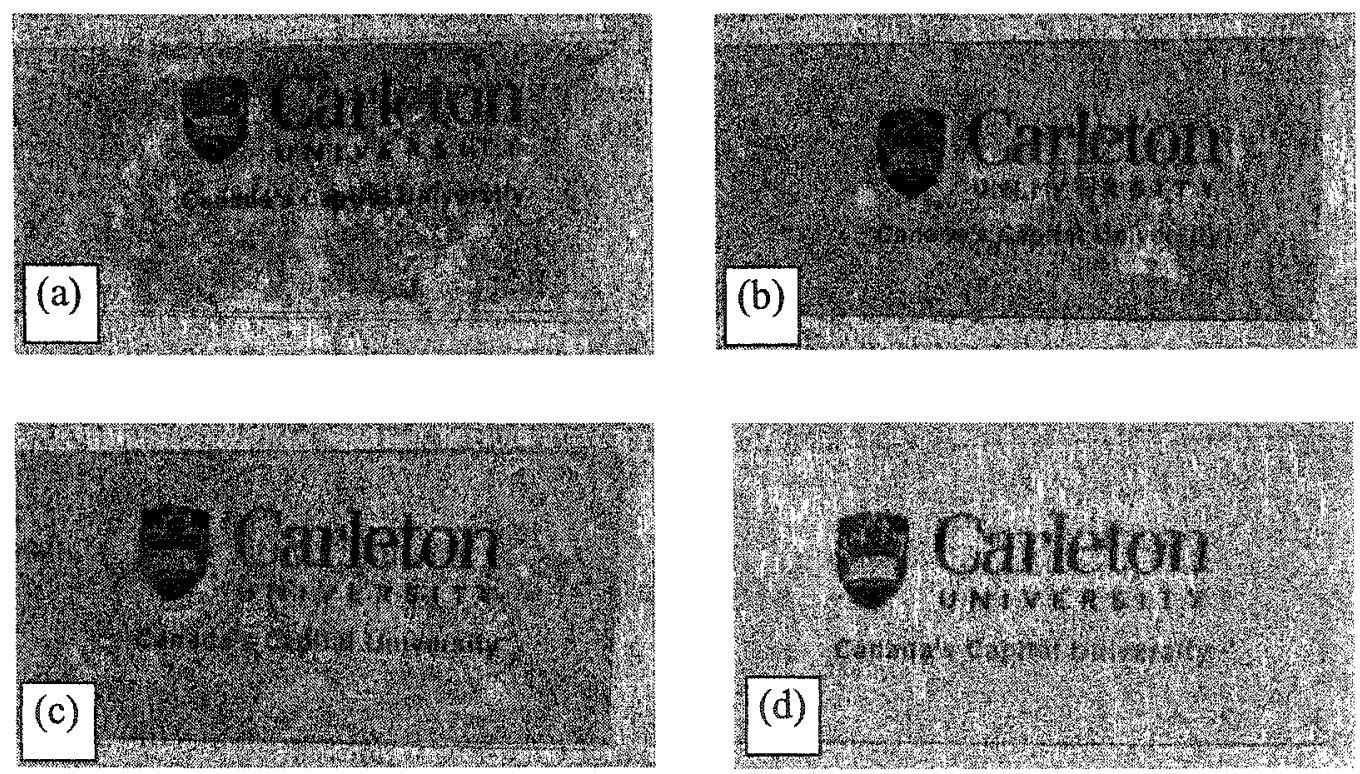

Figure 5.9 Transparency of different samples (a) $\mathrm{C}_{12}$ (b) $\mathrm{C}_{12} / \mathrm{PE}=80 / 20$ (c) $\mathrm{C}_{12} / \mathrm{KemS}=80 / 20$ and $(\mathrm{d}) \mathrm{C}_{12} / \mathrm{KemE}=80 / 20$. All the samples are slowcooled. 
The slow cooled samples of $\mathrm{KemE}$ and the blends containing 2-10\% KemE show imperfect foul leaf clover patterns in SALS, consistent with the optical microscopy observations. The slow cooled samples containing $15 \%$ and $20 \% \mathrm{KemE}$ and the quenched samples containing $2-15 \% \mathrm{KemE}$ show usual four leaf clover patterns in SALS. The SALS patterns for the quenched samples of $\mathrm{C}_{12}$ and their blends are presented in Figure 5.10.
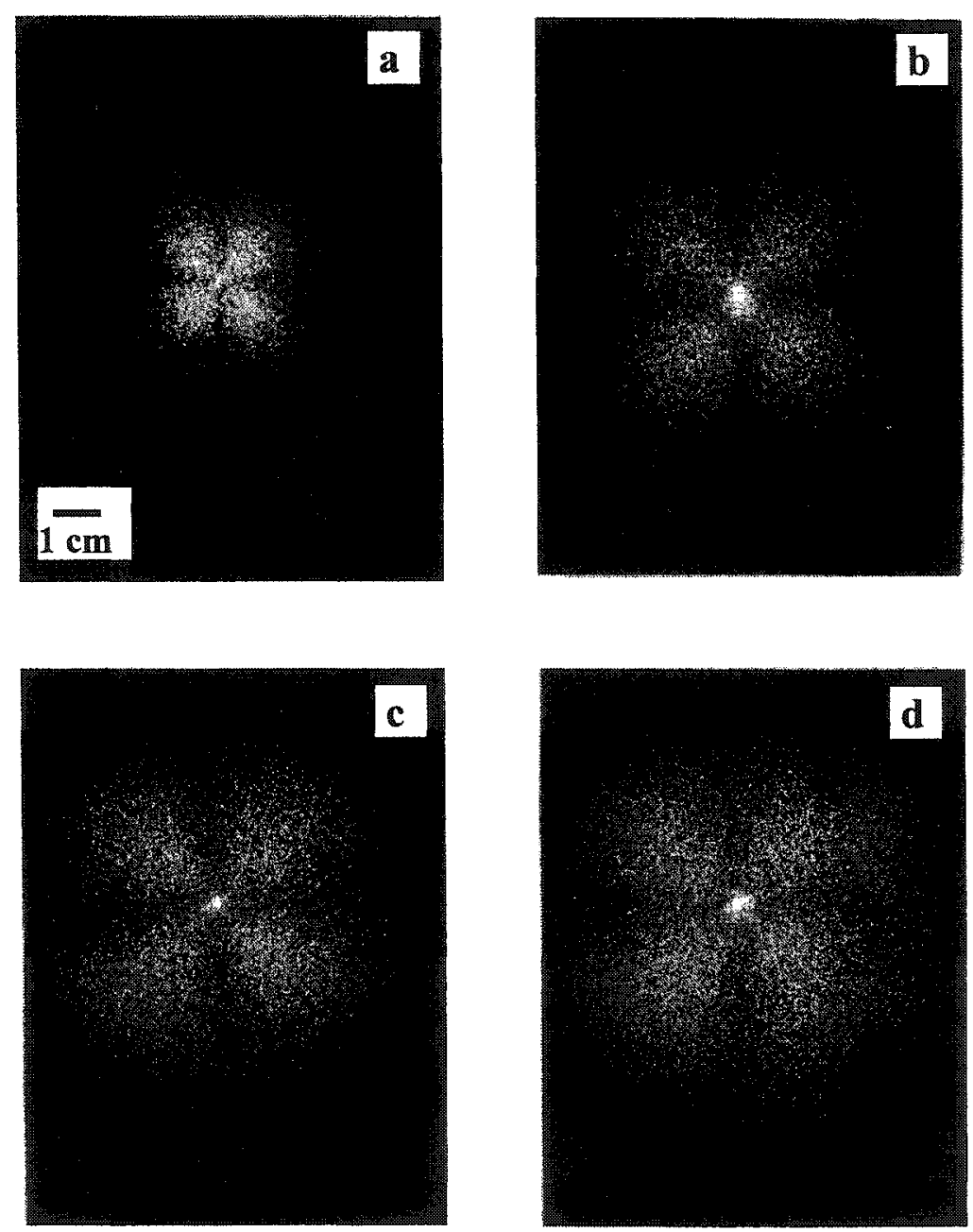

Figure 5.10 $\mathrm{H}_{\mathrm{v}}$ scattering pattern for the quenched sample of (a) $\mathrm{C}_{12}$ and $\mathrm{C}_{12} / \mathrm{kemE}$ blends at composition of (b) $98 / 02$ (c) $90 / 10$ (d) $85 / 15$. 
The $H_{v}$ scattering patterns in Figure 5.10 were recorded with the same sample-film distance for all these samples. The figure shows that the four leaf clover pattern becomes larger with increasing incorporation of $\mathrm{KemE}$ in the blends, indicating a decrease in the size of the spherulites. Figure 5.11 shows that the spherulite size decreases with an increase in the concentration of $\mathrm{KemE}$ in $\mathrm{C}_{12}$. It should be noted that the spherulite size obtained from the slow cooled sample of $80 / 20$ blend of $\mathrm{C}_{12} / \mathrm{C}_{16}$ (Chapter 3 ) was $10 \mu \mathrm{m}$, which is comparable with the $80 / 20$ blend of $\mathrm{C}_{12} / \mathrm{KemE}$ in this study.

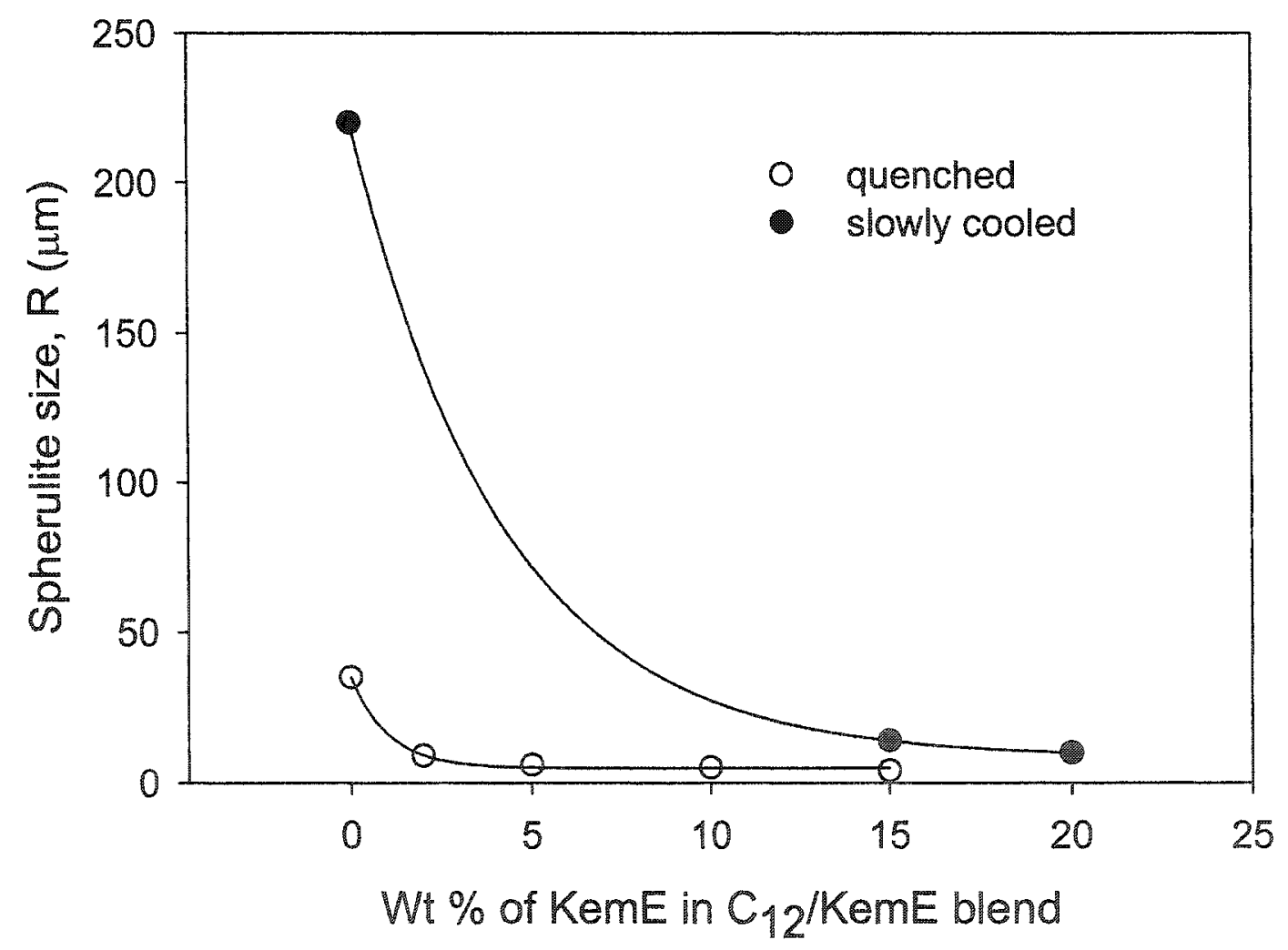

Figure 5.11 Spherulite size as a function of $\mathrm{w} \%$ of $\mathrm{KemE}$ in $\mathrm{C}_{12} / \mathrm{KemE}$ blends. 
The DSC thermograms of $\mathrm{C}_{12}, \mathrm{KemE}$ and of their blends are shown in Figure 5.12. The melting point of $\mathrm{KemE}$ is $74^{\circ} \mathrm{C}$. Similar to $\mathrm{C}_{12} / \mathrm{PE}$ and $\mathrm{C}_{12} / \mathrm{KemS}$ blends, $\mathrm{C}_{12} / \mathrm{KemE}$ blends exert a mutual diluent effect, resulting in a depression of melting points of both $\mathrm{C}_{12}$ and $\mathrm{KemE}$. For example, in the DSC thermogram of the slow cooled blend containing $20 \% \mathrm{KemE}$, the melting peak of $\mathrm{C}_{12}$ appears at $71^{\circ} \mathrm{C}$ and the melting peak of $\mathrm{KemE}$ appears as a shoulder at $68^{\circ} \mathrm{C}$ (see Figure 5.12).

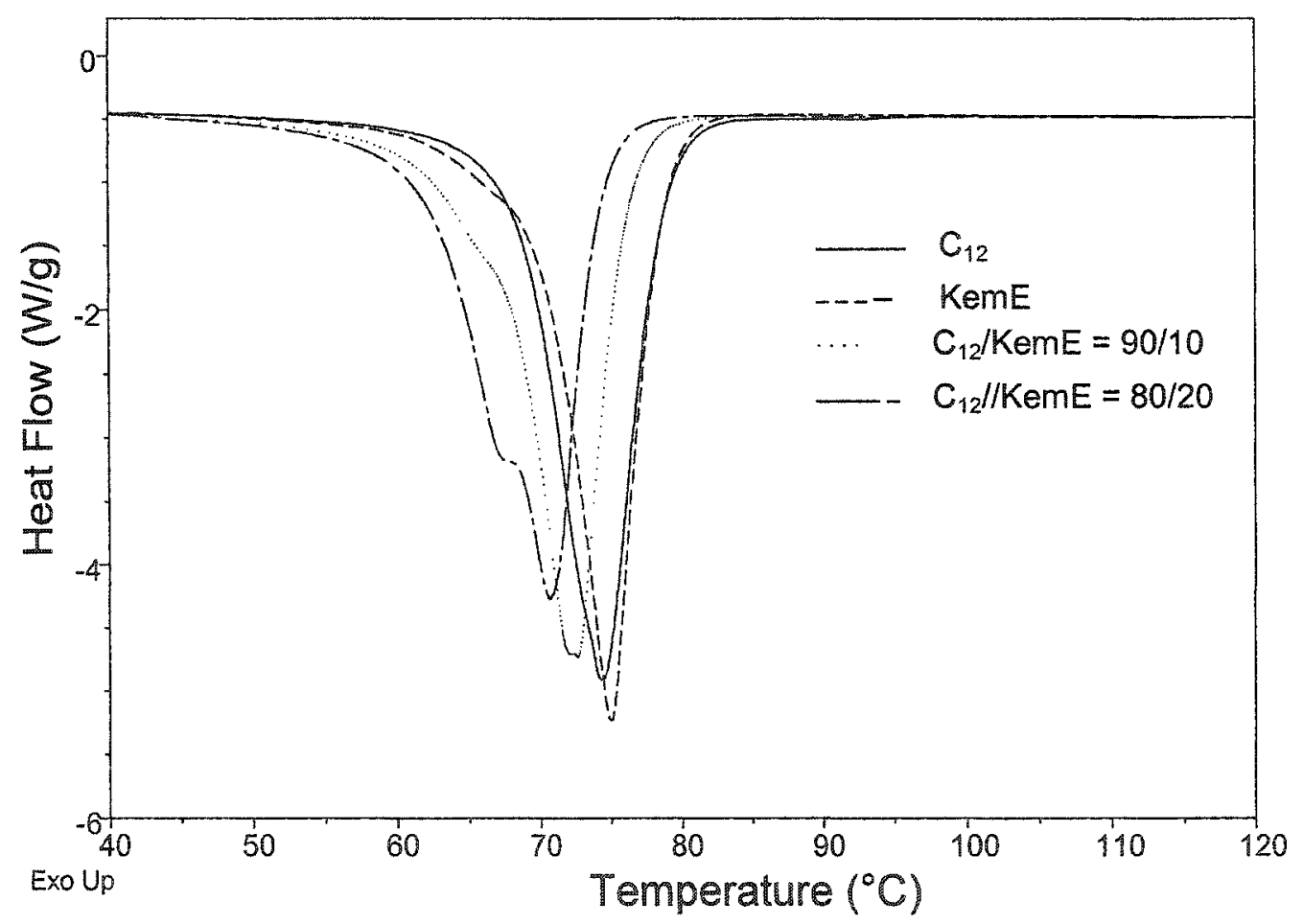

Figure 5.12 DSC thermograms of $\mathrm{C}_{12}, \mathrm{KemE}$ and of their blends 
The heat of fusion of $\mathrm{C}_{12} / \mathrm{KemE}$ blends are shown in Table 5.1 which shows a decrease in the heat of fusion with increasing KemE concentration in the blend. However, these results do not lead to a definite conclusion, since the decrease in the heat of fusion for $\mathrm{C}_{12} / \mathrm{KemE}$ blends might be due to the fact that the heat of fusion of $\mathrm{KemE}$ is lower than that of $\mathrm{C}_{12}$.

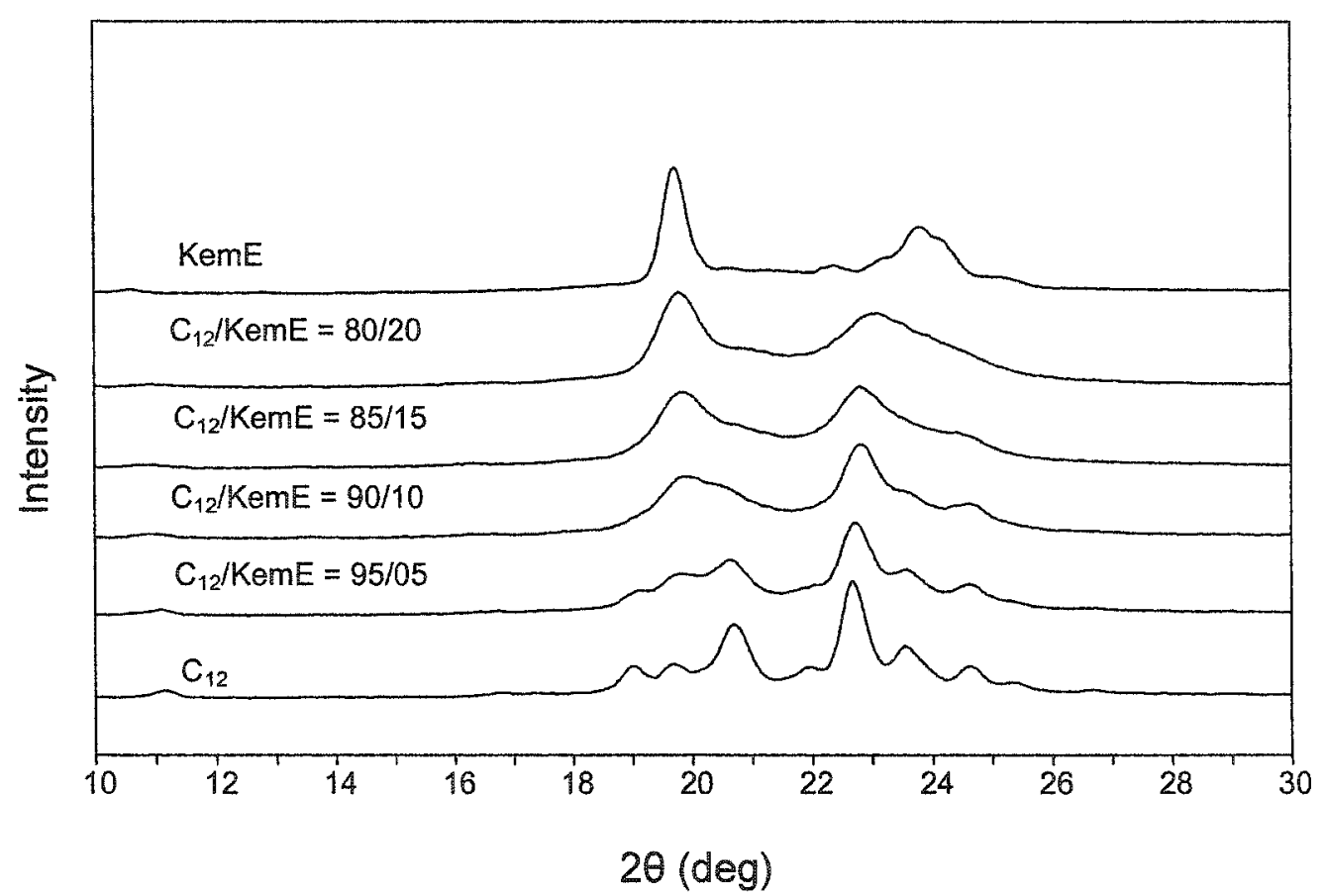

Figure $5.13 \quad X$-ray diffractograms of the binary blends of $C_{12} / \mathrm{KemE}$ along with those of $\mathrm{C}_{12}$ and $\mathrm{KemE}$.

In contrast to the $X$-ray diffractograms of $C_{12} / \mathrm{PE}$ and $C_{12} / K e m S$ blends, the $X$-ray diffractograms of $\mathrm{C}_{12} / \mathrm{KemE}$ blends indicate significant changes in the crystal structure of $\mathrm{C}_{12}$. Figure 5.13 shows that increasing incorporation of $\mathrm{KemE}$ in the blend results in a 
reduction of number of peaks as well as their broadening. The sharp peak of $C_{12}$ at $2 \theta=$ $22.8^{\circ}(d=3.9 \AA)$, which corresponds to the plane of hydrogen bonding ${ }^{1}$, becomes a broad hump in the $80 / 20$ blend of $\mathrm{C}_{12} / \mathrm{KemE}$, indicating a significant decrease in crystallinity in the sample. Figure 5.14 shows the crystallite size and the full width at half maximum (fwhm) at $d=3.9 \AA$, as a function of blend composition. There is an increase in the fwhm and a decrease in the crystallite size as the amount of KemE increases in the blend. For $80 / 20$ blends of $\mathrm{C}_{12} / \mathrm{KemE}$, the fwhm increases from 0.37 to $1.95 \mathrm{rad}$ on the $2 \theta$ scale and the crystallite size decreases from 230 to $60 \AA$.

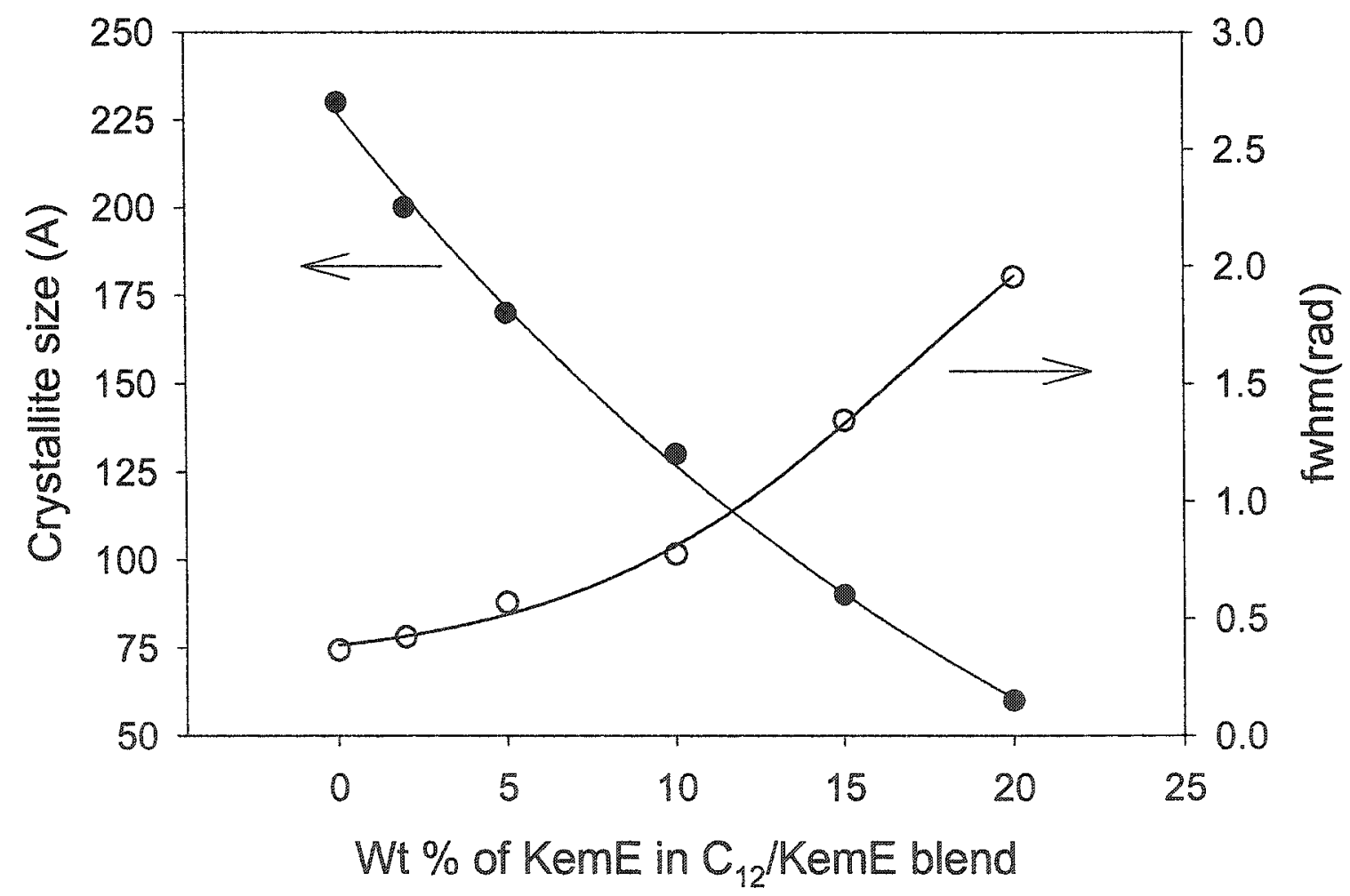

Figure 5.14 The crystallite size and the full width at half maximum corresponding to the reflection at $22.8^{\circ}$ as a function of $\mathrm{C}_{12} / \mathrm{KemE}$ blend composition. 
The $\mathrm{IR}$ spectra of $\mathrm{C}_{12} / \mathrm{KemE}$ blends show some noticeable changes. The $\mathrm{C}=\mathrm{O}$ stretching frequency of $\mathrm{KemE}$ is $1636 \mathrm{~cm}^{-1}$. The blends show two carbonyl bands, one at 1686 , another at $1658 \mathrm{~cm}^{-1}$. The intensity of the carbonyl band at $1658 \mathrm{~cm}^{-1}$ increases as the amount of KemE increases in the blend. The carbonyl band at $1658 \mathrm{~cm}^{-1}$ indicates the possibility that there might be some exchange of hydrogen bonds between $\mathrm{C}_{12}$ and $\mathrm{KemE}$. To further explore this possibility, we extended the series by preparing blends containing $20,40,50,60$ and $80 \% \mathrm{KemE}$. Table 5.2 shows the $\mathrm{C}=\mathrm{O}$ and $\mathrm{NH}$ stretching frequency of all the blends.

Table 5.2 $\mathrm{C}=\mathrm{O}$ and $\mathrm{NH}$ frequency of $\mathrm{C}_{12} / \mathrm{KemE}$ blends

\begin{tabular}{cll}
\hline Wt \% of KemE & $v \mathrm{C}=\mathrm{O}\left(\mathrm{m}^{-1}\right)$ & $v \mathrm{NH}\left(\mathrm{cm}^{-1}\right)$ \\
\hline 0 & 1686 & 3337 \\
5 & 1686, & 3337 \\
10 & 1686,1659 & 3336 \\
15 & 1686,1658 & 3335 \\
20 & 1686,1657 & 3335 \\
40 & 1686,1647 & 3330 \\
50 & 1686,1644 & 3330 \\
60 & 1686,1641 & 3330 \\
80 & 1686,1638 & 3330 \\
100 & 1636 & 3330 \\
\hline
\end{tabular}




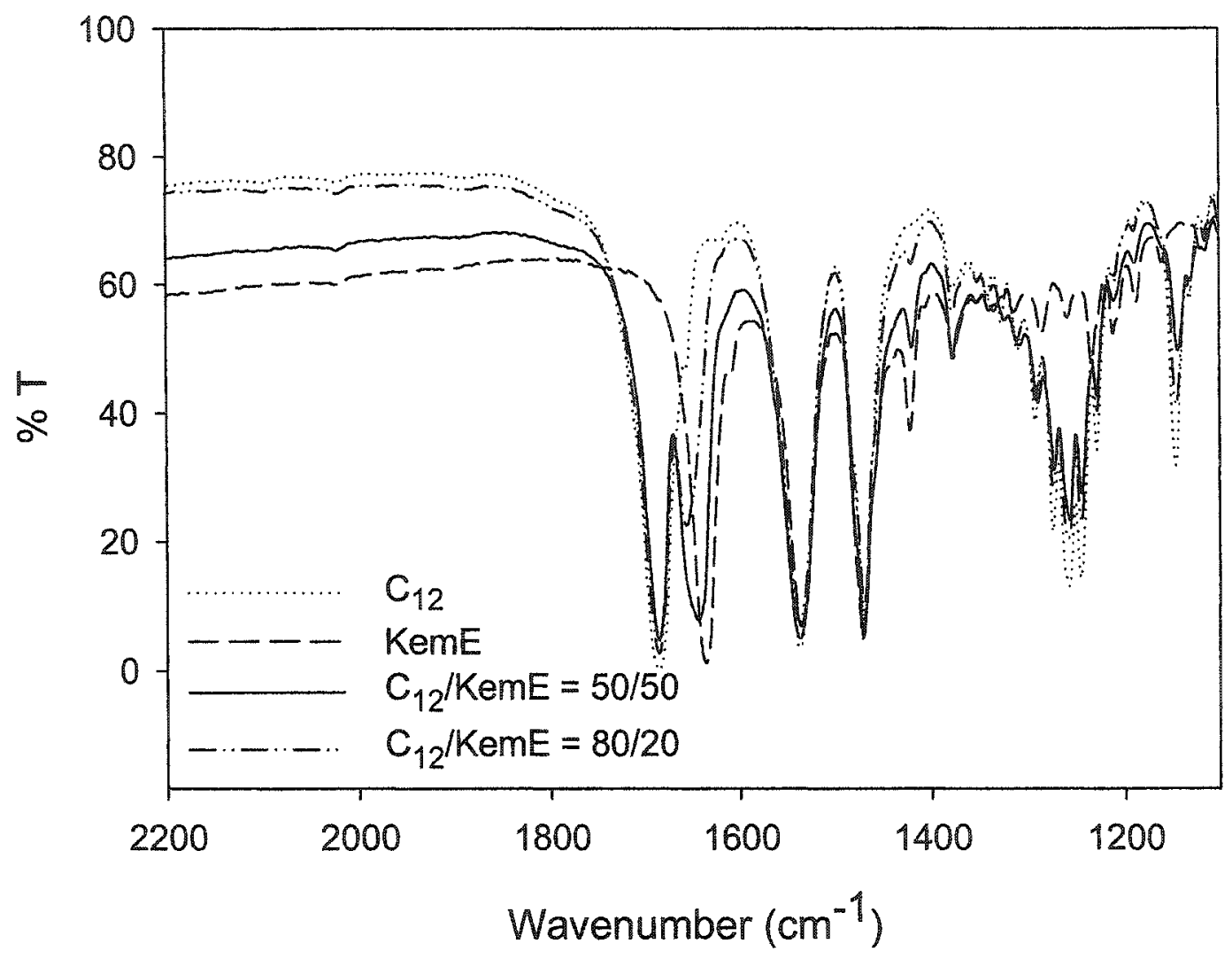

Figure 5.15 FTIR spectra of $\mathrm{C}_{12}$, KemE and their blends.

Table 5.2 shows that the $\mathrm{NH}$ bands of $\mathrm{C}_{12}$ and $\mathrm{KemE}$ are very close; therefore, they merge into one band in the blend. This table as well as Figure 5.15 show that there is a gradual shift of $\mathrm{C}=\mathrm{O}$ stretching frequency of $\mathrm{KemE}$ as the amount of $\mathrm{C}_{12}$ increases in the blend. It seems that at higher concentration of $C_{12}$ in the blend, some of the $C_{12}$ molecules form $\mathrm{H}$-bond with $\mathrm{KemE}$, resulting in a shift of $\mathrm{C}=\mathrm{O}$ stretching frequency of $\mathrm{KemE}$. When $\mathrm{KemE}$ is the major component, there is not much interchange of $\mathrm{H}$-bond between $\mathrm{C}_{12}$ and $\mathrm{KemE}$, since $\mathrm{KemE}$ forms stronger H-bonds among themselves. If there is an 
interchange of hydrogen bonds between $\mathrm{C}_{12}$ and $\mathrm{KemE}$, then the insertion of $\mathrm{KemE}$ in $\mathrm{C}_{12}$ network will provide a misfit in the crystal lattice of $\mathrm{C}_{12}$, which explains the decrease in crystallinity in the blends as is evident from their $\mathrm{x}$-ray diffraction patterns. This decrease in crystallinity has contributed significantly to improve the transparency of the samples. In fact, there are examples in the literature ${ }^{3}$ where the nucleating ability of a substance was found to be greater if it can provide a small crystallographic misfit.

The question arises as to why the same change is not happening in case of using KemS. It might be the molecular structure of KemE that is favoring the exchange of H-bonds. The hydrogen bondable group forms the head group in KemS (Figure 5.1). On the other hand, in both $\mathrm{C}_{12}$ and $\mathrm{KemE}$, the hydrogen bondable group is positioned between the long alkyl chains. This might facilitate the alignment of the $\mathrm{C}_{12}$ and $\mathrm{KemE}$ and therefore an easy exchange of H-bonds. This also explains the changes we observed in case of the blends of homologous carbamates. Their structural similarities and similar strength of $\mathrm{H}$-bonds favor the exchange of $\mathrm{H}$-bonds. Although it does not affect the extent of hydrogen bond, as is evident from the $\mathbb{I R}$, it does affect the packing of alkyl chains which results in a decrease in crystallinity, heat of fusion and a significant improvement in transparency.

\subsection{Conclusions}

It was found that the spherulite size of the carbamate is unaffected up to $5 \mathrm{wt} \%$ of $\mathrm{PE}$ and KemS in the blend. Further increase in the wt $\%$ of PE or KemS in the blend reduces the spherulite size of the carbamate. However, phase separation takes place at all compositions of KemS in the blend. PE was found to be more effective in reducing the 
spherulite size of the carbamates. Neither PE nor KemS affects the type or extent of hydrogen bonding of the carbamate. The crystal structure of the carbamate is not affected with the addition of $\mathrm{PE}$ of $\mathrm{KemS}$ and the transparency of the sample does not improve significantly as compared to that of pure carbamate. Thus, the reduction in the spherulite size of $\mathrm{C}_{12}$ in these blends is due to the small crystals of $\mathrm{PE}$ or KemS acting as nucleating agents; this did not improve the transparency due to the phase separation.

On the other hand, significant improvement of the transparency was achieved when the carbamate was blended with KemE. Blending reduces the crystallite and spherulite size, heat of fusion and crystallinity. The sign of birefringence of the spherulites changes from positive to negative as the wt $\%$ of KemE increases in the blend. FTIR spectra indicate an exchange of hydrogen bonds between the carbamate and KemE. Insertion of KemE in the hydrogen bonded network of the carbamate causes a misfit in the crystal lattice of the carbamate which reduces the crystallinity of the carbamate. The change in packing of the alkyl chains of the carbamate is reflected by the broadening of the peak at $\mathrm{d}=3.9 \AA$ in the X-ray diffractogram, which corresponds to the plane of hydrogen bonding, i.e. the distance between two alkyl chains.

Although there are several theories regarding heterogeneous nucleation ${ }^{3-9}$, it is still somewhat a mystery as to the mechanism of the nucleating agents ${ }^{10}$. As a result, searching for effective nucleating agents is more or less an empirical process. Although the heterogeneous nucleation of $\mathrm{C}_{12}$ by $\mathrm{PE}$ and $\mathrm{KemS}$ results in the reduction of spherulite/crystal size, they cannot provide as much transparency as is achieved by the 
KemE or by blending the carbamate with another carbamate. Clearly, H-bonding is playing an important role in controlling the morphology of self-assembling carbamate systems. The findings of this study can help to design effective nucleating agents to control the morphology of self-assembling systems. 


\subsection{References}

1. Moniruzzaman, M.; Goodbrand. B.; Sundararajan, P.R. J. Phys. Chem. B 2003, 107,8416 .

2. Moniruzzaman, M.; Sundararajan, P.R. Pure Appl. Chem. 2004, 76, 1353.

3. Dovbreva, A.; Alonso, M.; Gonzalez, M.; DE Saja, J.A. J. Appl. Polym. Sci. 1997, 63,349 .

4. Willems, J.W. Experimentia, 1967, 23, 409.

5. Mauritz, K.A.; Baer, E.; Hopfinger, A. J. J. Polym. Sci., Macromol. Rev. 1978, 13,1 .

6. Binsbergen, F.L. Polymer, 1970, 11, 253.

7. Binsbergem, F.L. J. Polym. Sci., Polym. Sympos. 1977, 59, 11.

8. Lotz, B.; Wittmann, J.C.; J. Polym. Sci., Part B: Polym. Phys.1981, 25, 1079.

9. Lotz, B.; Wittmann, J.C. Macromol. Chem. 1984, 185, 2043.

10. Mercier, J.P. Polym. Eng. Sci. 1990, 30, 270. 
Chapter 6

Low Molecular Weight Organogels Based on Carbamates 


\subsection{Introduction}

This chapter reports the first example of a family of low molecular weight organogels based on carbamates with alkyl side chains of different lengths. In recent years, there has been a growing interest in the properties and structures of low molecular-weight organic gelators (LMOGs, molecules whose molecular mass is $\leq 3000^{1}$ ) and their organogels. A wide variety of LMGOs have been discovered during the last few decades e.g. fatty acid derivatives $^{2 \mathrm{a}, \mathrm{b}}$, steroid derivatives ${ }^{2 \mathrm{c}, \mathrm{d}}$, anthryl derivatives ${ }^{2 \mathrm{e}}$, gelators containing steroidal and condensed aromatic rings ${ }^{2 f, g}$, amino acid type gelators $^{2 h, i}, n$-alkanes ${ }^{2 j}$, etc. These organogels exhibit striking properties with respect to self-assembly phenomena ${ }^{3,4}$; the gelator molecules self-assemble through highly specific interactions which allows preferentially one-dimensional growth. This one-dimensional growth usually results in the formation of fibers, strands or tapes. The elongated objects join in three-dimensional networks that encapsulate the solvent, thereby preventing the liquid from flowing. The network structure formed by the LMOGs is held together solely by non-covalent forces, including hydrogen bonding, $\pi$ stacking and solvophobic effects ${ }^{5}$. The self assembly process in LMOG organogels starting from a single molecule to fibers and ultimately an entangled network is completely reversible; the gel can be transformed into sol and then back into gel repeatedly by heating the sample above and below the sol $\leftrightarrow$ gel transition temperature. 


\subsection{Structural Requirements for LMOGs}

Structural requirements for low molecular weight organic gelators are still poorly understood $^{1,3}$. Most organogelators have been found by serendipity rather than design ${ }^{3}$. Several attempts have been made to correlate the structure and gel forming ability of a small organic molecule and therefore to establish a guideline for the design of novel gelling agents ${ }^{2 e, g, h, 6,7,8}$. Unfortunately, conclusions derived from such studies have proven applicable only to limited subclasses of structures ${ }^{1}$. However, from the results of the above studies, van $\mathrm{Esch}^{5}$ has outlined some important requirements for the formation of low molecular weight organic gels:

1) The presence of strong self-complementary and unidirectional intermolecular interactions to enforce one-dimensional self-assembly;

2) Control of fiber-solvent interfacial energy to control solubility and to control crystallization; and

3) Some factor to induce fiber-crosslinking for network formation.

\subsection{Applications of LMOG Gels}

LMOG organogels have not been exploited yet to the same extent as polymer gels or hydrogels. However, the results of the extensive research of several groups during the last few years on the structure, properties and applications of LMOG organogels are clearly indicating that the potential for application of these organogels is enormous. The welldefined structure of these organogels, the coexistence of highly ordered fibers with a liquid phase, the large interfacial area and the possibility to entrap solutes with the 
network pores make organogels very attractive materials for membrane and separation technology, catalysis or drug delivery ${ }^{5}$. Such gels may be convenient matrices for inks, paints, cosmetics etc. where on-demand flow is desirable ${ }^{1}$. They have potential applications in crystal engineering, to grow novel morphs and specific sizes or shapes of crystals from the liquid components ${ }^{9}$. Properly engineered fuels may be gelled and made to flow by warming only when needed for combustion; this will prevent the dispersion of the fuel over large areas if the fuel tank ruptures ${ }^{10,11}$. The organic aerogels obtained from the supercritical drying of organogels in $\mathrm{CO}_{2}{ }^{12}$ are highly interesting materials for application in separation processes as well as for use as novel dielectric or insulating materials and as support for catalysis. Moller ${ }^{13}$, Weiss ${ }^{14}$ and Nolte ${ }^{15}$ have reported the preparation of nanostructured materials by using the organogelators as a template. The regular arrangements LMOGs in their strand network have also been exploited for the formation of molecular wires ${ }^{16}$. The use of LMOGs for the preparation of $\mathrm{pH}$ sensitive light- and metal-responsive gels ${ }^{17,18}$, magnetosensitive gels ${ }^{19}$ and quasi-solid electrolytes $^{20}$ are only a few examples of the exciting possibilities of this promising area of research.

\subsection{Carbamates as the LMGOS}

The discovery of the gels reported in this chapter was serendipitous. In the process of searching for a suitable solvent to grow single crystals of the carbamates, we observed the cloudy appearance of the solution of the carbamates in benzonitrile and immobilization of the solvent even at a low concentration of the carbamates. Unfortunately, these carbamates were not found to form gels in a wide variety of solvents 
because of the insolubility of the long chain carbamates in most solvents. Although gelation occurs in toluene, a high concentration of the carbamate is required for the gel formation. In this chapter, we present the characteristics of carbamate/benzonitrile gels and the morphology of their xerogels.

\subsection{Preparation of the Gels}

The gels were prepared by dissolving a weighed amount of carbamate in $5 \mathrm{ml}$ benzonitrile in a $10 \mathrm{ml}$ beaker under heat $\left(60-70^{\circ} \mathrm{C}\right)$ and then cooling down the solution slowly to room temperature. Another series of gels were prepared by quenching the carbamate/benzonitrile solution using an ice bath. The beaker was covered with a watch glass and was inverted to confirm whether benzonitrile is completely immobilized by the carbamate in the gel.

\subsection{Preparation of the Films}

$0.1 \mathrm{M}$ solutions of the carbamates in benzonitrile were used to cast the films. The carbamate was dissolved in benzonitrile at $60-70^{\circ} \mathrm{C}$. The resulting hot solution was then poured onto a silanized aluminum plate maintained at $60^{\circ} \mathrm{C}$ and an aluminum draw bar was used to spread the solution across the hot aluminum surface. The hot plate was turned off to cool down the hot Aluminum surface slowly. The resulting film was dried at room temperature for 48 hours and then vacuum dried for 48 hours. 


\subsection{Results and Discussion}

The minimum concentration of the carbamates required for gel formation was found to decrease with the alkyl chain length. For gel formation by slow cooling, it was 0.16 , $0.015,0.012,0.011,0.008$ mol.dm $^{-3}$ for $\mathrm{C}_{4}, \mathrm{C}_{7}, \mathrm{C}_{8}, \mathrm{C}_{10}$ and $\mathrm{C}_{12}$ respectively; these data are plotted in Figure 6.1 as a function of the number of carbons at the alkyl side chain of the carbamates. The figure shows a drastic reduction in the amount of the carbamate required for gel formation as the alkyl chain length increases from $\mathrm{C}_{4}$ to $\mathrm{C}_{7}$.

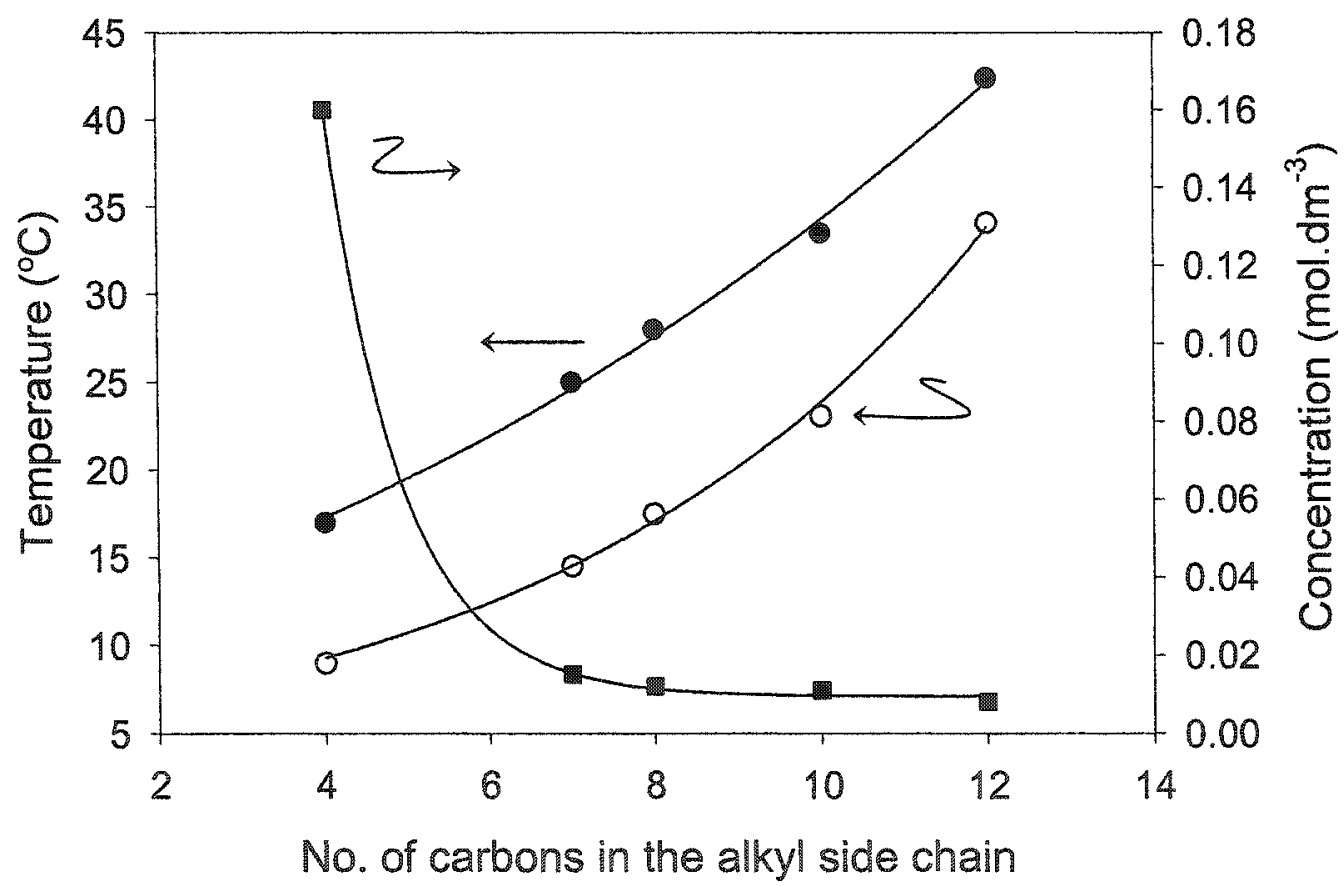

Figure 6.1 The minimum concentration required for gel formation and the sol-gel transition temperatures for carbamate/benzonitrile gels $(0.06 \mathrm{M}$, quenched) as a function of number of carbons at the alkyl side chain of the carbamates. ( $)$ from gel to solution; (o) from solution to gel. 
When the $0.06 \mathrm{M}$ solutions of $\mathrm{C}_{4}, \mathrm{C}_{7}, \mathrm{C}_{8}, \mathrm{C}_{10}$ and $\mathrm{C}_{12}$ in benzonitrile were quenched, they formed gels and benzonitrile was completely immobilized by the carbamates. However, when the gels were kept at room temperature, $\mathrm{C}_{4} /$ benzonitrile gel reverts to a solution. $\mathrm{C}_{16}$ and $\mathrm{C}_{18}$ did not immobilize the solvent completely. When the solution of carbamate in benzonitrile was slowly cooled to room temperature, $\mathrm{C}_{4}$ did not form a gel even at a concentration of $0.1 \mathrm{~mol} \mathrm{dm}^{-3}$; the $0.06 \mathrm{M}$ solution of $\mathrm{C}_{7}$ formed gel after 4 hours, $\mathrm{C}_{8}$ took 40 minutes whereas $\mathrm{C}_{10}$ and $\mathrm{C}_{12}$ took 10 minutes to form the gel. As with the quenched solution, $\mathrm{C}_{16}$ and $\mathrm{C}_{18}$ did not immobilize the solvent completely when the solution was slow-cooled. Gels from $\mathrm{C}_{7}$ and $\mathrm{C}_{8}$ were semitransparent, whereas gels from $\mathrm{C}_{10}$ and $\mathrm{C}_{12}$ were opaque. When held in the light, $\mathrm{C}_{7}$ and $\mathrm{C}_{8}$ showed a bluish tinge from Tyndall scattering ${ }^{21}$. The gels were found to be birefringent under the optical microscope.

Abdallah and Weiss ${ }^{1}$ found that with simple alkanes as organogelators, the gelator efficiency increases with chain length. However, in the case of the carbamates with alkyl side chains, gelation occurs in a narrow range of alkyl side chain length, between $C_{7}$ and $\mathrm{C}_{12}$. Even in this case, as noted above, the time required for gelation decreases significantly with the chain length. Longer alkyl side chains $(>12)$ lead to crystallization and precipitation rather than gel formation. The van der Waals interaction between the alkyl chains seems to predominate beyond a certain chain length. Our previous study on these carbamates (chapter 3), slow cooled or quenched from the melt showed that the heat of fusion and X-ray crystallinity (plotted as a function of the alkyl side chain length) increased sharply beyond an alkyl chain length of 12. This parallels the lack of gel formation with the $\mathrm{C}_{16}$ and $\mathrm{C}_{18}$ carbamates. 


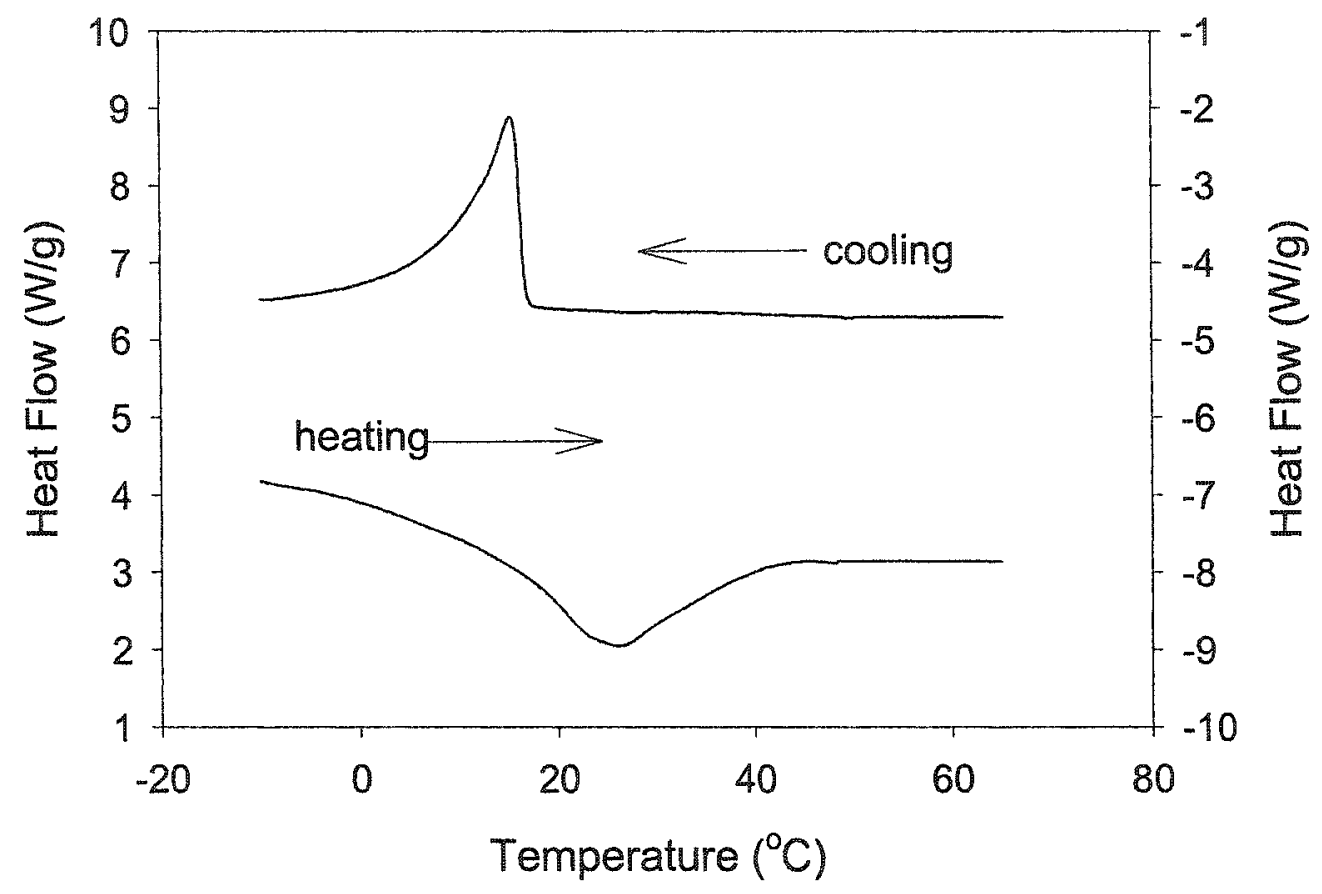

Figure 6.2 DSC curves of $\mathrm{C}_{8}$ /benzonitrile gel with $\mathrm{C}_{8}$ concentration of $0.04 \mathrm{~mol}$ $\mathrm{dm}^{-3}$. Heating and cooling rate: $10^{\circ} \mathrm{C} \mathrm{min}^{-1}$.

\subsubsection{Sol-gel Tramsitions}

The DSC thermograms of the gels showed well-defined thermo-reversible sol-gel transitions. Figure 6.2 shows the DSC thermogram of the quenched gel of $\mathrm{C}_{8}$ with a 0.04 $M$ concentration of the carbamate. As the gel was heated, an endothermic peak $(\Delta H=6.1$ $\mathrm{J} / \mathrm{g}$ ) due to the transition from gel to solution was observed. When the solution was cooled down, it exhibited an exothermic peak $(\Delta \mathrm{H}=-5.8 \mathrm{~J} / \mathrm{g})$ due to the transition from 
solution to gel. Repeated heating and cooling showed similar transition behavior. For all the slow cooled gels, the transition temperature from gel to solution was slightly higher $\left(2-3^{\circ} \mathrm{C}\right)$ than that of quenched gel. Figure 6.1 shows the sol-gel transition temperatures of the quenched gel of different carbamates. A concentration of $0.06 \mathrm{~mol} . \mathrm{dm}^{-3}$ of each carbamate was used to prepare these gels. It is seen that the transition temperatures from solution to gel and vice versa increase with the length of alkyl side chain in the carbamate. In all the gels, the transition temperature from gel to solution was found to be $8-10^{\circ} \mathrm{C}$ higher than that from the solution to gel. The onset of the appearance of cloudiness was $3-4{ }^{\circ} \mathrm{C}$ below the transition temperature from solution to gel.

To examine the effect of concentration of the gel-forming compound on the sol-gel transition temperature, a series of $\mathrm{C}_{8}$ /benzonitrile gel with different concentrations of $\mathrm{C}_{8}$ was prepared and the transition temperatures are plotted in Figure 6.3 as a function of concentration of $\mathrm{C}_{8}$. The transition temperatures for gel to solution and solution to gel increase with the concentration of $\mathrm{C}_{8}$ in benzonitrile. As mentioned above, the transition temperatures were only about $2-3^{\circ} \mathrm{C}$ higher for the slow cooled gels. 


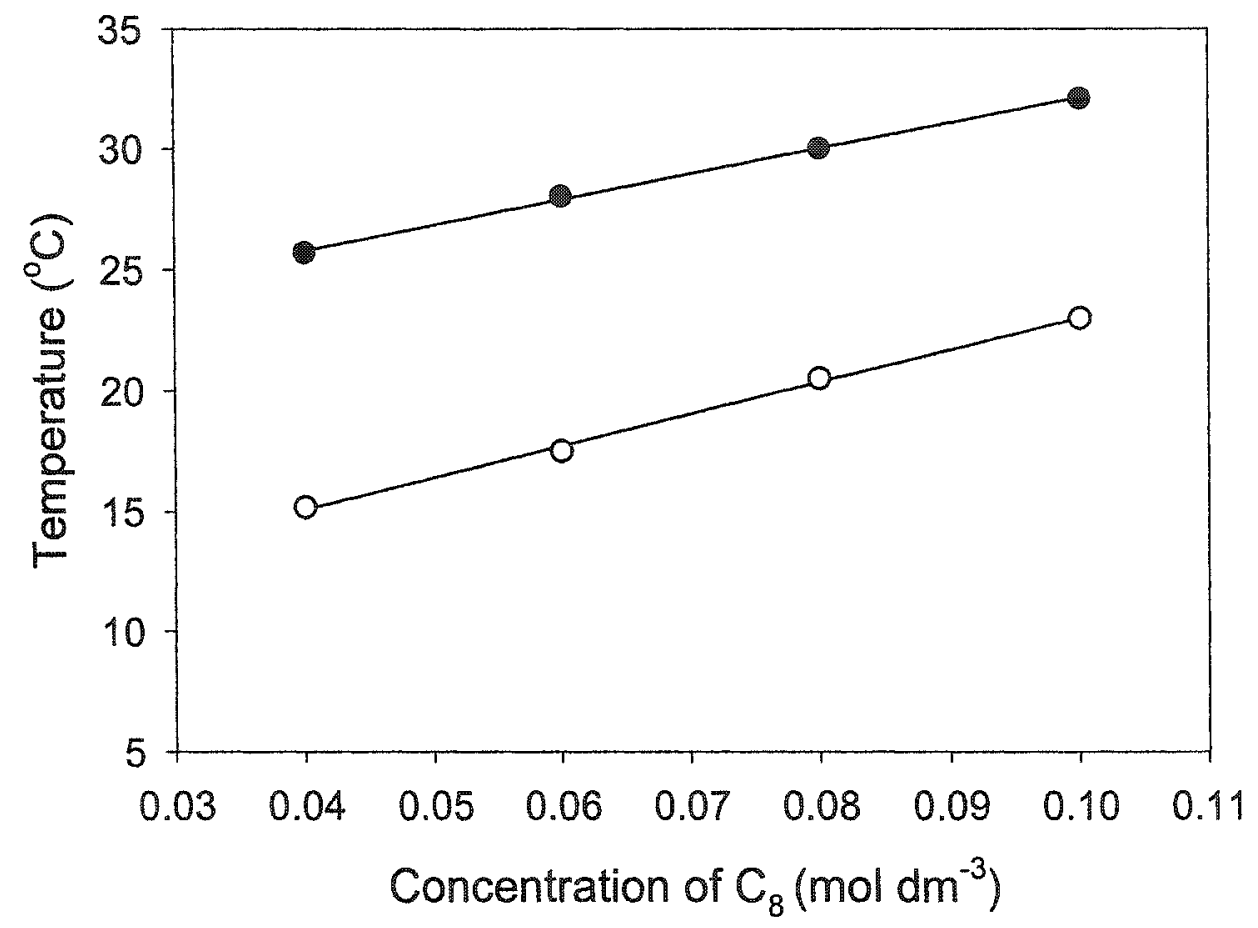

Figure 6.3 Sol-gel transition temperatures for $\mathrm{C}_{8}$ /benzonitrile gels as a function of concentration of $\mathrm{C}_{8}:(-)$ from gel to solution; (o) from solution to gel. 


\subsubsection{Morphology of the Xerogels}

Figure 6.4 shows the SEM images of the xerogels (dried gels) of $\mathrm{C}_{7}$ and $\mathrm{C}_{8}$. Also, the SEM images of the xerogels of $\mathrm{C}_{10}$ and $\mathrm{C}_{12}$ are shown in Figure 6.5. These xerogels were obtained by drying the gels at room temperature for one week and then drying under vacuum for two days. A 0.06 mol. $\mathrm{dm}^{-3}$ solution of the carbamate in benzonitrile was used to prepare these gels. The quenched samples of $\mathrm{C}_{7}$ and $\mathrm{C}_{8}$ (Fig. $6.4 \mathrm{a}$ and $6.4 \mathrm{~b}$ respectively) showed long fibers of uniform thickness. The average thickness of the fiber is $500 \mathrm{~nm}$ and $700 \mathrm{~nm}$ for $C_{7}$ and $C_{8}$ respectively. In the slow cooled sample of $C_{7}$ (Fig. $6.4 \mathrm{c}$ ), the thickness of the fibers increased to $1500 \mathrm{~nm}$. The larger thickness observed for the slow cooled sample is consistent with the higher crystallinity and spherulite size of samples slow cooled rather than quenched from the melt ${ }^{22}$ (chapter 3). Aggregation of fibers as ropes occurs in the slow cooled sample of $\mathrm{C}_{8}$ (Fig. 6.4d), with an average thickness of $6500 \mathrm{~nm}$. The fibers from the quenched gel of $\mathrm{C}_{10}$ (Fig. 6.5a) were thinner and shorter than those of $\mathrm{C}_{7}$ and $\mathrm{C}_{8}$. Although in the slow cooled gel of $\mathrm{C}_{10}$ (Fig. 6.5c) the fiber density increases, the fibers were still shorter than those of $\mathrm{C}_{7}$ and $\mathrm{C}_{8}$ and they did not show rope-like aggregates. When the quenched gel of $\mathrm{C}_{12}$ was kept at room temperature for several days, it formed crystals interconnected by three-dimensional network of thin filaments (Fig. 6.5b). This network is more pronounced and well defined in the slow cooled sample of $\mathrm{C}_{12}$ (Fig. $6.5 \mathrm{~d}$ ). The filaments of the network were $c a .400$ $\mathrm{nm}$ in diameter. Figure $6.6 \mathrm{a}$ and $6.6 \mathrm{~b}$ show the SEM images of the samples obtained from the drying of $\mathrm{C}_{16}$ /benzonitrile and $\mathrm{C}_{18}$ /benzonitrile solution respectively. The dried sample from the slow cooled and quenched solution of $\mathrm{C}_{16}$ and $\mathrm{C}_{18}$ did not show any fiber in SEM, rather they show flake-like morphology. 

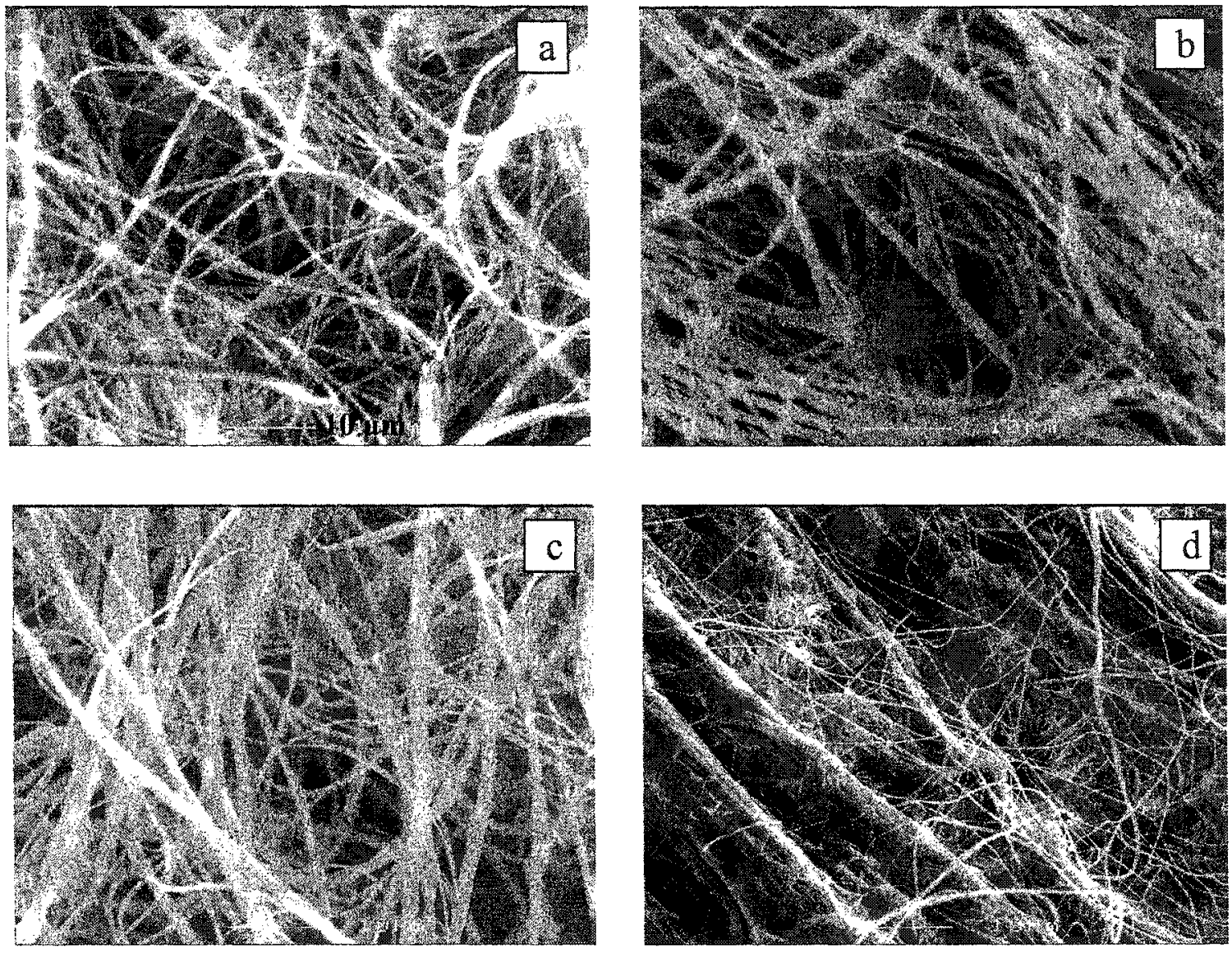

Figure 6.4 SEM images of the xerogels obtained from the quenched gels of $C_{7}$ and $\mathrm{C}_{8}$ (a and b respectively); from the slow cooled gels of $\mathrm{C}_{7}$ and $\mathrm{C}_{8}$ ( $\mathrm{c}$ and $\mathrm{d}$ respectively). 

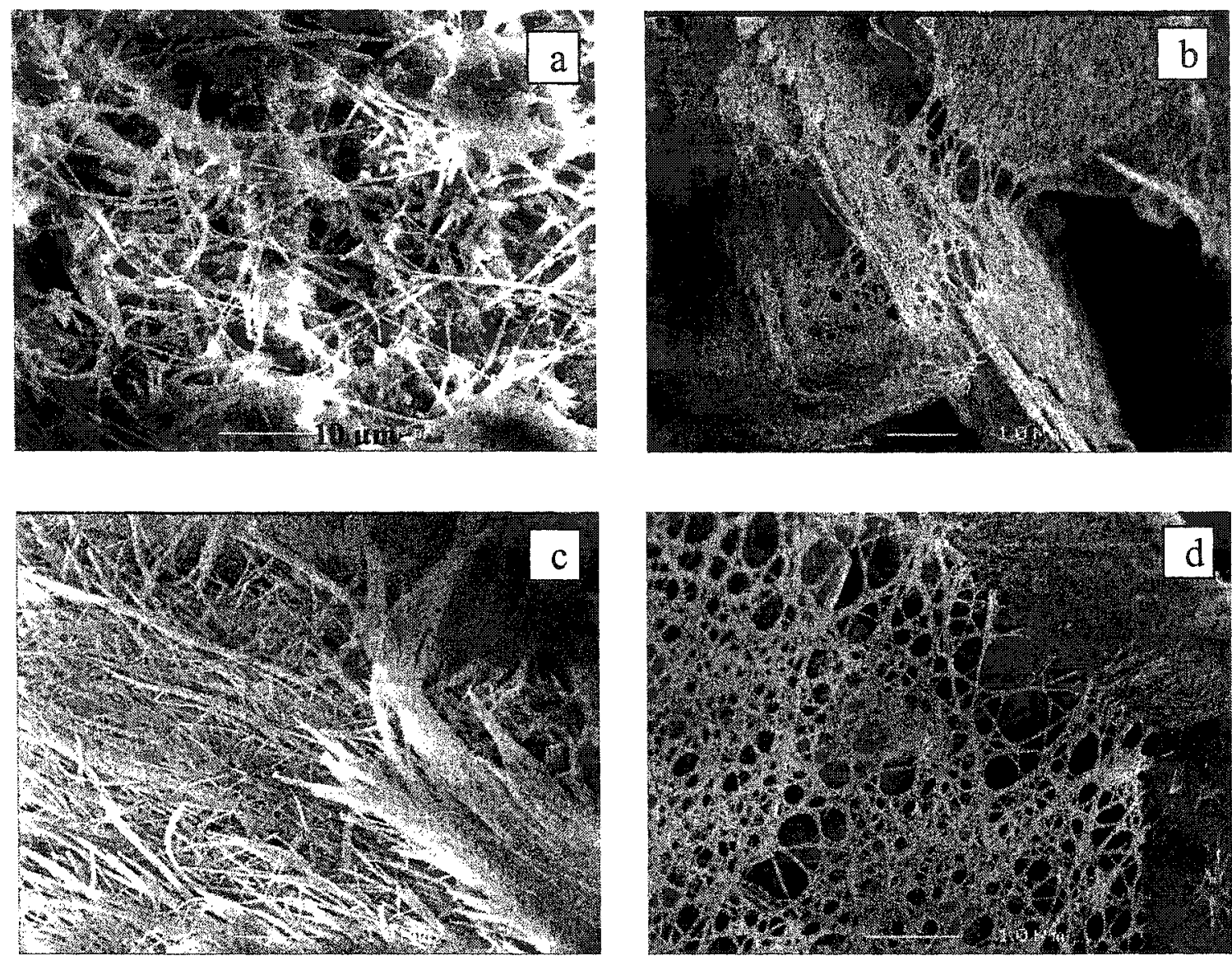

Figure 6.5 SEM images of the xerogels obtained from the quenched gels of $\mathrm{C}_{10}$ and $\mathrm{C}_{12}$ ( $\mathrm{a}$ and $\mathrm{b}$ respectively); from the slow cooled gels of $\mathrm{C}_{10}$ and $\mathrm{C}_{12}$ ( $\mathrm{c}$ and d respectively). 

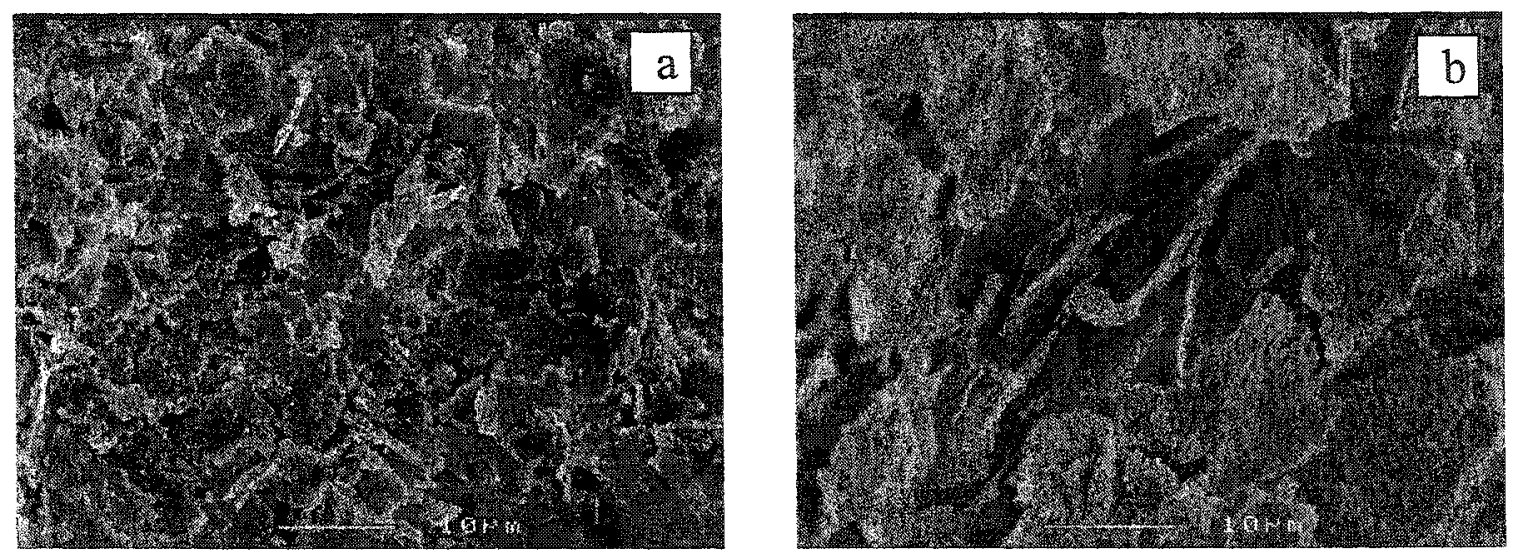

Figure 6.6 SEM images of the dried samples obtained from the slow cooled solutions of (a) $\mathrm{C}_{16}$ / benzonitrile and (b) $\mathrm{C}_{18}$ /benzonitrile.

The formation of fibers with uniform cross-sections in the gel indicates that gelation is a consequence of a phenomenon in which crystal growth is retarded along two axes or accelerated along the third. Again, the uniform cross sections suggest a process that prohibits growth beyond certain limits along two axes but allows essentially unlimited growth along the third ${ }^{1}$. In this study, this unlimited growth of the fibers was found to be affected by the length of the alkyl side chain of the carbamate which finally ceased the gel formation ability of the carbamate. The dependence of the thickness of the fibers as well as their lengths could perhaps be used advantageously to tailor the morphology for specific applications. 
It is reasonable to assume that the accelerated crystal growth along one direction is a result of a predominant interaction (hydrogen bond etc) along this direction. Figure $6.7 \mathrm{a}$ shows the X-ray diffraction pattern recorded from a few pieces of the fibers from the $\mathrm{C}_{8}$ carbamate, and the schematic of this diagram (Fig 6.7b). Since the fibers were fragile, it was difficult to align them as a bundle. However, some orientation is evident from the Xray pattern. The reflection along the meridional direction corresponds to a spacing of 3.9 $\AA$, which is the distance between the molecules along the hydrogen bonding direction (see Figure 6.7c). Based on this, we propose that the growth of the fibers occurs along the hydrogen bonding plane. The spacing of the equatorial reflection in Figures $6.7 \mathrm{a}$ and $6.7 \mathrm{~b}$ is $4.4 \AA$, which is the distance between the planes of hydrogen bonds (see Figure $6.7 \mathrm{c}$ ).

The effect of concentration on the morphology of the xerogels is shown in Figure 6.8. It is seen that with an increase in concentration of $\mathrm{C}_{8}$ from $0.04 \mathrm{~mol} \mathrm{dm}^{-3}$ to $0.1 \mathrm{~mol} \mathrm{dm}$, the thickness of the fiber did not increase significantly, only the density of the fibers did. However, the increase in concentration of $\mathrm{C}_{8}$ reduced the gel formation time significantly for the slow cooled gel, from 3 hours for the $0.04 \mathrm{M}$ solution to 10 minutes for the $0.1 \mathrm{M}$ solution.

\subsubsection{Films from the Organogels}

The films obtained from the organogels of $C_{7}, C_{8}, C_{10}$ and $C_{12}$ were opaque. Because of their high crystallinity, the films were fragile. However, the formation of films from these low molecular weight compounds indicates the strength of the hydrogen bonded network formed in the gels. 


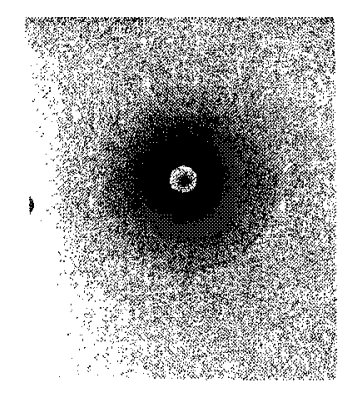

(a)

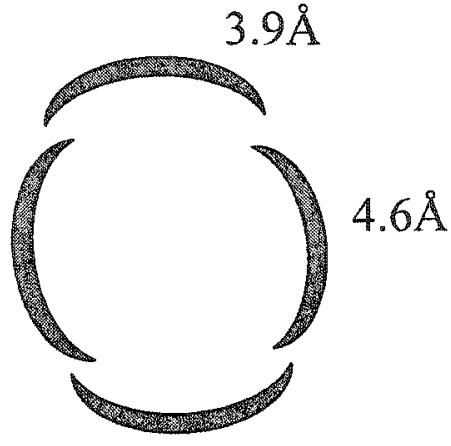

(b)

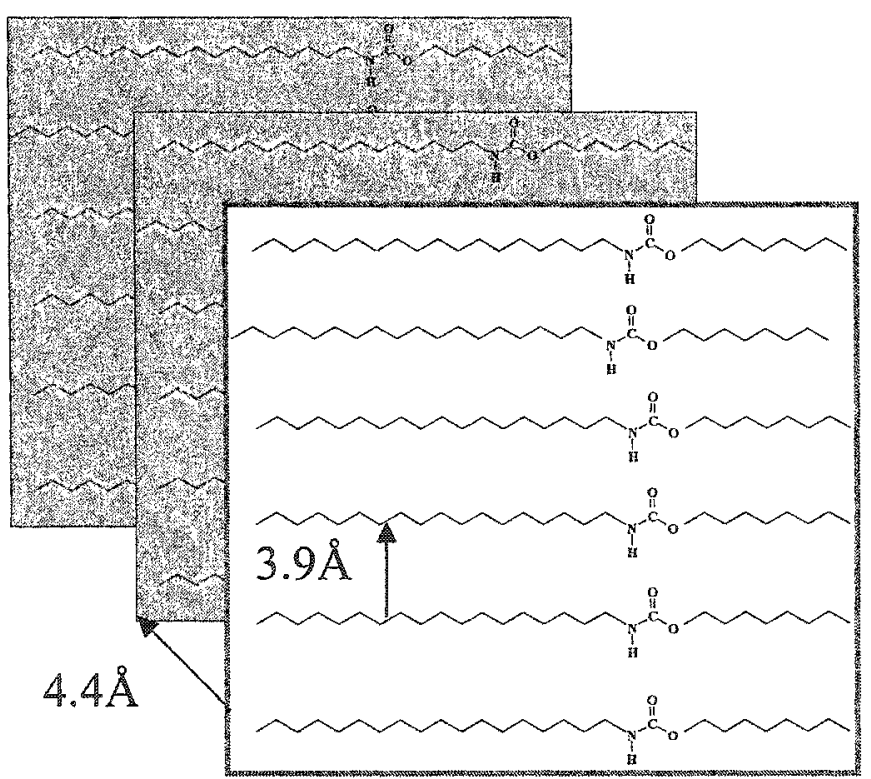

(c)

Figure 6.7 (a) X-ray diffraction pattern obtained from the fibers of $\mathrm{C}_{8}$ xerogel (b) schematic of $\mathrm{X}$-ray and (c) molecular packing in $\mathrm{C}_{8}$. 

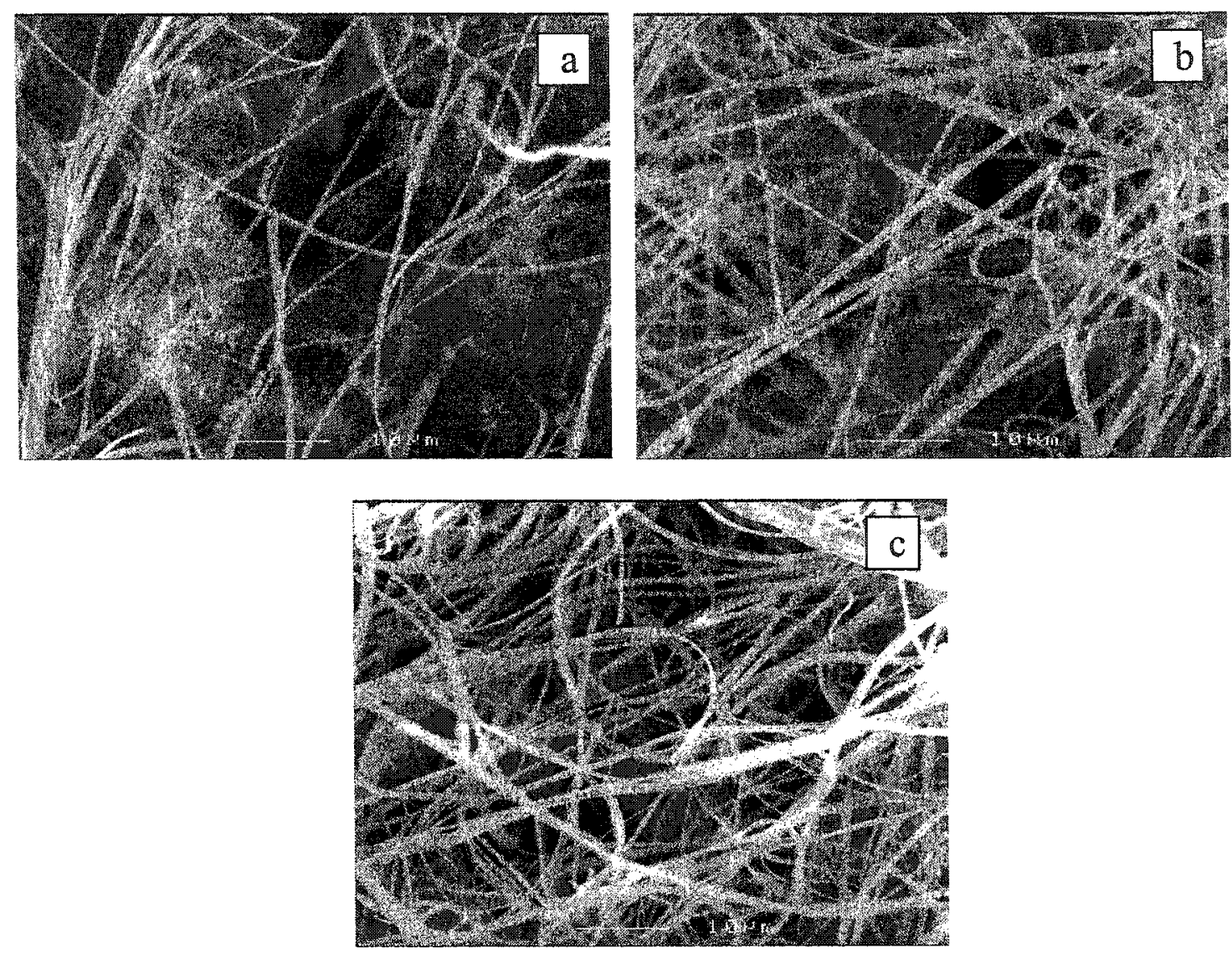

Figure 6.8 SEM images of the xerogels obtained from $\mathrm{C}_{8}$ /benzonitrile gels at different concentration of $\mathrm{C}_{8}:(\mathrm{a}) 0.04 \mathrm{M}$ (b) $0.08 \mathrm{M}$ (c) $0.1 \mathrm{M}$

\subsection{Conclusions}

A novel family of organogels based on long chain carbamates has been prepared. Their gel formation ability depends on the length of the alkyl side chains of the carbamates. The gels are birefringent and they show well defined themo reversible sol-gel transitions. The transition temperatures for gel to solution and solution to gel increase 
with the increasing concentration of the carbamate in the solvent. The xerogels show long fibers of uniform thickness. The thickness of the fibers is affected by the gel formation procedure and by the length of the alkyl chains of the carbamates. The thickness of the fibers is unaffected by the concentration of the carbamates, but the gel formation time decreases with an increase in the concentration of the carbamate. The unlimited growth of the fibers in the gel in one direction ceases after a certain length of the carbamate. The dependency of the one-dimensional growth of the fiber on the alkyl chains was not reported before.

Most of the LMOGs reported so far contain either aromatic rings ${ }^{2 e, 23,24}$, chiral cholesterol moieties $^{2(c, d), 6,23,24,25}$, or more than one hydrogen-bondable groups ${ }^{2(a, b, j,), 7,26,27,28,29}$ in their structures. $\pi$ stacking of the aromatic rings, association of the chiral cholesterol moieties or formation of 3D network of hydrogen bonds favours the gel formation process. The hydrogen bondable groups are, in most cases, on the periphery of the gelator structure ${ }^{7,26,27,28,29}$. In our study, the gelators contain only one hydrogen bondable group which is sandwiched between alkyl chains. There is no report of a systematic study in the literature which explores the differences in morphology of the fibers in the xerogels depending on the rate of cooling of the LMOG organogels. Here we have discussed the differences in morphology of the xerogels from the slow cooled and quenched gels from a homologous series of LMOGs. We have shown here for the first time that LMOG solutions can be used for casting films. The dependence of gel-forming capability on the length of the alkyl side chain has also been established with the homologous series of carbamates. 
The structure-property relationship of the low molecular weight organic gelators has not been fully exploited yet and many questiones are still unanswered. Discoveries of new families of LMOGs along with the existing literature can unfold this relationship. Considering the many potential applications of low molecular weight organic gels, a better understanding of these systems is highly demanding. The family of LMOGs described in this chapter could contribute in this regard. However, further investigations are necessary to get an insight into this system, especially how the length of the alkyl chains affect the gel formation ability. 


\subsection{References}

1 Abdallah, D.J.; Weiss, R.G. Adv. Mater. 2000, 12, 1237.

2 (a) Pilpel, N.; Chem. Rev. 1963, 63, 221.

(b) Uzu, Y. J. Jpn. Oil Chem. Soc. 1975, 24, 261.

(c) Martin-Borret, O; Ramasseul, R.; Rassat, R. Bull. Soc. Chim. Fr. 1979, 7-8, III-401.

(d) Bujanowski, V.J.; Katsoulis, D.E.; Ziemelis, M.J. J. Mater. Chem. 1994, 4, 1181 .

(e) Brotin, T.; Utermohlen, R.; Fages, F.; Bouas-Laurent, H.; Desvergne, J.P.; J. Chem. Soc., Chem. Commun. 1991, 416.

(f) Lin. Y-c.; Weiss, R.G. Macromolecules, 1987, 20, 414.

(g) Murata, K.; Aoki, M.; Susuki, T.; Harada, T.; Kawabata, H.; Komori, T.; Ohseto, F.; Ueda, K.; Shinkai, S. J. Am. Chem. Soc. 1994, 116, 6664.

(h) Campbell, J.; Kuzma, M.; Labes, M. Mol. Cryst. Liq. Cryst. 1983, 95, 45.

(i) Hanabusa, K.; Tange, J.; Taguchi, Y.; Koyama, T.; Shirai, H. J. Chem. Soc. Chem. Commun. 1993, 390.

(j) Abdallah, D.J.; Weiss, R.G. Langmuir 2000, 16, 352.

3 Terech, P.; Weiss R.G. Chem. Rev. 1997, 97, 3133.

4 van Esch, J.; Schoonbeek, F.; de Loos, M.; Veen, E.M.; Kellogg, R.M.; Feringa, B.L. Nato ASI ser. C 1999, 527, 233.

5 van Esch, J.H.; Feringa, B.L. Angew. Chem. Int. Ed. 2000, 39, 2263. 
6 Mukkamala, R.; Weiss, R.G. Langmuir 1996, 12, 1474.

7 Kamiyama, T.; Yasuda, Y.; Shirota, Y. Polym. J. $1999,31,1165$.

8 Lu, L.; Cocker, T.M.; Bachman, R.E.; Weiss, R.G. Langmuir 2000, 16, 20.

9 Henisch, H.K. Crystal growth in gels, University Press: Pennsylvania 1970; p.1.

10 Srivastava, S.P.; Saxena, A.K.; Tendon, R.S.; Shekher, V. Feul 1997, 76, 625.

11 Singh, P.; Folger, S.; Nagarajan, N. J. Rheol. 1999, 43, 1437.

12 Shi, C.; Huang, Z.; Kilic, S.; Xu, J.; Enick, R.M.; Beckman, E.J.; Carr, A.J.; Melendez, R.E.; Hamilton, A.D. Science 1999, 286, 1450.

13 Beginn, U.; Keinath, S.; Moller, M. Macromol. Chem. Phys. 1998, 199, 2379

14 Gu. W.; Lu, L.; Chapman, G.B.; Weiss, R.G. Chem. Commun. 1997, 543

15 Hafkamp, R.J.; Kokke, B.P.A.; Danke, I.M.; Geurts, H.P.M.; Rowan, A.E.; Feiters, M.C.; Nolte, R.J.M. Chem. Commun. 1997, 545.

16 Terech, P. Ber. Bunsenges. Phys. Chem. 1998, 102, 1630.

17 Murata, K.; Aoki, M.; Suzuki, T.; Harada, T.; Kawabata, H.; Komori, T.; Ohseto, F.; Ueda, K.; Shinkai, S. J. Am. Chem. Soc. 1994, 116, 6664.

18 Murata, K.; Aoki, M.; Nishi, T.; Ikeda, A.; Shinkai, S. J. Chem. Soc. Chem. Commun. 1991, 1715.

19 Li, S.; John, V.T.; Irvin, G.C.; Rachakonda, S.H.; McPherson, G.L.; O'Conner, C.J. J. Appl. Phys. 1999, 85, 5965.

20 Watase, M.; Itagaki, H. Bull. Chem. Soc. Jpn. $1998,71,1457$.

21 Daniels, F.; Alberty, R.A. Physical Chemistry, $2^{\text {nd }}$ ed.; Wiley: New York, 1961; p 578. 
22 Moniruzzaman, M.; Goodbrand, B.; Sundararajan, P.R. J. Phys. Chem. B 2003, 107,8416 .

23 Itoh, T.; Katsoulis, D.E.; Mita, I. J. Mater. Chem. 1993, 3, 1303.

24 Smith, J.M.; Katsoulis, D.E. J. Mater. Chem. 1995, 5, 1899.

25 Mukutamala, R.; Weiss, R.J. J. Chem. Soc., Chem. Commun. 1995, 375.

26 Yasuda, Y.; Iishi, E.; Inada, H.; Shirota, Y. Chem. Lett. 1996, 575.

27 Hanubasha, K.; Okui, K.; Karaki, K.; Koyama, T. Sherai, H. J. Chem. Soc., Chem. Commun. 1992, 1371.

28 Hanubasha, K.; Matsumoto, Y.; Miki, T.; Koyama, T.; Shirai, H. J. Chem. Soc., Chem. Commun. 1994, 1401.

29 de Vries, E. J.; Kellogg, R.M.; J. Chem. Soc., Chem. Commun. 1993, 238. 
Chapter 7

Conclusions and Recommendations for Future Work 


\subsection{Conclusions}

The purpose of this thesis was to study the thermal behaviour and morphology of some long chain carbamates and modify the crystalline morphology of these self-assembling compounds. Due to the diverse applications of these carbamates, we were interested in investigating their structure and properties.

It was found in this study that most of the long chain carbamates exhibit spherulitic morphology with negative birefringence, indicating the tangential orientation of chains within the spherulites. The length of the alkyl side chains as well as the cooling rate influences the morphology, heat of fusion, crystallinity and crystallite size. In some cases, the cooling rate alters the optic axis with respect to the spherulitic axis. Blending of two homologous carbamates reduces the crystal/spherulite size, heat of fusion and crystallinity and improves the transparency of the sample significantly. The carbamates exert a mutual plasticizer effect in the blend resulting in the depression of the melting point of the parent compounds. Blending of two homologous carbamates does not affect the extent of hydrogen bonding, but does affect the packing of alkyl side chains of the carbamates, which results in changes in the morphology. Investigations on different blend systems indicate that the change in packing of the alkyl side chains is caused by the exchange of hydrogen bonds between the components in the blends.

In the absence of exchange of hydrogen bonds, blending does not result in significant improvement of transparency of the sample. Morphological investigations on the blends

of carbamate with stearic acid, Kemamide $S$ and polyethylene reveal this fact. Thermal 
analysis of carbamate/stearic acid blends indicates that carbamate induces polymorphism in stearic acid in the quenched blend. A metastable phase is formed which is converted to the most stable $\mathrm{C}$ form on heating.

Low molecular weight polyethylene, which is a non-hydrogen bonded system but has alkyl chains similar to the carbamates, reduces the spherulite size of carbamates through heterogeneous nucleation more efficiently than the commercial clarifier Kemamide S. However, the commercial clarifier Kemamide $\mathrm{E}$ shows much better efficiency as compared to polyethylene in terms of improving the transparency of the sample. This improvement of transparency is achieved through the reduction of crystallinity which results from exchange of hydrogen bonds between the carbamate and Kemamide E. Insertion of Kemamide $\mathrm{E}$ in the hydrogen bonded network of the carbamate causes a misfit in the crystal lattice of the carbamate, therefore affecting the crystallinity of the carbamate. The efficiency of Kemamide $\mathrm{E}$ in improving the transparency of the carbamate is comparable to that of the blends of two homologous carbamates.

Long chain carbamates form birefringent gels in benzonitrile which show well-defined thermo-reversible sol-gel transitions. The length of the alkyl chain affects the gel formation ability, sol-gel transition temperatures and the morphology of the xerogels. The xerogels show long fibers of uniform thickness with unlimited growth along one axis. The length of the alkyl side chains of the carbamates affects this unlimited growth of the fibers and finally ceases the gel formation ability of the carbamate. 


\subsection{Recommendations for Future Work}

In the present work, we have used a homologous series of long chain mono-carbamates to investigate the structure-morphology relationship. Further study using bis-carbamates and inverse bis-carbamates can give us a more complete view of this relationship. This work has begun ( $\mathrm{S}$. Khanna, Ph.D. thesis).

The morphology was controlled in the present study, by blending two homologous carbamates. This has been accomplished without any reduction in the extent of hydrogen bonding. Further investigation should be undertaken using different self-assembling compounds to examine whether this is applicable to other self-assembling systems. For example, the morphology of a fatty acid might be controlled by blending it with a homologous fatty acid.

As mentioned in chapter 3 , because of the presence of the polar urethane group and alkyl moiety, long chain carbamates can be considered as model compounds for high molecular weight polyurethanes. Morphological investigations on polyurethanes having different length of the alkyl segments should be undertaken to validate this hypothesis. The possibility of controlling the morphology of polyurethane by blending it with different polyurethanes having different lengths of the alkyl segments should be examined.

The gel formation ability of bis-carbamates and inverse bis-carbamates in different solvents should be investigated. An in-depth study should be undertaken to understand 
how the length of the alkyl side chains affect the gel formation ability. The rate of cooling on the gel morphology should be examined; and the porosity should be correlated with the method of gel preparation. Potential applications of these organogels should be explored. 